\title{
Manual de planeación didáctica para educación secundaria
}

Rosa Isela Moreno Arias, Juan José Irigoyen Morales,

Karla Fabiola Acuña Meléndrez y Miriam Yerith Jiménez

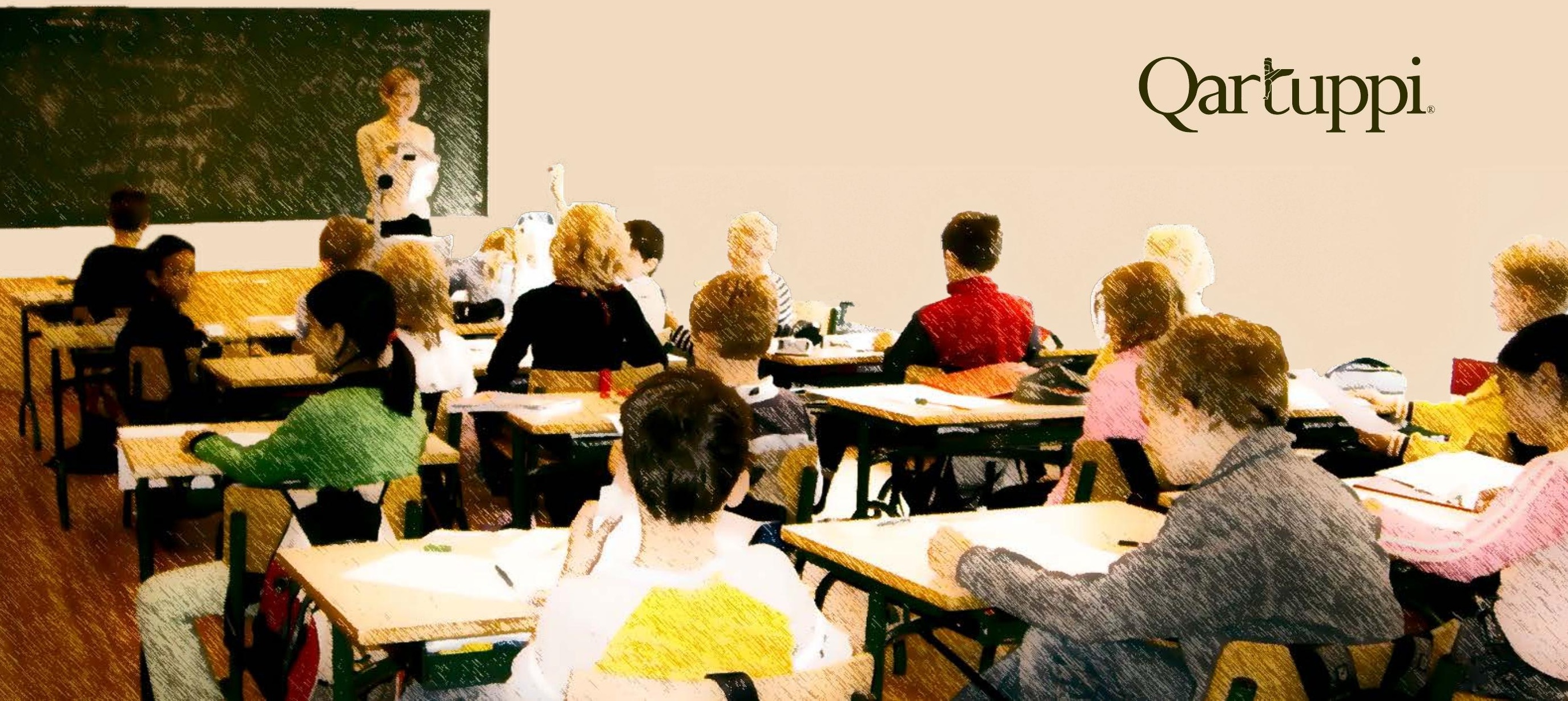


Se agradece la valiosa colaboración de:

Jamné Saraid Dávila Inda

y Pedro Elio Rey Murrieta

Manual de planeación didáctica para educación secundaria

1a. edición, diciembre 2016.

ISBN 978-607-97326-7-7

DOI 10.29410/QTP.16.11

D.R. @ 2016. Qartuppi, S. de R.L. de C.V.

Calle Real 63, Col. Villa Satélite

Hermosillo, Sonora 83200 México

http://www.qartuppi.com

Edición y Diseño: Qartuppi, S. de R.L. de C.V.

Diseño de portada: León Felipe Irigoyen Morales 


\section{Índice}

$\left[\begin{array}{lll}5 & - & 7\end{array}\right.$ Módulo 1. Presentación

$1 \frac{1}{8}$

I 8 I

ᄂ -$\lrcorner$

$r-7$

15 |

L -$\lrcorner$

| 4 - ᄀ |

L -$\lrcorner$

$r-7$

1681

Módulo 2. La práctica docente

Módulo 3. La noción de competencia y las condiciones básicas para su habilitación

Módulo 4. Planeación de las interacciones didácticas bajo un enfoque por competencias

Módulo 5. Descripción del aprendizaje esperado utilizando el nivel de complejidad funcional, el contenido y la habilidad requerida en el estudiante

| 83 I Módulo 6. Especificación de los criterios de logro a satisfacer

L -$\lrcorner$

$r-\urcorner$

| 96 |

L -$\lrcorner$

$r-\frac{10}{20}$

$\mid 113$ |

Módulo 7. Especificación de las actividades según los criterios de logro a satisfacer

\section{Referencias}


1. Este manual está diseñado para ser utilizado de manera individual.

2. También puede ser utilizado de manera grupal (en forma de taller), es importante que usted y los participantes inicien expresando las expectativas que tienen con respecto al mismo. Si este fuera el caso, en un primer momento usted y los participantes se presentarán ante sus compañeros, enseguida se reunirá en grupo y en un tiempo de 10 a 15 minutos analizarán y escribirán las expectativas que les genera asistir a este taller, algunas preguntas que pueden orientar esta actividad son las siguientes: ¿qué espero del taller?, ¿qué quiero que suceda?, ¿qué estoy dispuesto a aportar para lograrlo?, ¿qué espero del coordinador del taller?
Asimismo, también pueden describir tres situaciones de su vida profesional en las que se requiere aplicar los conocimientos aprendidos en el taller. Al finalizar puede exponer sus conclusiones al grupo apoyándose en un rotafolio en un tiempo máximo de 5 minutos. En un segundo momento el coordinador presentará la propuesta de trabajo y responderá dudas, en caso de que sea necesario usted podrá modificar la propuesta de trabajo a partir de la sugerencia. 


\section{Módulo 1 Presentación}

Objetivo: Exponer a los usuarios la lógica general del manual. 


\section{Presentación}

El propósito de este manual es servir de apoyo para el diseño y elaboración de planeaciones didácticas desde una concepción funcional del desarrollo psicológico. El diseño de unidades de aprendizaje está sustentado en competencias y en la taxonomía de Ribes y López (1985). Esta versión puede ser aplicada con fines de capacitación a profesores en servicio y estudiantes normalistas con especialidad de español y matemáticas (el énfasis está puesto en el nivel de secundaria pero puede ser utilizado como apoyo en cualquier otro nivel), pues integra los aprendizajes, contenidos, así como los criterios de tarea y logro esperados.
La propuesta de enseñanza recomendada está caracterizada por acciones planeadas que tienen como finalidad el aprendizaje del alumno, mediante experiencias directas acerca de un tema de interés, desarrollando sus competencias comunicativas en un trabajo colaborativo (SEP, 2011).

En el diseño de unidades didácticas se han desarrollado propuestas desde diversas teorías psicológicas, particularmente la Teoría Interconductual, en donde la enseñanza-aprendizaje se concreta en las interacciones didácticas. Dichas interacciones se establecen entre el estudiante, el objeto referente y el 
discurso didáctico, estos supuestos han permitido realizar diversas propuestas para establecer interacciones didácticas idóneas para desarrollar competencias en diferentes niveles de aptitud funcional. Irigoyen, Acuña y Jiménez (2011a) indican que la planeación expresa claramente lo que se enseñará, el cómo se realizará y la exhibición de los desempeños tanto del profesor como del alumno.

Por su parte León, Morales, Silva y Carpio (2011) señalan que en la planeación: "Se desarrollan habilidades y competencias para describir tareas, actividades y circunstancias en la interacción con alguien que necesita aprender" (p. 91). Asimismo, Silva (2009) considera que los docentes deben delimitar el comportamiento que debe desarrollar el alumno, pues: "esta delimitación adquiere la forma de objetivo de aprendizaje y puede estar dirigido al desarrollo de alguna clase específica de habilidad (por ejemplo, habilidades de investigación, técnicas de discusión, tecnologías de aplicación, metodologías de evaluación, etc.)" (p. 55).

El manual está constituido por seis módulos; cada uno de ellos está estructurado con la siguiente secuencia: objetivo, instrucciones y aprendizajes esperados, con una serie de materiales y ejercicios como apoyo.

Esperamos que este manual sea de utilidad para los diferentes docentes e interesados en el ámbito de la educación. 


\section{Módulo 2 \\ La práctica docente}

Objetivo: Describir las características de la práctica docente.

Instrucciones: Lea el Texto 1: "Características de un profesor formado" y anote las ideas principales. A su vez, escriba en una hoja en blanco los comentarios o preguntas que surjan de la lectura.

Aprendizaje esperado: Justificar la importancia de la práctica docente. 
Texto 1.

\section{Características de un profesor "formado"}

Para la Psicología, la educación -en tanto conceptorefiere al proceso por medio del cual un individuo (léase alumno) modifica, cambia o altera su comportamiento en relación a su ambiente, dicho cambio es probabilizado por la mediación -ya sea directa o indirecta- ejercida por otro individuo (léase docente). Al interior del ámbito educativo existen profesiones o especialidades que cumplen la función de "poner en práctica ante problemas concretos el conocimiento producido por las disciplinas científicas (como la Psicología básica) y tecnológicas (como la Psicología educativa), además del propio conocimiento generado por su propia práctica profesional" (Ibáñez, 2009, p. 74), a saber: la pedagogía y la didáctica. Por un lado, la pedagogía refiere al estudio de los métodos y técnicas de enseñanza; mientras que la didáctica, por su parte, hace referencia a la planeación curricular del aprendizaje, así como de aquellas actividades, estrategias y situaciones relativas a la enseñanza (Ibáñez, 2009).

En este contexto, podemos decir que existen dos tipos de profesores: los que estudian para llegar a serlo y los que lo son de hecho, sin haber estudiado la docencia. Los primeros cursaron una carrera en alguna Escuela Normal y, por lo general, trabajan como docentes en los niveles básicos. Los segundos son profesionistas egresados de alguna otra carrera e imparten clases en los niveles medio-superior y superior.
En el primer caso, cuando se habla de los Programas de Formación de Profesores (PFP), se hace referencia tanto a los estudios mismos de licenciatura como a los cursos de actualización, especialización o posgrado que se imparten esporádicamente a los maestros en servicio. En el segundo caso, los PFP se refieren a todos aquellos esfuerzos sistematizados e institucionalizados encaminados a alcanzar la profesionalización de la docencia, a través de la superación académica de la planta de profesores. Mientras que el primer tipo de PFP está normado por la Secretaría de Educación Pública y se desarrolla de manera estandarizada en toda la república mexicana, en el segundo depende totalmente de cada Institución de Educación Superior (IES), pública o privada, que lo establece.

Existen programas que se orientan de manera exclusiva a la formación didáctico-pedagógica, otros que se orientan exclusivamente a la formación disciplinaria, y otros que integran ambos aspectos. Ante esta diversidad de programas es necesario plantear la siguiente pregunta: ¿qué se entiende por formar a un profesor?, o ¿cómo se concibe a un profesor adecuadamente formado?, se puede decir que un profesor formado se desempeña de manera efectiva según Silva et al. (2014) en los siguientes ámbitos: 


\section{Planeación didáctica}

Un buen profesor elabora pertinentemente los objetivos de aprendizaje generales y específicos, respondiendo a cuestionamientos como qué se debe aprender, para qué se debe aprender algo, en qué situaciones debe aprenderse y cómo demostrar que se ha aprendido.

\section{Exploración competencial}

Un buen profesor identifica y evalúa el desempeño del alumno previo a la situación de aprendizaje, con el objetivo de hacer las adecuaciones necesarias al plan elaborado previamente.

\section{Explicitación de criterios}

Un buen profesor prescribe los criterios disciplinarios y didácticos que deberán regular el comportamiento del alumno. Los primeros se relacionan con aspectos exclusivos del ámbito que se enseña, por ejemplo: español, matemáticas, ciencias naturales; mientras que los segundos, refieren a aspectos como la hora de la clase, la relación entre el docente y el alumno y de este último con sus demás compañeros.

\section{Ilustración}

Un buen profesor describe al alumno lo que debe de hacerse para cumplir con el objetivo de aprendizaje, en qué situación se debe hacer y para qué debe hacerse. Es necesario que dicha descripción se lleve a cabo por medio del ejemplo de un experto en la materia, el cual puede o no ser el mismo docente.

\section{Práctica supervisada}

Un buen profesor expone al alumno ante situaciones de aprendizaje controladas, en las cuales supervisa y corrige el desempeño de este momento a momento.

\section{Retroalimentación}

Un buen profesor pone en contacto al alumno con lo que hizo, para qué lo hizo y en qué situación lo llevó a cabo, describiendo las variaciones posibles en el desempeño del mismo.

\section{Evaluación}

Un buen profesor contrasta el desempeño real del alumno con un desempeño ideal o esperado en relación con el objetivo de aprendizaje planeado. Dicho contraste se lleva a cabo a través de un sistema de valoración con el fin de identificar el grado en que el desempeño real satisface o cumple el desempeño ideal. 


\section{Existen dos tipos de profesores}

\begin{tabular}{|c|c|}
\hline Los que estudian para llegar a serlo & $\begin{array}{c}\text { Los que lo son de hecho, } \\
\text { sin haber estudiado para eso }\end{array}$ \\
\hline $\begin{array}{c}\text { Cursaron una carrera en alguna } \\
\text { como docentes en los niveles básicos }\end{array}$ & $\begin{array}{c}\text { Son profesionistas egresados de alguna otra carrera } \\
\text { y, por lo general, imparten clases en los niveles } \\
\text { medio-superior y superior }\end{array}$ \\
\hline
\end{tabular}

\section{Programas de Formación de Profesores (PFP)}

Cuando se habla de PFP, se hace referencia tanto a los estudios mismos de licenciatura como a los cursos de actualización, especialización o posgrado que se imparten esporádicamente

a los maestros en servicio

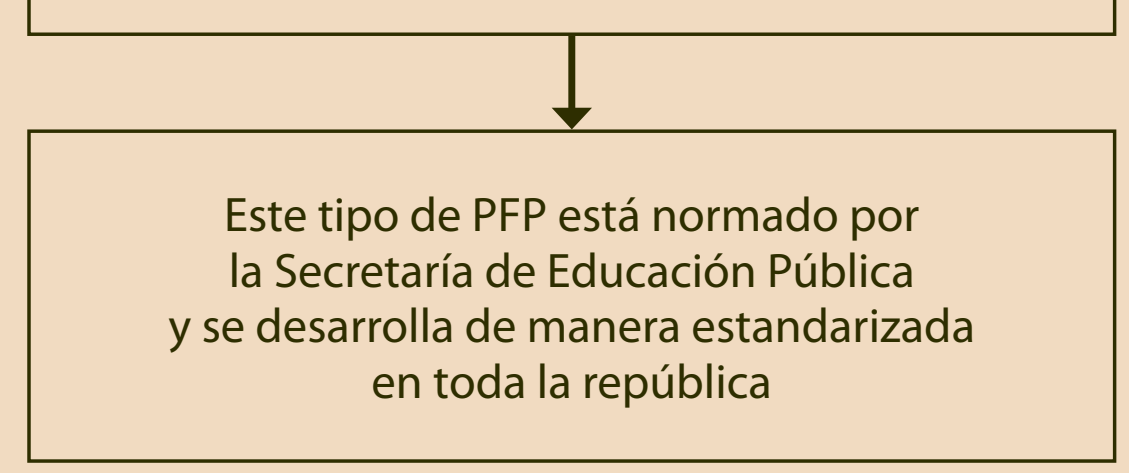

Los PFP se refieren a todos aquellos esfuerzos sistematizados e institucionalizados encaminados a alcanzar la profesionalización de la docencia,

a través de la superación académica de la planta de profesores

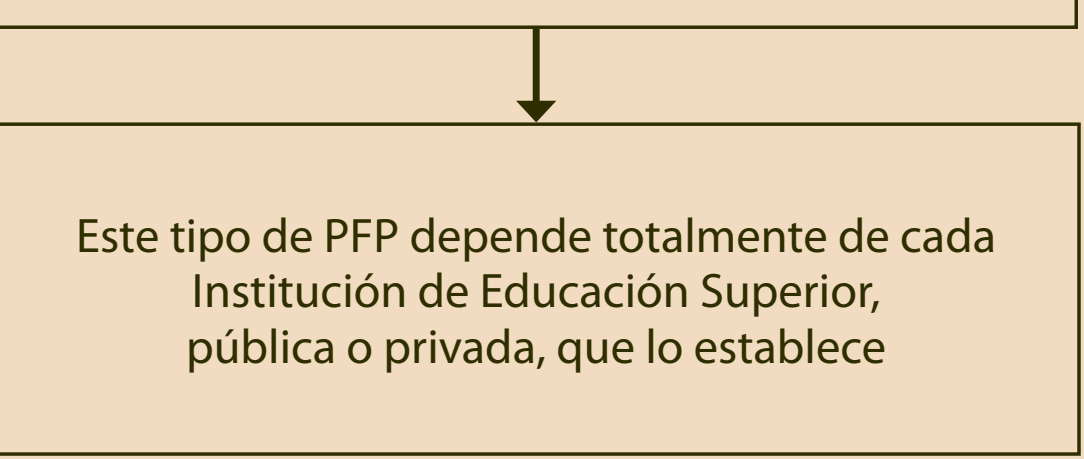




\section{Ejercicio 2.1.}

Realice la lectura del Texto 1 y redacte un resumen

\section{Sugerencias para llevar a cabo un resumen:}

1. Identificar mediante la lectura, el tema central y los subtemas que se desarrollan en el texto.

2. Identificar la estructura del texto, es decir, las partes que lo componen (títulos, subtítulos, etc.).

3. Escribir notas breves sobre o al margen de los párrafos del texto.

4. Subrayar la información sustancial o relevante del texto.

5. Elaborar un esquema de contenido para ilustrar gráficamente las relaciones entre los elementos del texto.

\section{Condiciones de un buen resumen:}

Brevedad: se ajusta a las ideas centrales del texto.

Exactitud: refleja el contenido del texto con precisión. Exhaustividad: contiene la totalidad de ideas relevantes del texto.

Objetividad: se limita a acotar lo expuesto por el autor del texto. 


\section{Ejercicio 2.2.}

Redacte un párrafo no menor a 10 renglones en el cual exprese

su opinión argumentando la importancia de la práctica docente.

\section{Preguntas guía:}

- ¿Cuál es mi papel como docente en la sociedad actual?

- ¿Qué tan significativa es mi práctica para el alumnado?

- ¿Adapto los contenidos y contexto para desarrollar un aprendizaje o sólo soy reproductor de ello?

- ¿Considero los cambios que implica el nuevo currículum o desisto, y continúo realizando mi práctica desde lo que yo conozco?

- ¿Busco fortalecer mi práctica docente?

- ¿Comparto con otros docentes mis inquietudes y expectativas?

Una vez terminado el ejercicio se sugiere guardar. 
Rúbricas ejercicio 2.1. y 2.2.

\begin{tabular}{|c|c|l|}
\hline \multicolumn{3}{|c|}{ Ejercicio 2.1. Elaboración de un resumen } \\
\hline Niveles de ejecución & Puntaje & \multicolumn{1}{c|}{ Descripción } \\
\hline Inicial & 1 & El participante escribe fragmentos del texto. \\
\hline En desarrollo & 2 & El participante incluye ideas secundarias. \\
\hline Alcanzado & 3 & $\begin{array}{l}\text { El participante identifica información especifica del texto sin } \\
\text { la intervención del tallerista, incluye ideas principales y secundarias. }\end{array}$ \\
\hline
\end{tabular}

\begin{tabular}{|c|c|l|}
\hline \multicolumn{3}{|c|}{ Ejercicio 2.2. Redacción de una justificación } \\
\hline Niveles de ejecución & Puntaje & \multicolumn{1}{c|}{ Descripción } \\
\hline Inicial & 1 & $\begin{array}{l}\text { El participante evalúa su práctica docente considerando su experiencia pero el texto no } \\
\text { es coherente y no es claro en lo que comunica. }\end{array}$ \\
\hline En desarrollo & 2 & $\begin{array}{l}\text { El participante evalúa su práctica docente considerando su experiencia, comunica su } \\
\text { opinión pero sus argumentos no son convincentes. }\end{array}$ \\
\hline Alcanzado & 3 & $\begin{array}{l}\text { El participante vincula el contenido del texto con su práctica docente, comunica } \\
\text { de manera pertinente y argumenta. }\end{array}$ \\
\hline
\end{tabular}




\section{Módulo 3}

\section{La noción de competencia y las condiciones básicas para su habilitación}

Objetivo: Identificar algunos términos asociados a las competencias y a las condiciones básicas para generarlas en el aula.

Instrucciones: Lea el Texto 2: "Habilidades y competencias" y el Texto 2.1:

"La noción de competencia", apunte las definiciones de los conceptos:

habilidad, competencia y criterio de logro.

\section{Aprendizaje esperado:}

- Describir la pertinencia de los ejemplos de competencia propuestos a partir de los términos conceptuales: habilidad, competencia y criterio de logro.

- Justificar la habilitación de competencias en la interacción didáctica a partir de cada elemento y su condición en las asignaturas de español y matemáticas. La redacción debe incluir necesariamente la terminología conceptual revisada en esta sesión. 


\section{Texto 2.}

\section{Habilidades y competencias}

Uno de los principios pedagógicos que sustentan el plan de estudios 2011 (SEP, 2011) refiere al énfasis del desarrollo de competencias. Sin embargo, existe una relación estrecha entre competencia y habilidad, por ello es necesario diferenciarlas.

A partir de la perspectiva que se presenta, las habilidades se definen como un conjunto finito de acciones que guardan correspondencia con la forma y las características de los objetos que participan de dichas acciones (Ribes, 2011).

Esto se ejemplifica de la siguiente manera:

- La habilidad de tocar el piano implica múltiples movimientos de los dedos, muñecas y antebrazos, pero no se afirma la habilidad de tocar piano sólo porque una persona pueda hacer esos movimientos en cualquier superficie, tiene que hacerlos en un teclado y siguiendo e interpretando una partitura determinada. En este sentido queda claro que una habilidad o destreza no consiste sólo en ejercitar un patrón de movimientos determinados, sino que ese ejercicio debe hacerse en correspondencia con el objeto y la solicitud para ejecutar cierta pieza musical, lo anterior indica que existe pertinencia y correspondencia de la conducta implicada.
- Para comparar números fraccionarios, el alumno deberá señalar la cantidad representada por " $7 / 8$ " $\mathrm{y}$ "4/5" en un círculo.

- Para identificar el sujeto, el verbo y el predicado en diferentes oraciones, el alumno deberá subrayar con color rojo el sujeto, con color verde el verbo y con color azul el predicado.

Por tanto, se dice que alguien es hábil cuando su comportamiento se ajusta a las características del objeto o acontecimiento con el que se relaciona. 
Texto 2.1.

La noción de competencia

Las competencias, por su parte, se definen como el ejercicio de un conjunto de habilidades que satisfacen un criterio de logro - especificaciones que debe cumplir el estudiante al realizar una actividad académica-determinado por un nivel de aptitud particular (Ribes, 2011).

Por ejemplo:

- Utilizar estrategias de análisis de diferentes textos expositivos para ser un lector crítico,

- Escribir su opinión respecto a la importancia y la enseñanza que se pueden derivar de los textos que leyó y argumentar su comentario.

Para conocer si un alumno ha aprendido una competencia o habilidad particular, Guevara (2006) indica la importancia de especificar el criterio de logro que se pretende que el estudiante alcance en cada competencia especificada en el programa.

Supongamos que un aprendizaje esperado podría señalar "que el alumno aprenda a escribir", pero no indica cómo tiene que escribir para decir que ya "aprendió" dicha competencia. En el caso de esta competencia (escribir), puede ser de mucha ayuda indicar si se pretende que el alumno escriba letras, palabras, frases, oraciones o textos. Asimismo, se recomienda precisar si se pretende que escriba por copia, dictado o producción personal y, en este último caso especificar, además, si se requiere la redacción de recados, peticiones, responder cuestionarios a partir de textos, realizar escritos reseñando o describiendo, o bien, si se pretende que logre un nivel de redacción de textos originales con terminología y argumentaciones precisas.

Por tanto, el criterio establece las características que debe cumplir un comportamiento para ser efectivo en una circunstancia determinada.

Es importante evitar redactar competencias como los ejemplos siguientes:

- "Que los alumnos comprendan la importancia de...".

- "Reflexione sobre la importancia de...."

- "Que los niños reconozcan los principales...."

- "Que el alumno relacione los temas...."

- "Valore la necesidad de...."

- "Que el alumno conozca las causas de...."

Ahora bien, ¿en qué se distingue una habilidad de una competencia? Las habilidades siempre forman parte de una competencia, pero lo que define a la competencia no son las habilidades que la componen sino el criterio diferenciado que determina qué habilidades son pertinentes y funcionales para un logro determinado. 
Modelo de Interacción Didáctica:

condiciones básicas para la generación de competencias

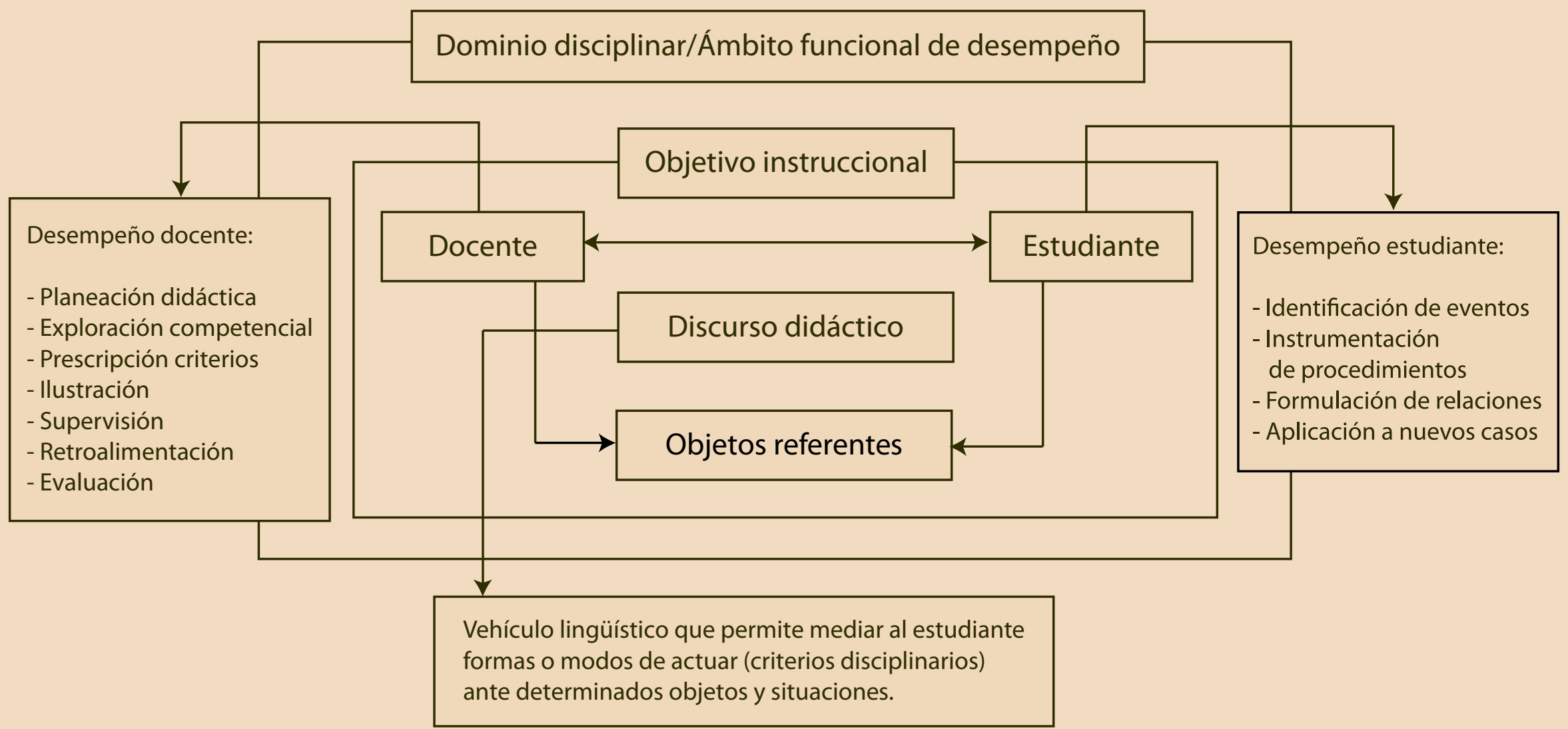

Fuente: J.J. Irigoyen, K. Acuña y M. Jiménez (2011b, p. 85). 


\section{Docente}

La educación consiste esencialmente en auspiciar la generación de competencias mediante el discurso didáctico. En la mayoría de los casos, los maestros son quienes formulan dicho discurso, y para que éste sea eficaz, deben ser capaces de:

- Cumplir con eficacia los aprendizajes esperados de lo que enseñan.

- Expresar ante sus alumnos cómo se cumple el criterio de logro esperado.

- Ejemplificar ante los alumnos el desempeño esperable según el criterio de logro.

- Disponer las situaciones didácticas necesarias para que el alumno practique "el cómo" se alcanza el criterio de logro esperado.

- Informar puntualmente al alumno sobre sus aciertos o errores a lo largo del proceso de aplicación del conocimiento. 


\section{Ejemplo}

Imagine que el profesor iniciará el ciclo escolar con lo siguiente:

Proyecto 1: Somos escritores de artículos.

Aprendizaje esperado: Comparar información sobre un tema para escribir artículos.

Criterio de logro: Contrastar las distintas formas de manejar un mismo tema en diferentes fuentes.

Es recomendable que el profesor especifique enfáticamente cada uno de los elementos anteriores y subraye la importancia de cumplir con los criterios de logro, puesto que son las especificaciones que debe de efectuar el estudiante al realizar la actividad académica y lo que finalmente será su desempeño.

Asimismo, se espera que el profesor domine el tema, por tanto, en clase compara información de diferentes artículos, y expresa ante sus alumnos detalladamente el cómo debe de alcanzarse el criterio de logro esperado.

Inmediatamente ejemplifica el cómo se desarroIla la actividad, planteándose las siguientes preguntas en voz alta sobre la manera en la que los autores ex- presan sus ideas: ¿explican claramente fenómenos y procesos?, ¿argumentan opiniones con base en datos precisos o en los que se han comprobado otros especialistas o, por el contrario, descalifican estos mediante pruebas contundentes?; dice al grupo cómo identificar esta información en artículos previamente leídos y la escribe en el pizarrón.

Enseguida solicita a los alumnos que se reúnan en equipos, lean un artículo con un tema de interés y posteriormente realicen el mismo procedimiento que él ejemplificó.

Por último, los alumnos exponen los argumentos de los autores de los artículos y el profesor señala los aciertos e indica los aspectos a mejorar. 


\section{Discurso Didáctico}

El principio fundamental en el que se basa el discurso didáctico es que sólo aquel que domina una competencia puede enseñarla, y aun cuando se enseña primordialmente con base en la demostración y el ejemplo, se requiere de reglas, instrucciones y descripciones que expliquen los criterios bajo los cuales dichos ejemplos y demostraciones son efectivos, las diversas maneras en que otros ejemplos y ejercicios de una competencia pueden también serlo.

El discurso didáctico no consiste únicamente en lecciones verbales sobre lo que se debe y no hacer y en cómo hacerlo, sino que consiste en la exposición aunada a la práctica como demostración, ejemplificación y ejercicio del desempeño aprendido, por ello el discurso didáctico puede adoptar distintos modos: ya sea oral, como el que se manifiesta en una conferencia; escrito, como textos; gráfico, como el de un diagrama que representa un proceso; y cinematográfico, como el que se presenta a través de videos, todos ellos vinculados a un hacer práctico integrado en un episodio de interacción didáctica.

Para ejercitar el discurso didáctico, es necesario que el profesor posea el conocimiento acerca de lo que habla en la forma de saber "cómo" e indique el cómo llegó a ejercitarlo, permite que el profesor enuncie el cómo se logra el criterio especificado en los aprendizajes esperados; por tanto, en el discurso didáctico se plantea el problema a resolver y su relación entre el desempeño y la satisfacción de un criterio en términos de su resultado (Ribes, 1990).

\section{Estudiante}

Los siguientes aspectos inherentes al alumno son fundamentales para la generación de competencias:

- Recordemos que el discurso didáctico del profesor genera un tipo de respuesta lingüística en el alumno, esta respuesta puede ser como escucha, observador, lector, dibujante, escritor y hablante.

- El discurso didáctico es más eficaz cuando el alumno tiene un conocimiento previo de la asignatura (conceptos, procedimientos, métodos, modelos, teorías) pues este factor puede influir positivamente en la generación de competencias.

- El desempeño del alumno en una actividad o problema es coherente con el criterio de logro establecido por el profesor.

\section{Objetos referentes}

Mediante el discurso didáctico propiciado por el profesor, el alumno tiene contacto con los objetos o eventos de la asignatura los cuales pueden:

- Estar físicamente presentes tal cual son.

- Ser sustitutos (réplicas artificiales, videos, fotografías o dibujos).

- No estar presentes (ser linguísticamente mediados). 


\section{Ejemplo}

Un alumno de anatomía humana puede leer un texto en el que se describe un determinado órgano en presencia del cadáver (objeto real), ante una réplica de plástico, una fotografía del órgano o un esquema (sustitutos); todavía puede leer en ausencia de cualquiera de los objetos anteriores, dejando, como se dice, "todo a la imaginación". Según el ejemplo anterior se promueven diferentes grados de efectividad en el aprendizaje de una competencia.

A manera de conclusión: lo anterior permite señalar la pertinencia de relacionar el discurso didáctico con la realidad o con objetos sustitutos pues con ello se presentan mejores condiciones para la generación de competencias. En ellos el alumno tiene contacto directo con los aspectos ambientales sobre los que deberá actuar según los criterios especificados en el discurso.

Además, el estudiante observará los objetos y sus características, ensayará un procedimiento, elegirá el objeto preciso conforme a un criterio de logro, analizará un objeto o fenómeno conforme a un ejemplar, o transformará un objeto de acuerdo a ciertas normas. En función de estos primeros contactos es que se puede hablar de la posible transferencia del aprendizaje a situaciones similares, proceso definitorio de la formación basada en competencias. 


\section{Ejercicio 3.1.}

Realice la lectura del Texto 2: "Habilidades y competencias" y el Texto 2.1: "La noción de competencia", apunte las definiciones de los siguientes conceptos: Habilidad, Competencia y Criterio de logro.
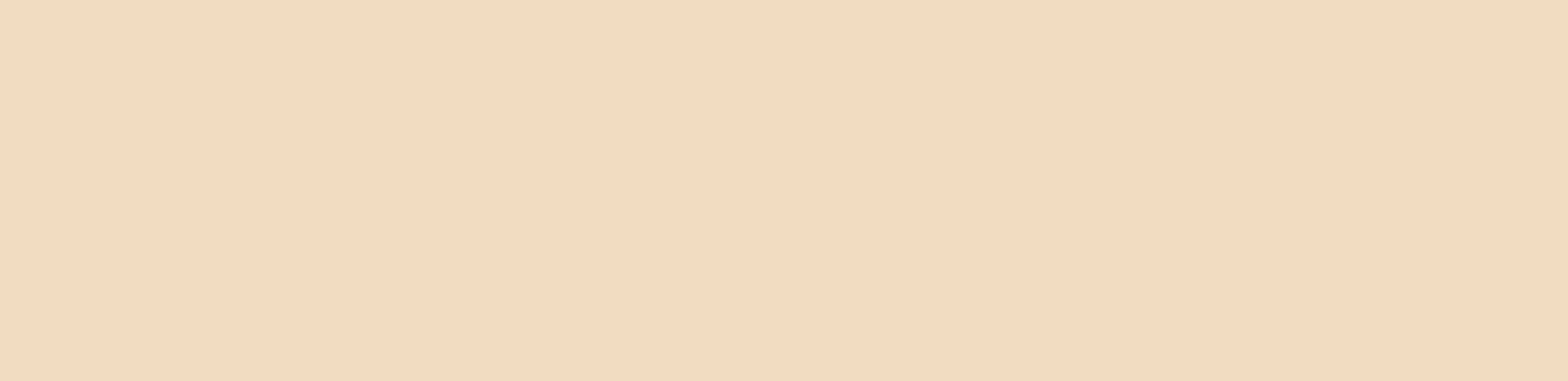

Una vez terminado el ejercicio se sugiere guardar.

\section{Ejercicio 3.2.}

Clasifique en los recuadros los siguientes ejemplos en habilidad, competencia y criterio de logro.

\begin{tabular}{|c|c|}
\hline Ejemplo & Respuesta \\
\hline $\begin{array}{l}\text { Emplear los modos y tiempos verbales apropiados para indicar derechos } \\
\text { y responsabilidades al escribir reglamentos para destinatarios específicos. }\end{array}$ & Competencia \\
\hline $\begin{array}{l}\text { Escribir la adaptación de un guión de teatro que cumpla con lo siguiente: } \\
\text { a) recupere elementos de la obra original; b) estructurada en actos y escenas; } \\
\text { c) describa el ambiente de la obra empleando acotaciones. }\end{array}$ & Habilidad \\
\hline $\begin{array}{l}\text { Comparar las características y funciones de los mitos y leyendas } \\
\text { a partir de la lectura de "El Pípila" y"La Llorona". }\end{array}$ & Criterio de logro \\
\hline
\end{tabular}




\section{¿Qué debe contener la redacción de una competencia?}

- Habilidad: establece el conjunto de respuestas y los eventos o los objetos ante los que se deberá responder de una manera particular.

- Criterio de logro: establece el tipo de desempeño efectivo ante una actividad académica variada.

\section{¿Qué debe contener la redacción de una habilidad?}

- Habilidad: establece el conjunto de respuestas y eventos u objetos ante los que se deberá responder de una manera particular.

\section{¿Qué debe contener la redacción de un criterio de logro?}

- Criterio de logro: establece la especificación del desempeño efectivo ante una actividad académica variada. 


\section{Ejercicio 3.2.}

\begin{tabular}{|l|l|}
\hline \multicolumn{1}{|c|}{ Ejemplo } & \\
\hline $\begin{array}{l}\text { A partir de la lectura de la obra literaria "La Odisea”, describe cinco características } \\
\text { físicas de los personajes principales y escríbelas en tu cuaderno. }\end{array}$ & \\
\hline $\begin{array}{l}\text { Emplear los modos y tiempos verbales apropiados para indicar derechos } \\
\text { y responsabilidades, al escribir reglamentos para destinatarios específicos. }\end{array}$ & \\
\hline $\begin{array}{l}\text { Buscar cinco fuentes de información seleccionando la información más } \\
\text { importante, cita los autores de referencia, para escribir un ensayo con extensión } \\
\text { mínima de una cuartilla sobre el tema "La igualdad entre hombres y mujeres". }\end{array}$ & \\
\hline $\begin{array}{l}\text { Buscar información para elaborar un trabajo escrito sobre la biodiversidad, } \\
\text { seleccionando la más importante (Proyecto 3: Resúmenes organizados. } \\
\text { Primer grado). }\end{array}$ & \\
\hline $\begin{array}{l}\text { Emplear signos de puntuación y acotaciones al escribir el guión adaptado } \\
\text { de una obra de teatro clásico (Proyecto 13: Adaptar una obra de teatro clásico } \\
\text { al contexto actual. Primer grado). }\end{array}$ & \\
\hline
\end{tabular}




\section{Ejercicio 3.2.}

\begin{tabular}{|l|l|}
\hline \multicolumn{1}{|c|}{ Ejemplo } & \\
\hline $\begin{array}{l}\text { Leer cada párrafo en voz alta y subrayar las ideas importantes del texto } \\
\text { "México tiene un plan contra la influenza" (Proyecto 1: Para analizar } \\
\text { y compartir textos. Tercer grado). }\end{array}$ & \\
\hline $\begin{array}{l}\text { Escribir a mano o en procesador de textos el artículo elaborado sobre } \\
\text { la predicción sísmica; incluya ilustraciones, fotografías, gráficas y tablas } \\
\text { (Proyecto 1: Somos escritores de artículos. Segundo grado). }\end{array}$ & \\
\hline $\begin{array}{l}\text { Discriminar la información que debe incluir en un reporte de entrevista, } \\
\text { empleando el diálogo directo y la narración para redactarlo } \\
\text { (Proyecto 10: Conversemos sobre lo que sabes. Segundo grado). }\end{array}$ & \\
\hline $\begin{array}{l}\text { Elaborar comentarios por escrito del cuento “iDiles que no me maten!” } \\
\text { a partir de su argumentación, tomando los siguientes puntos: las razones } \\
\text { de su elección, el análisis de la variante dialectal que emplea el autor } \\
\text { y su apreciación. }\end{array}$ & \\
\hline
\end{tabular}

Una vez terminado el ejercicio se sugiere guardar. 


\section{Ejercicio 3.3.}

Elabore tres ejemplos de competencia a partir de los contenidos de la asignatura de español o matemáticas, argumentando su pertinencia considerando los conceptos y contenidos revisados. Es indispensable que utilice la terminología del texto.

\begin{tabular}{|c|c|}
\hline Ejemplo de competencia (español) & Pertinencia \\
\hline $\begin{array}{l}\text { Identificar los roles de los distintos } \\
\text { participantes de una mesa redonda } \\
\text { y justificar la importancia de los mismos. }\end{array}$ & $\begin{array}{l}\text { Este ejemplo es pertinente debido a que contiene los siguientes } \\
\text { elementos: } \\
\text { a. Habilidad: la identificación depende de las características del } \\
\text { objeto de conocimiento "los roles de los distintos participan- } \\
\text { tes de una mesa redonda". } \\
\text { b. Criterio de logro: especifica el nivel de desligamiento del } \\
\text { desempeño ante una actividad académica variada. }\end{array}$ \\
\hline
\end{tabular}

Ejemplo de competencia (matemáticas)

Justificar la fórmula para calcular la longitud de la circunferencia y el área del círculo, explicitando el número pi como la razón entre la longitud de la circunferencia y el diámetro.

\section{Pertinencia}

Este ejemplo es pertinente debido a que contiene los siguientes elementos:

a. Habilidad: la justificación depende de las características del objeto de conocimiento "la fórmula para calcular la longitud de la circunferencia y el área del círculo".

b. Criterio de logro: especifica que el desempeño efectivo es considerado como tal en tanto se "explicite el número pi como la razón entre la longitud de la circunferencia y del diámetro". 


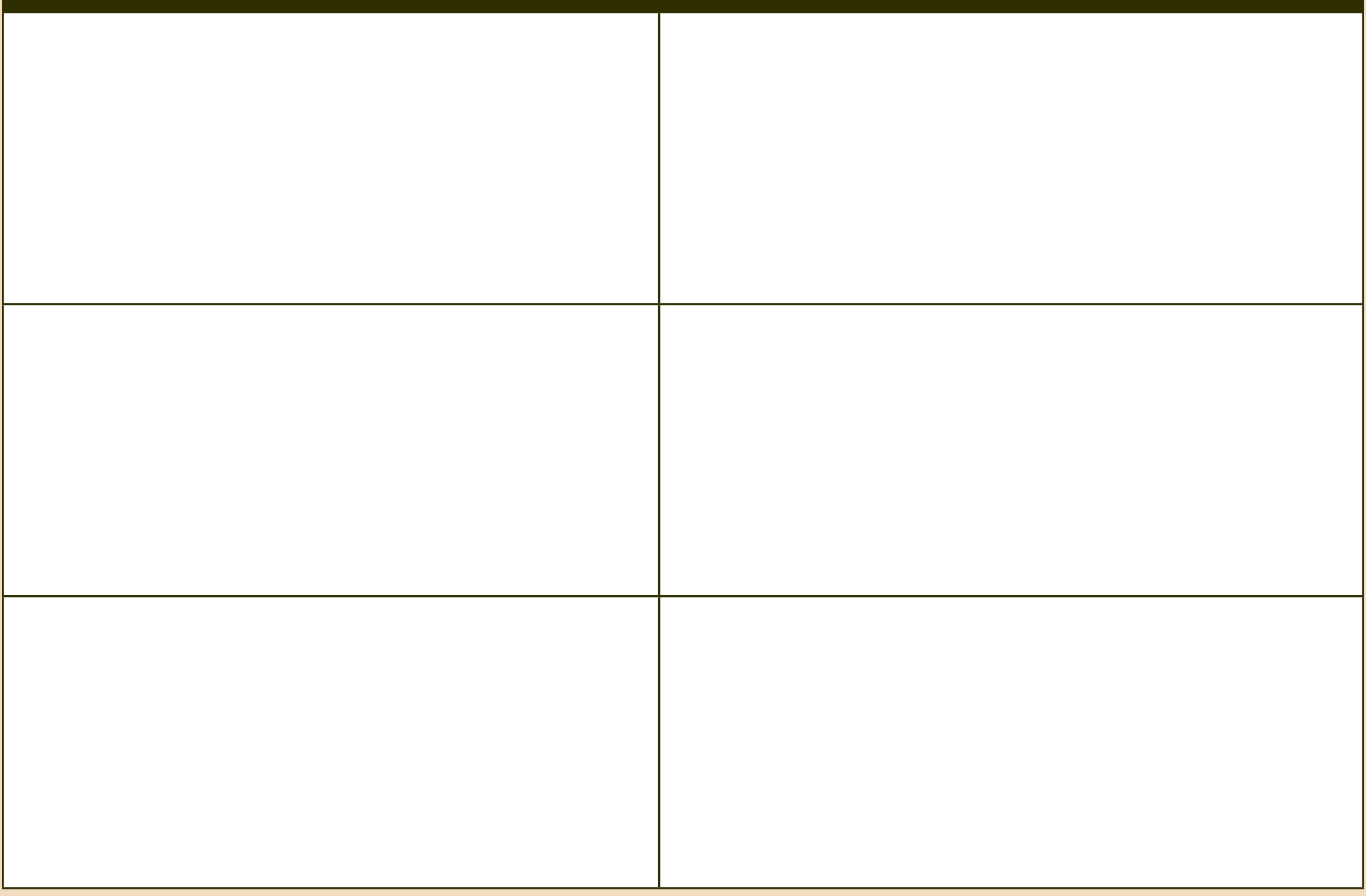

Una vez terminado el ejercicio se sugiere guardar. 
Ejercicio 3.4.

Realice un glosario de los siguientes conceptos; al finalizar habrá que compartirlo con el grupo.

\begin{tabular}{|c|c|}
\hline Concepto: & Definición \\
\hline \multicolumn{2}{|l|}{ Habilidad } \\
\hline \multicolumn{2}{|l|}{ Competencia } \\
\hline \multicolumn{2}{|l|}{ Criterio de logro } \\
\hline \multicolumn{2}{|c|}{ Nivel de complejidad } \\
\hline \multicolumn{2}{|l|}{ Docente } \\
\hline \multicolumn{2}{|l|}{ Discurso didáctico } \\
\hline \multicolumn{2}{|l|}{ Estudiante } \\
\hline Objeto referente & \\
\hline
\end{tabular}

Una vez terminado el ejercicio se sugiere guardar. 


\section{Ejercicio 3.5.}

De acuerdo a su práctica docente especifique en qué secuencia (del 1 al ll) aplicaría las siguientes condiciones en el proceso para auspiciar competencias. Coloque el número secuencial que considere.

\begin{tabular}{|l|l|}
\hline El alumno practica el "cómo" se logra el criterio esperado. & \\
\hline El profesor muestra que domina el tema. & \\
\hline El profesor especifica el nombre del proyecto. & \\
\hline El profesor informa durante el proceso de aplicación del conocimiento aciertos o errores. & \\
\hline El profesor expresa cómo debe lograrse el criterio del aprendizaje esperado. & \\
\hline El profesor especifica el aprendizaje esperado. & \\
\hline El profesor propicia el discurso didáctico con objetos presentes, ausentes o sustitutos. & \\
\hline El profesor ejemplifica el desempeño según el criterio de logro. & \\
\hline El profesor especifica el criterio de logro. & \\
\hline El profesor indaga los conocimientos previos de los alumnos (conceptos, métodos, modelos, teorías). & \\
\hline El profesor cumple con eficacia lo que enseña. & \\
\hline
\end{tabular}

Una vez terminado el ejercicio se sugiere guardar. 


\section{Ejercicio 3.6.}

A partir de un video seleccionado a criterio del instructor o del participante que ilustre una interacción didáctica tipo (por ejemplo YouTube), identifique las condiciones que propicia el profesor para generar competencias en clase. Después, especifique sugerencias en aquellas que sea necesario desarrollar, recuerde utilizar la terminología del texto leído anteriormente al plantear las sugerencias. Utilice la siguiente lista de cotejo y al finalizar comparta sus respuestas con el grupo.

\begin{tabular}{|l|l|l|l|l|l|}
\hline \multicolumn{1}{c}{ Condición Elemento } & \multicolumn{1}{c}{$\begin{array}{l}\text { Cumple la condición en } \\
\text { la interacción didáctica }\end{array}$} \\
\hline \multirow{5}{*}{ El maestro } & $\begin{array}{l}\text { Si Parcialmente No } \\
\text { Expresa ante sus alumnos cómo se } \\
\text { cumple el criterio de logro del } \\
\text { aprendizaje esperado mediante el } \\
\text { cual va a evaluar. }\end{array}$ & & & & \\
\cline { 2 - 6 } & $\begin{array}{l}\text { Ejemplifica ante sus alumnos el } \\
\text { desempeño para cumplir el criterio } \\
\text { de logro. }\end{array}$ & & & & \\
\cline { 2 - 6 } & $\begin{array}{l}\text { Informa y corrige puntualmente al } \\
\text { alumno sobre sus aciertos o errores a } \\
\text { lo largo del proceso de aplicación del } \\
\text { conocimiento. }\end{array}$ & & & & \\
\hline
\end{tabular}




\begin{tabular}{|c|c|c|c|c|c|}
\hline \multirow[t]{2}{*}{ Elemento } & \multirow[t]{2}{*}{ Condición } & \multicolumn{3}{|c|}{$\begin{array}{l}\text { Cumple la condición en } \\
\text { la interacción didáctica }\end{array}$} & \multirow[t]{2}{*}{ Sugerencia } \\
\hline & & Si & Parcialmente & No & \\
\hline \multirow{3}{*}{$\begin{array}{l}\text { El discurso } \\
\text { didáctico }\end{array}$} & $\begin{array}{l}\text { El profesor posee el conocimiento acer- } \\
\text { ca del tema en la forma de saber "cómo". }\end{array}$ & & & & \\
\hline & $\begin{array}{l}\text { Dispone las circunstancias (espacio, } \\
\text { contenidos, materiales y ejercicios } \\
\text { variados) para que el alumno pueda } \\
\text { desempeñarse con base en un criterio } \\
\text { de logro. }\end{array}$ & & & & \\
\hline & $\begin{array}{l}\text { El discurso didáctico del profesor } \\
\text { genera un tipo de respuesta lingüística } \\
\text { en el alumno. }\end{array}$ & & & & \\
\hline \multirow{3}{*}{$\begin{array}{l}\text { Los objetos } \\
\text { referentes } \\
\text { del discurso } \\
\text { didáctico }\end{array}$} & $\begin{array}{l}\text { Mediante el discurso didáctico el } \\
\text { alumno tiene contacto con objetos } \\
\text { físicamente presentes tal cual son. }\end{array}$ & & & & \\
\hline & $\begin{array}{l}\text { Mediante el discurso didáctico el } \\
\text { alumno tiene contacto con objetos } \\
\text { sustitutos. }\end{array}$ & & & & \\
\hline & $\begin{array}{l}\text { Mediante el discurso didáctico el } \\
\text { alumno tiene contacto con objetos } \\
\text { no presentes. }\end{array}$ & & & & \\
\hline
\end{tabular}




\begin{tabular}{|c|c|c|c|c|c|}
\hline \multirow[t]{2}{*}{ Elemento } & \multirow[t]{2}{*}{ Condición } & \multicolumn{3}{|c|}{$\begin{array}{l}\text { Cumple la condición en } \\
\text { la interacción didáctica }\end{array}$} & \multirow[t]{2}{*}{ Sugerencit } \\
\hline & & Si & Parcialmente & No & \\
\hline \multirow{3}{*}{ El alumno } & $\begin{array}{l}\text { Mediante el discurso didáctico que } \\
\text { genera el profesor se identifica si el } \\
\text { alumno tiene conocimientos previos } \\
\text { del tema de la asignatura (conceptos, } \\
\text { procedimientos, métodos, modelos } \\
\text { o teorías). }\end{array}$ & & & & \\
\hline & $\begin{array}{l}\text { El desempeño del alumno en una } \\
\text { actividad o problema es coherente con } \\
\text { el criterio de logro establecido por el } \\
\text { profesor en la generación de } \\
\text { conocimiento de mayor complejidad. }\end{array}$ & & & & \\
\hline & $\begin{array}{l}\text { Mediante el discurso didáctico el } \\
\text { alumno tiene contacto con objetos o } \\
\text { eventos según el dominio o disciplina. }\end{array}$ & & & & \\
\hline
\end{tabular}




\section{Ejercicio 3.7.}

Justifique por qué es necesario que las interacciones didácticas promuevan el establecimiento de las competencias en la asignatura de Español o Matemáticas. La redacción debe incluir necesariamente la terminología conceptual revisada en esta sesión. Puede apoyarse en el texto revisado.

\section{¿Qué términos debe}

\section{contener la justificación?}

- Habilidad.

- Competencia.

- Criterio de logro.

- Nivel de complejidad.

- Docente.

- Discurso didáctico.

- Estudiante.

- Objeto referente.

Una vez terminado el ejercicio se sugiere guardar. 
Rúbricas ejercicios 3.1. al 3.7.

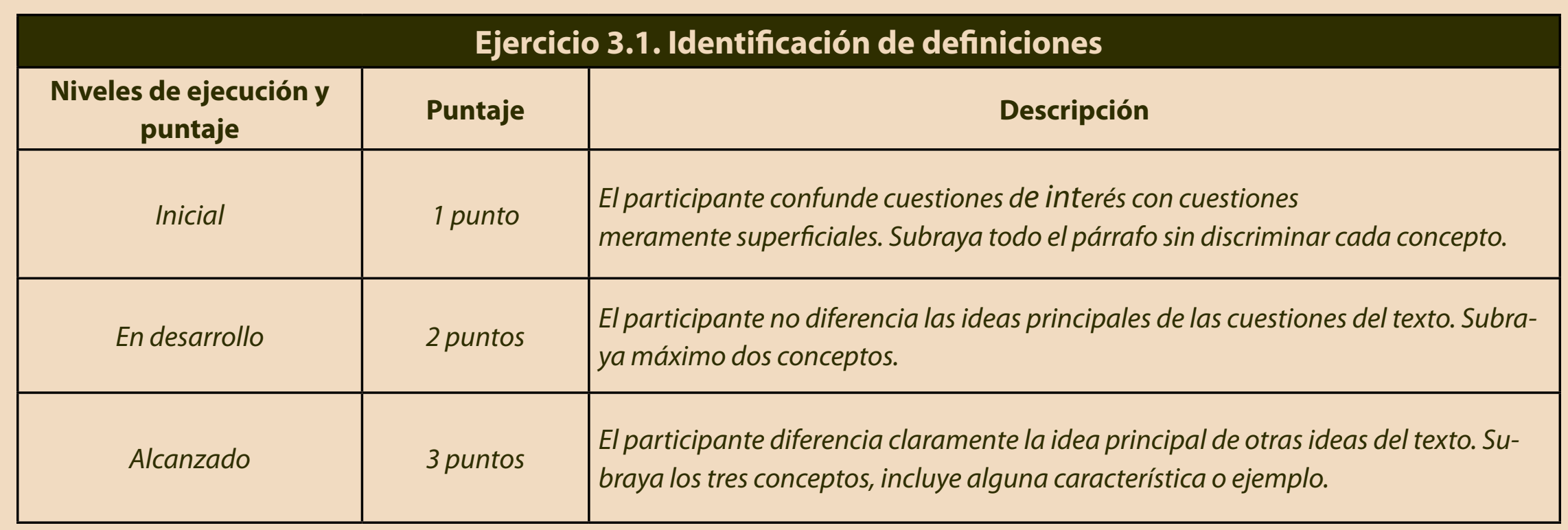




\begin{tabular}{|c|c|l|}
\hline $\begin{array}{c}\text { Niveles de ejecución } \\
\text { y puntaje }\end{array}$ & Puntaje & Ejercicio 3.2. Clasificación de ejemplos \\
\hline Inicial & 2 punto & $\begin{array}{l}\text { El participante no identifica los aspectos y la descripción de cada término en las } \\
\text { actividades presentes en la interacción didáctica mediante el discurso didáctico. } \\
\text { Clasifica las actividades académicas generadas en la interacción didáctica median- } \\
\text { te el discurso didáctico pero no hay correspondencia con cada término. Asocia por } \\
\text { lo menos dos ejemplos con su respectivo término. }\end{array}$ \\
\hline En desarrollo & 3 puntos & $\begin{array}{l}\text { El participante identifica parcialmente los aspectos y la descripción de cada término } \\
\text { en las actividades presentes en la interacción didáctica mediante el discurso didác- } \\
\text { tico, compara y clasifica las actividades académicas generadas en la interacción } \\
\text { didáctica mediante el discurso didáctico pero no todas corresponden al término. } \\
\text { Asocia por lo menos cuatro ejemplos con su respectivo término. }\end{array}$ \\
\hline Alcanzado & $\begin{array}{l}\text { El participante identifica diferencialmente los aspectos y la descripción de cada tér- } \\
\text { mino en las actividades presentes en la interacción didáctica mediante el discurso } \\
\text { didáctico, compara y clasifica las actividades académicas generadas en la interac- } \\
\text { ción didáctica mediante el discurso didáctico según el término al que corresponde. } \\
\text { Asocia por lo menos siete ejemplos con su respectivo término. }\end{array}$ \\
\hline
\end{tabular}




\begin{tabular}{|c|c|l|}
\hline $\begin{array}{c}\text { Niveles de ejecución } \\
\text { y puntaje }\end{array}$ & Puntaje & Ejercicio 3.3. Elaboración del ejemplo \\
\hline Inicial & 2 punto & $\begin{array}{l}\text { El participante elabora ejemplos adecuados con situaciones didácticas, pero no } \\
\text { identifica aspectos principales y la descripción de uno o dos niveles funcionales y } \\
\text { reproduce literalmente el ejemplo del texto. }\end{array}$ \\
\hline En desarrollo & $\begin{array}{l}\text { El participante elabora ejemplos adecuados y se relacionan con situaciones didác- } \\
\text { ticas y contenidos de español pero no aporta nuevas propuestas, identifica algunos } \\
\text { de los aspectos principales (nombre del proyecto, habilidades, criterio de logro y } \\
\text { nivel de complejidad) así como la descripción del término competencia, los interre- } \\
\text { laciona y expresa el ejemplo con sus propias palabras. }\end{array}$ \\
\hline Alcanzado & 3 puntos & $\begin{array}{l}\text { El participante elabora ejemplos adecuados y en algunos casos innovadores con } \\
\text { respecto a situaciones didácticas y contenidos de español y matemáticas, identi- } \\
\text { fica los aspectos principales (nombre del proyecto, habilidades, criterio de logro y } \\
\text { nivel de complejidad) y la descripción del término competencia, los interrelaciona y } \\
\text { expresa con claridad el ejemplo con sus propias palabras. }\end{array}$ \\
\hline
\end{tabular}




\begin{tabular}{|c|c|l|}
\hline $\begin{array}{c}\text { Niveles de ejecución } \\
\text { y puntaje }\end{array}$ & Puntaje & \multicolumn{1}{|c|}{ Ejercicio 3.3. Justificación de la pertinencia } \\
\hline Inicial & Dunto & $\begin{array}{l}\text { El participante sostiene su ejemplo sin basarse en los aspectos del término compe- } \\
\text { tencia pero integra los contenidos de la asignatura. Excluye los aspectos principales } \\
\text { yla descripción del término competencia. El texto no es coherente y no hace enten- } \\
\text { der qué es lo que quiere comunicar. }\end{array}$ \\
\hline En desarrollo & 3puntos & $\begin{array}{l}\text { El participante sostiene su ejemplo en algunos aspectos del término competencia } \\
\text { pero integra los contenidos de la asignatura. Considera uno o dos aspectos princi- } \\
\text { pales y la descripción del término competencia proveniente de la lectura como base } \\
\text { de su justificación. Comunica las razones que avalan el ejemplo pero no convencey } \\
\text { utiliza algunos términos. }\end{array}$ \\
\hline Alcanzado & $\begin{array}{l}\text { El participante sostiene su ejemplo en los aspectos principales del término compe- } \\
\text { tencia e integra los contenidos de la asignatura. Considera los aspectos principales } \\
\text { yla descripción del término competencia como base de su justificación. Comunica } \\
\text { bien las razones que avalan el ejemplo utilizando la terminología del texto. }\end{array}$ \\
\hline
\end{tabular}




\begin{tabular}{|c|c|l|}
\hline $\begin{array}{c}\text { Niveles de ejecución } \\
\text { y puntaje }\end{array}$ & Puntaje & Ejercicio 3.4. Elaboración del glosario \\
\hline Inicial & Descripción \\
\hline En desarrollo & 2 puntos & $\begin{array}{l}\text { El participante elabora un glosario que contiene menos del } 40 \text { \% de los elementos y } \\
\text { condiciones para generar competencias, las características enunciadas de los elemen- } \\
\text { tos y condiciones para generar competencias son un poco confusas o limitadas. Las } \\
\text { características enunciadas son más bien explicaciones que se extienden sin precisar } \\
\text { lo importante. Tiene notables errores ortográficos, de acentuación o conjugación de } \\
\text { verbos, escribe de modo irregular pero se entiende. }\end{array}$ \\
\hline Alcanzado & $\begin{array}{l}\text { El participante elabora un glosario que contiene el 75 \% de los elementos y condi- } \\
\text { ciones para generar competencias, las características enunciadas de los elementos y } \\
\text { condiciones para generar competenciales son bastante claras. Las características o } \\
\text { explicaciones de los elementos y condiciones para generar competencia expresan lo } \\
\text { sustancial de ellos pero se puede ser aún más sintético. Tiene muy pocos errores orto- } \\
\text { gráficos de acentuación o conjunción de verbos. Su letra es legible casi en su totalidad. }\end{array}$ \\
\hline 3 puntos & $\begin{array}{l}\text { El participante elabora un glosario que contiene todos los elementos y condiciones } \\
\text { para generar competencias y las características enunciadas son completas y concisas. } \\
\text { La descripción de sus características es breve y sustanciosa, no hay exceso de palabras } \\
\text { ni dificultades ni circunlocuciones ociosas. No tiene errores ortográficos de acentua- } \\
\text { ción, de conjunción de verbos y la letras es legible, bien cuidada. }\end{array}$ \\
\hline
\end{tabular}




\begin{tabular}{|c|c|c|}
\hline $\begin{array}{c}\text { Niveles de ejecución } \\
\text { y puntaje }\end{array}$ & Puntaje & Descripción \\
\hline Inicial & 1 punto & $\begin{array}{l}\text { El participante identifica en la secuencia de } 0 \text { a } 4 \text { condiciones del proceso para la } \\
\text { generación de competencias. }\end{array}$ \\
\hline En desarrollo & 2 puntos & $\begin{array}{l}\text { El participante identifica en la secuencia de } 5 \text { a } 8 \text { condiciones del proceso para la } \\
\text { generación de competencias. }\end{array}$ \\
\hline Alcanzado & 3 puntos & $\begin{array}{l}\text { El participante identifica en la secuencia de } 9 \text { a } 11 \text { condiciones del proceso para la } \\
\text { generación de competencias. }\end{array}$ \\
\hline
\end{tabular}




\section{Ejercicio 3.6. Identificación de competencias docentes}

\begin{tabular}{|c|c|c|}
\hline $\begin{array}{c}\text { Niveles de ejecución } \\
\text { y puntaje }\end{array}$ & Puntaje & Descripción \\
\hline Inicial & 1 punto & $\begin{array}{l}\text { El participante no identifica las condiciones básicas para la generación de competen- } \\
\text { cias y cada uno de sus elementos en las actividades presentes en la interacción didácti- } \\
\text { ca mediante el discurso didáctico. Clasifica las actividades académicas generadas en la } \\
\text { interacción didáctica mediante el discurso didáctico pero no hay correspondencia con } \\
\text { las condiciones básicas para la generación de competencias y cada uno de sus elemen- } \\
\text { tos. Asocia máximo dos ejemplos con las condiciones básicas para la generación de } \\
\text { competencias y cada uno de sus elementos. }\end{array}$ \\
\hline En desarrollo & 2 puntos & $\begin{array}{l}\text { El participante identifica parcialmente los aspectos y la descripción de las condiciones } \\
\text { básicas para la generación de competencias y cada uno de sus elementos en las acti- } \\
\text { vidades presentes en la interacción didáctica mediante el discurso didáctico. Compara } \\
\text { y clasifica las actividades académicas generadas en la interacción didáctica mediante } \\
\text { el discurso didáctico pero no todas corresponden con las condiciones básicas para la } \\
\text { generación de competencias y cada uno de sus elementos. Asocia por lo menos cuatro } \\
\text { ejemplos con su respectivo término. }\end{array}$ \\
\hline Alcanzado & 3 puntos & $\begin{array}{l}\text { El participante identifica diferencialmente los aspectos y la descripción de las condi- } \\
\text { ciones básicas para la generación de competencias y cada uno de sus elementos en } \\
\text { las actividades presentes en la interacción didáctica mediante el discurso didáctico. } \\
\text { Compara y clasifica las actividades académicas generadas en la interacción didáctica } \\
\text { mediante el discurso didáctico según las condiciones básicas para la generación de } \\
\text { competencias y cada uno de sus elementos al que corresponde. Asocia por lo menos } \\
\text { siete ejemplos con su respectivo término. }\end{array}$ \\
\hline
\end{tabular}




\begin{tabular}{|c|c|l|}
\hline $\begin{array}{c}\text { Niveles de ejecución } \\
\text { y puntaje }\end{array}$ & Puntaje & Ejercicio 3.7. Promoción de competencias \\
\hline Inicial & Dunto & $\begin{array}{l}\text { El participante sostiene su sugerencia sin basarse en las condiciones necesarias para } \\
\text { desarrollar competencias pero integra los contenidos de la asignatura. Excluye los } \\
\text { aspectos principales y las condiciones necesarias para desarrollar competencias. El } \\
\text { texto no es coherente y no hace entender qué es lo que quiere comunicar. }\end{array}$ \\
\hline En desarrollo & 3 puntos & $\begin{array}{l}\text { El participante sostiene su sugerencia en algunas de las condiciones necesarias para } \\
\text { uno o dos aspectos principales y las condiciones necesarias para desarrollar } \\
\text { competencias provenientes de la lectura como base de su justificación. Comunica } \\
\text { las razones que avalan sus sugerencias pero no convence y utiliza algunos términos. }\end{array}$ \\
\hline Alcanzado & $\begin{array}{l}\text { El participante sostiene su sugerencia en los aspectos principales de las condiciones } \\
\text { necesarias para desarrollar competencias e integra los contenidos de la asignatura. } \\
\text { competencias como base de su justificación. Comunica bien las razones que avalan } \\
\text { su sugerencia utilizando la terminología del texto. }\end{array}$ \\
\hline
\end{tabular}




\section{Módulo 4 \\ Planeación de las interacciones didácticas bajo un enfoque por competencias}

Objetivo: Identificar los niveles de complejidad que a partir de este momento llamaremos niveles de complejidad funcional.

Instrucciones: Lea el Texto 3: “La definición del nivel de complejidad funcional de las competencias" e identifique los conceptos principales, para ubicar las tareas en los diferentes niveles de complejidad y justificarlo con la terminología revisada.

Aprendizaje esperado: Argumentar por escrito la congruencia entre el ejemplo realizado con su respectivo nivel funcional, empleando la terminología ya mencionada. 
Texto 3.

La definición del nivel de complejidad funcional de las competencias

Recordemos que la competencia se define como un conjunto de habilidades que satisfacen un criterio de logro en un nivel determinado de complejidad (Ribes, 2012), es decir, las competencias difieren entre sí en cuanto al grado de abstracción requerido para su realización. No es lo mismo ser capaz de nombrar los elementos de la Tabla Periódica que calcular un proceso químico; tampoco es lo mismo recitar el Primer Principio de la Termodinámica que calcular la energía que se requiere para aumentar la temperatura de un cuerpo determinado. En ambos ejemplos, es evidente que la competencia de calcular es "más compleja" que citar, pero también es probable que para calcular sea necesario haber aprendido primero a citar o a llamar las cosas por su nombre (Ibáñez, 2007), pero, ¿cómo se planea didácticamente en diferentes grados de complejidad?

La planeación de las actividades es una tarea que requiere de un marco de referencia teórico, que nos permita definir por ejemplo el nivel de complejidad funcional de una competencia, sobre todo si se quiere desarrollar de forma sistemática las competencias que integran los aprendizajes esperados.
Las teorías del aprendizaje generalmente no ofrecen una solución a este problema. Por ejemplo, Gagné y Briggs (1979), aunque ofrecen una tipología de aprendizaje (actitudes, habilidades motoras, información, habilidades intelectuales y estrategias cognoscitivas), sus categorías son cualitativamente diferentes entre sí, representando dominios separados, y sólo postulan relaciones jerárquicas entre los subtipos de habilidades intelectuales. Por su parte, las teorías del desarrollo psicológico aunque enfocan a la evolución del comportamiento, frecuentemente lo hacen como un proceso ligado necesariamente a la ontogenia del individuo, lo cual dificulta concebir el aprendizaje de las competencias como un proceso que puede ocurrir paralelamente a la maduración biológica.

El desarrollo de las competencias sigue un orden que fue reconocido por los pedagogos, por lo menos desde Comenio, conocido como el "Padre de la Pedagogía" quién publicó en 1657 su Didáctica Magna. Comenio pensaba que la enseñanza en las escuelas debía seguir un orden que observamos en la Naturaleza. Según este pedagogo, la Naturaleza procede de lo más fácil a lo más difícil y, en consecuencia, es necesario reformar las escuelas con el fin de ejercitar de la misma manera a los alumnos, primero en los sentidos, después la memoria y luego el entendimiento $y$, por último el juicio. 


\section{Texto 3.1.}

La definición del nivel funcional de las competencias

La aguda propuesta de Comenio es esclarecedora y ejemplar al respecto de la graduación y prioridad que debe establecerse en la formación de habilidades a desarrollar en los estudiantes. Sin embargo, creemos que los avances científicos en Teoría de la Conducta pueden ofrecer bases congruentes para proponer un paradigma de formación de competencias (Ibáñez, 2007).

En principio se requiere de un modelo teórico que permita distinguir tipos de comportamientos en términos de su organización y funcionalidad, es decir, que distinga diferentes niveles de aptitud funcional en que puedan clasificarse los desempeños. La taxonomía de procesos comportamentales de Ribes y López (1985) nos permite realizar esta tarea. Dicha taxonomía está compuesta por los niveles funcionales contextual, suplementario, selector, sustitutivo referencial y sustitutivo no referencial, mismos que se desarrollarán a detalle en esta sesión. 


\section{Ejercicio 4.1.}

Lea cada uno de los niveles de complejidad funcional de las interacciones didácticas y anote los términos más importantes.
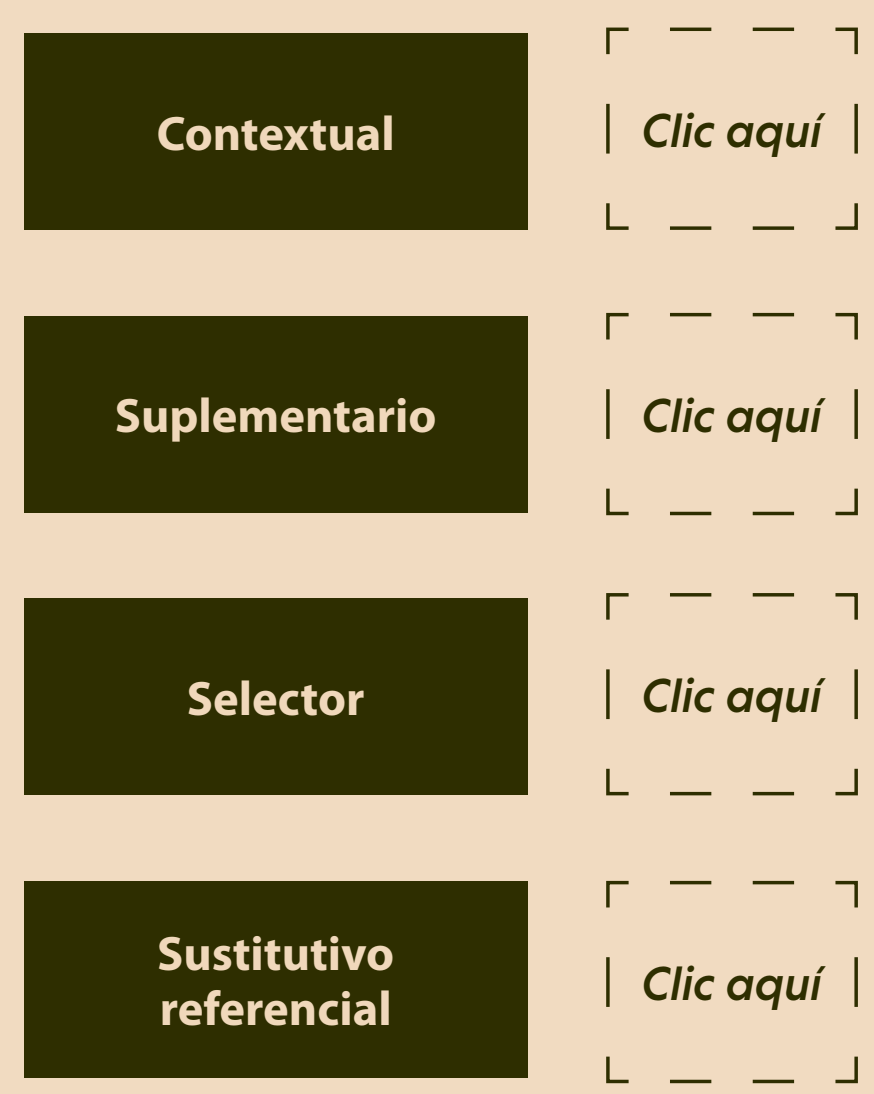

$\ulcorner--\urcorner$
$\mid$ Clic aquí $\mid$
$\llcorner-\ldots\rfloor$

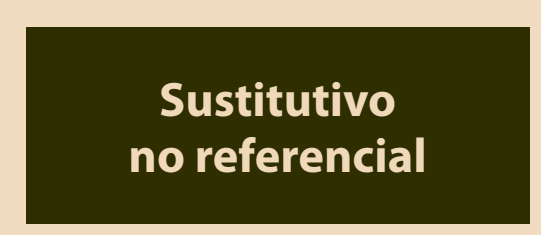

$\ulcorner--\neg$
$\mid$ Clic aquí |
$\llcorner-\ldots$

$\ulcorner------7$ Saltar al Ejercicio 4.2. 


\section{Contextual}

\section{Descripción}

En este nivel es necesario el discurso didáctico en la presencia de los objetos o situaciones del mundo real para establecer relaciones directas y diferenciales.

El propósito de este nivel es entrenar al alumno a identificar cómo se llama algo, cómo es o qué, cómo y cuándo sucedió o sucederá en algún momento (Ibáñez, 2007).

Considérese por ejemplo el estudio de la anatomía humana; es indispensable contar con la presencia de la estructura bajo análisis y un discurso que vaya señalando los nombres de cada una de sus partes y sus características.

\section{Ejemplo}

Enseñanza de la lectura

Los niños se limitan a pronunciar los sonidos, palabras o frases y párrafos o a copiar las letras o frases que se encuentran en un texto o en el pizarrón. Para el caso del lenguaje hablado tienen un papel de escuchas o de repetidores de la información, mientras que para el lenguaje escrito se limitan a deletrear los textos y copiarlos.

Se dice que el profesor promueve interacciones en un nivel contextual en sus alumnos, cuando expone un tema para que ellos lo escuchen o bien cuando la actividad en que los involucra se refiere exclusivamente a leer o repetir información, sin formular preguntas que vayan más allá de lo explícitamente contenido en el discurso o en el texto.

\section{Caso específico}

Proyecto 2. Poesía en voz alta (segundo grado)

Los alumnos en el lenguaje hablado leen y releen en voz alta poemas sintiendo su ritmo y sonoridad; mientras que en el lenguaje escrito trascribir una metáfora a su cuaderno es un ejemplo de este nivel. 


\section{Suplementario}

\section{Descripción}

Es fundamental el discurso didáctico para regular una acción o procedimiento que elabore el alumno y además que existan las condiciones necesarias para su realización.

El propósito del discurso didáctico en el nivel suplementario es instruir al alumno sobre cómo proceder ante los objetos o los eventos a partir de una situación particular para alcanzar cierta meta, y que el alumno responda con efectividad.

Un ejemplo de este nivel sería el discurso en el que se describe paso a paso un procedimiento o técnica para obtener algún producto o resultado (Ibáñez y Ribes, 2001).

Un ejemplo más: considérese el estudio de una técnica para el curtido de pieles, es ineludible contar con la piel y los químicos, y actuar conforme al procedimiento establecido siguiendo instrucciones. Ver un video en el que se presenta paso por paso la técnica, no garantiza el aprendizaje del aprendiz ni su realización.

\section{Ejemplo}

\section{Enseñanza de la lectura}

Los niños interactúan con los textos modificándolos de tal manera que ya no se limitan a responder diferencialmente a las letras, palabras o frases que leen o escriben sino que las modifican en el ámbito de la ortografía.

Se dice que el profesor promueve el nivel suplementario de la lecto-escritura cuando organiza ejercicios en donde los alumnos corrigen, completan o marcan un texto atendiendo a criterios ortográficos, tales como el uso de la "b" o la "v", acentos, clasificación de sustantivos, entre otros.

\section{Caso específico}

Proyecto 2. Poesía en voz alta (segundo grado)

Una actividad solicitada al estudiante es la elaboración de una rima consonante, para ello tiene que identificar los sonidos vocálicos y consonánticos a partir de cada verso, se promueve el nivel suplementario cuando el estudiante realiza el procedimiento para la creación de rimas consonantes: hace coincidir todos los sonidos de las vocales y consonantes a partir de la última vocal acentuada:

- No vayas al camposanto,

- Porque los sueños de amor,

- No muere, se mudan en llanto,

- Su forma de ave y flor. 


\section{Selector}

\section{Descripción}

Es necesaria la presencia de una gama de objetos y la acción del alumno sobre ellos en función de los criterios aportados por el discurso didáctico. En este caso es fundamental contar con la más amplia diversidad posible de objetos o características de tal manera que sea factible la aplicación de los criterios en situaciones novedosas.

En el nivel selector, el discurso didáctico ofrece al alumno un "esquema de decisión" que le permita elegir o conducirse con precisión ante un objeto o característica, pertinente a una dimensión, grupo o clase de objetos o eventos, para producir un efecto específico.

Como ejemplo se puede citar el discurso didáctico que refiere un sistema para clasificar animales según sus atributos morfológicos (Ibáñez y Ribes, 2001).

\section{Ejemplo}

Enseñanza de la lectura

Las interacciones del niño cuando lee y escribe se vuelven relativas a otros elementos del mismo texto, de tal manera que el niño selecciona segmentos del texto y los escribe en función del tipo de pregunta literal que se le formula. Así, el niño se desliga de la relación fija entre un texto y una acción (palabra impresa o pronunciación de la palabra impresa) y elige qué escribir en cada caso.

Se dice que un profesor promueve este nivel cuando involucra a sus alumnos en tareas que requieren seleccionar un segmento de un texto pertinente a preguntas particulares.

Un ejemplo sería cuando a partir de un texto, la maestra elabora preguntas del tipo "quién", "cuándo", "dónde", "por qué", "qué", de tal manera que la selección de segmentos del texto se vuelve relativa al tipo de pregunta formulada.

\section{Caso específico}

\section{Proyecto 2. Poesía en voz alta (segundo grado)}

Se promueve este nivel a partir de los siguientes ejercicios:

- Anotar las características del romanticismo.

- Considerando los poemas que has leído, ¿en qué difieren los de Gustavo Adolfo Bécquer y los de Rubén Darío?

- Clasifica los movimientos contemporáneos por etapas. 


\section{Sustitutivo}

referencial

\section{Descripción}

En este nivel se requiere que el alumno observe ejemplos de los fenómenos o procesos bajo estudio y la descripción discursiva simultánea de sus características y condiciones de ocurrencia.

En el nivel sustitutivo referencial, el discurso didáctico media linguísticamente las relaciones del individuo con respecto a los objetos o eventos que ocurren en una situación a partir de la referencia -necesariamente vía lenguaje-, a los objetos o acontecimientos de una situación diferente. Puede decirse que este tipo de discurso hace referencia a lo que se ha dicho o planteado acerca de determinados objetos o eventos, con el propósito de presentar al alumno una especie de modelo o ejemplar de cómo funcionan o se desarrollan las cosas.

Un ejemplo de este tipo de discurso es aquel que refiere cómo ocurre un proceso natural, como la fotosíntesis o la conservación de la energía (Ibáñez, 2007). 


\section{Sustitutivo}

referencial

\section{Ejemplo}

\section{Enseñanza de la lectura}

Los estudiantes interactúan de manera indirecta, a través del texto, con los contenidos del mismo y ponen en contacto indirecto a otra persona con diferentes acontecimientos, cuando ellos escriben. De tal manera que cuando leen textos apropiados a su edad y a su contexto de desarrollo, pueden decir si lo escrito corresponde con la realidad o no, vincularlo con sus experiencias, reelaborarlo con sus propias palabras, contestar preguntas recurriendo a su experiencia y no sólo a lo explícitamente contenido en el mismo. Mientras que al escribir comunican a otros sucesos que se presenciaron o las actividades realizadas en un día o un fin de semana, sus deseos o sus afectos, refiriendo eventos pasados o futuros y describiendo situaciones ausentes.

Se dice que un profesor promueve el nivel sustitutivo referencial cuando pide que los alumnos describan, de manera hablada o escrita, distintos acontecimientos, por ejemplo la visita a un museo o una feria.

Un ejemplo de este tipo de contacto ocurre cuando la maestra elabora una historia apoyándose en dibujos e involucra a los niños, a través de preguntas en la elaboración de la misma. Los niños escriben una historia, tomando como base el contenido de tres dibujos en secuencia. Los dibujos contienen preguntas que ayudan al niño a observar y describir los dibujos. Después cada niño platica a otro compañero lo que escribió.

\section{Caso específico}

Proyecto 2. Poesía en voz alta (segundo grado)

1. Los estudiantes interactúan de manera indirecta, a través del texto, con los contenidos del mismo y ponen en contacto indirecto a otra persona con diferentes acontecimientos, cuando ellos escriben. De tal manera que cuando leen textos apropiados a su edad y a su contexto de desarrollo, pueden decir si lo escrito corresponde con la realidad:

Realiza la lectura del poema La duquesa Job de Manuel Gutiérrez Nájera y comenta con tu equipo cómo son las charlas de sobremesa en tu casa. O quizá alguna vez, te han llamado la atención las charlas de algún lugar a donde hayas ido a comer; si es así, platica a tus compañeros lo sucedido.

\section{Vincularlo con sus experiencias:}

Después de leer el poema de Lope de Vega: Desmayarse, atreverse, estar furioso. ¿Qué ideas, sensaciones o sentimientos despierta en ti?

3. Reelaborarlo con sus propias palabras:

Elabora un cartel en el que ilustres tu interpretación y los efectos emotivos que te causó. 


\section{Sustitutivo no referencial}

\section{Descripción}

En este nivel se requiere que el alumno actúe sobre una amplia diversidad de objetos convencionales (valores, reglas, lenguaje algebraico, método científico, aspectos culturales como el refrán) en función de los métodos de transformación provistos en el discurso didáctico.

En este nivel, el propósito de este discurso es proporcionar al alumno un método o conjunto de criterios que le permitan relacionar, analizar, evaluar, modificar o transformar lo que se dice o se ha dicho acerca de algo.

Como ejemplo de este discurso en el nivel sustitutivo no referencial podemos citar aquel que refiere la aplicación de métodos matemáticos o estadísticos para evaluar cuantitativamente las diferencias aparentes entre grupos u objetos.

\section{Ejemplo}

\section{Enseñanza de la lectura}

En este último nivel, las interacciones de los niños referidas a la lectura y la escritura ya no se limitan a referir eventos, sino que los niños interactúan con las expresiones lingüísticas en su carácter de abstracciones construidas sobre los elementos concretos que guían, a manera de definiciones o sistemas, su contacto con los eventos o su entorno. Formas sencillas serían que los niños elaboren reglas de juego que deben guiar sus juicios y argumentaciones ante puntos de vista diferentes, y que ellos mismos pueden volver a reelaborar para resolver problemas derivados de su práctica.

Se dice que el profesor promueve este nivel de interacción cuando solicita que los alumnos elaboren un juicio con base en reglas o definiciones; o bien, que elaboren expresiones que busquen acercarse a la regularidad de un evento sencillo; o les pide que organicen objetos atendiendo a definiciones y argumentando el porqué de su organización.

También se promueve este nivel cuando los niños representan cada uno de los personajes contenidos en los dibujos de una historia, los compañeros les hacen preguntas sobre su caracterización y ellos contestan desde el personaje representado.

En educación primaria, desarrollar este nivel sustitutivo no referencial prepara a los estudiantes para el análisis científico de los fenómenos, utilizando la terminología correspondiente.

\section{Caso específico}

\section{Proyecto 2. Poesía en voz alta (segundo grado)}

- Los estudiantes interactúan con las expresiones lingüísticas en su carácter de abstracciones construidas sobre los elementos concretos que guían, a manera de definiciones o sistemas, su contacto con los eventos o su entorno:

La metáfora, por ejemplo, para referirse al mes de abril, Góngora dice: Era del año la estación florida. Para hablar de una nariz pronunciada, Quevedo escribió: Era un reloj de sol mal encarado.

- Los alumnos elaboran un juicio con base en reglas o definiciones:

¿Qué piensas del contenido poético de las canciones que te gustan?

- Los alumnos elaboran expresiones que busquen acercarse a la regularidad de un evento sencillo:

Elabora una metáfora. 


\section{Ejercicio 4.2.}

A partir de la lectura del Texto 3 y 3.1: "Niveles de complejidad funcional de las interacciones didácticas", realice un glosario con las características de los niveles funcionales contextual, suplementario, selector, sustitutivo referencial, sustitutivo no referencial.

\begin{tabular}{|c|c|}
\hline Conceptos & Definición \\
\hline Contextual & \\
\hline Suplementario & \\
\hline Selector & \\
\hline Sustitutivo referencial & \\
\hline Sustitutivo no referencial & \\
\hline
\end{tabular}




\section{Ejercicio 4.3.}

A partir de un video seleccionado a criterio del instructor o del participantes que ilustre una interacción didáctica tipo, identifique los niveles funcionales que mediante el discurso didáctico el profesor promueve, para ello utilice la siguiente lista de cotejo, al finalizar verifique y corrija sus respuestas.

\begin{tabular}{|c|c|}
\hline Nivel funcional & Actividades propiciadas en la interacción didáctica \\
\hline \multirow{4}{*}{ Contextual } & $\begin{array}{l}\text { Después de la presentación de cierta información, el profesor solicita que los alum- } \\
\text { nos reproduzcan (repitiendo, leyendo o escribiendo) lo que se acaba de decir o leer. }\end{array}$ \\
\hline & $\begin{array}{l}\text { El profesor solicita a los alumnos realizar cualquier actividad práctica que implica } \\
\text { copiar lo visto en la lección y los alumnos lo llevan a cabo. }\end{array}$ \\
\hline & El profesor solicita a los alumnos leer el nombre del autor y dónde se publicó el texto. \\
\hline & $\begin{array}{l}\text { El profesor reparte una fotocopia del texto que se proyecta en el pizarrón, } \\
\text { los alumnos leen en voz alta. }\end{array}$ \\
\hline \multirow{2}{*}{ Suplementario } & $\begin{array}{l}\text { El profesor solicita a los alumnos que realicen por escrito su resumen enlazando las } \\
\text { ideas principales utilizando nexos. }\end{array}$ \\
\hline & $\begin{array}{l}\text { El profesor pide a los alumnos que realicen una actividad que implica completar un } \\
\text { ejercicio o aplicar un procedimiento sin modelo presente y los alumnos lo realizan. }\end{array}$ \\
\hline
\end{tabular}




\begin{tabular}{|c|c|}
\hline Nivel funcional & Actividades propiciadas en la interacción didáctica \\
\hline \multirow{6}{*}{ Selector } & $\begin{array}{l}\text { El profesor elabora preguntas que requieren que el alumno elija de un producto } \\
\text { lingüístico o de una imagen, de manera condicional a la palabra-pregunta. El } \\
\text { alumno copia, repite o elije el segmento pertinente. }\end{array}$ \\
\hline & $\begin{array}{l}\text { El profesor pregunta los pasos para realizar un resumen, pasa a un alumno a escribir } \\
\text { en el pizarrón las respuestas, el profesor proporciona ayuda para generar respuestas } \\
\text { en caso de no contestar o sean incorrectas. }\end{array}$ \\
\hline & $\begin{array}{l}\text { El profesor indica que señalen un párrafo, para realizar esta tarea primero describe } \\
\text { el cómo identificar un párrafo y describe sus características, por último solicita } \\
\text { enumerar en el margen izquierdo los } 9 \text { párrafos e identificar la idea principal o } \\
\text { conceptos claves en equipo. }\end{array}$ \\
\hline & El equipo selecciona la idea principal del párrafo proyectado. \\
\hline & $\begin{array}{l}\text { El profesor dicta las preguntas ¿de qué trata este párrafo?, ¿el tema, idea principal } \\
\text { del párrafo 1?, lo anterior lo aplicarán en los párrafos subsecuentes del texto. }\end{array}$ \\
\hline & $\begin{array}{l}\text { El alumno lee y el profesor a partir del texto leído distingue entre el resumen y } \\
\text { síntesis, adicionalmente pregunta ¿cómo se elabora un resumen?, ¿cuáles son las } \\
\text { fases de la elaboración de un resumen?, ¿qué se debe evitar en un resumen?Y } \\
\text { explica. }\end{array}$ \\
\hline
\end{tabular}




\begin{tabular}{|c|c|}
\hline Nivel funcional & Actividades propiciadas en la interacción didáctica \\
\hline \multirow{4}{*}{$\begin{array}{l}\text { Sustitutivo } \\
\text { referencial }\end{array}$} & $\begin{array}{l}\text { El profesor realiza preguntas sobre el tipo de texto que es (informativo) para que } \\
\text { indiquen de qué trata. }\end{array}$ \\
\hline & $\begin{array}{l}\text { Antes o durante la exposición o lectura del tema, el profesor pide lean los títulos, } \\
\text { subtítulos e imágenes, para que digan lo que suponen que trata la lección, uno o } \\
\text { varios alumnos realizan la suposición. }\end{array}$ \\
\hline & $\begin{array}{l}\text { Solicita a un alumno leer el título "la verdadera comida rápida” para que diga de qué } \\
\text { va a tratar la lectura, posteriormente realice preguntas. }\end{array}$ \\
\hline & $\begin{array}{l}\text { Antes o durante la exposición o lectura de un tema, el profesor elabora preguntas } \\
\text { para que los alumnos refieran sus experiencias directas con los contenidos de la } \\
\text { lección. Uno o varios de ellos reportan sus experiencias. }\end{array}$ \\
\hline $\begin{array}{l}\text { Sustitutivo } \\
\text { no referencial }\end{array}$ & $\begin{array}{l}\text { El profesor solicita que los alumnos emitan un juicio argumentado con base en } \\
\text { reglas o definiciones. }\end{array}$ \\
\hline
\end{tabular}


Ejercicio 4.4.

Realice un ejemplo de cada nivel según su práctica, puede apoyarse en la descripción y ejemplos de los niveles funcionales en situaciones didácticas; argumente por qué su ejemplo pertenece a cada nivel, recuerde utilizar la terminología estudiada.

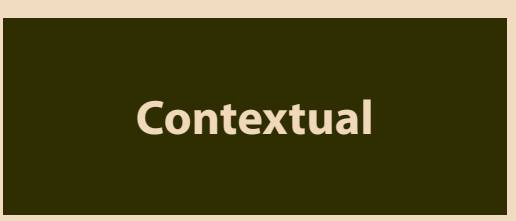

$\ulcorner--\neg$

| Clic aquí |

$\left\llcorner-\_\right\lrcorner$

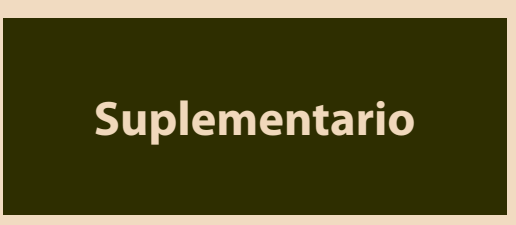

$\ulcorner--\neg$

| Clic aquí |

ᄂ $-\perp$

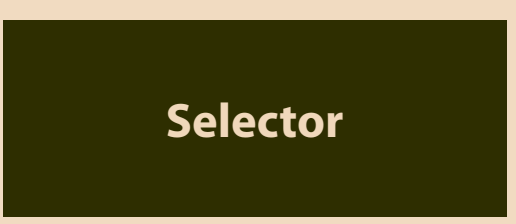

$\Gamma-7$

| Clic aquí |

ᄂ $-\perp$

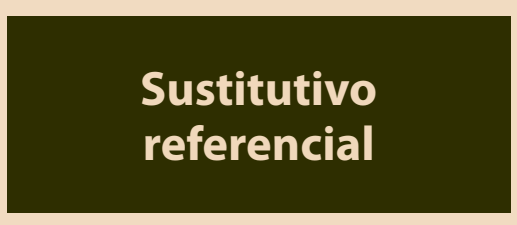

$\Gamma-7$

| Clic aquí |

ᄂ $-\perp$

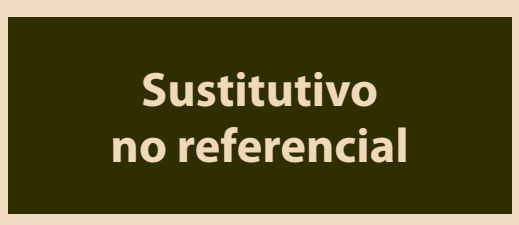

$\ulcorner--\urcorner$

| Clic aquí |

ᄂ $-\perp$ 


\section{Contextual}

\section{Ejemplo}

\section{Descripción}

En este nivel es necesario el discurso didáctico en la presencia de los objetos o situaciones del mundo real para establecer relaciones directas y diferenciales.

El propósito de este nivel es entrenar al alumno de cómo se llama algo, cómo es o qué, cómo y cuándo sucedió o sucederá algo en cierta parte en algún momento (Ibáñez, 2007).

Considérese por ejemplo el estudio de la anatomía humana; es indispensable contar con la presencia de la estructura bajo análisis y un discurso que vaya señalando los nombres de cada una de sus partes y sus características.

\section{Justificación empleando terminología conceptual}




\section{Suplementario}

\section{Descripción}

Es fundamental el discurso didáctico para regular una acción o procedimiento que elabore el alumno y además que existan las condiciones necesarias para su realización.

El propósito del discurso didáctico en el nivel suplementario es instruir al alumno sobre cómo proceder ante los objetos o los eventos a partir de una situación particular para alcanzar cierta meta, y que el alumno responda con efectividad.

Un ejemplo de este nivel sería el discurso en el que se describe paso a paso un procedimiento o técnica para obtener algún producto o resultado (Ibáñez y Ribes, 2001).

Un ejemplo más: considérese el estudio de una técnica para el curtido de pieles, es ineludible contar con la piel y los químicos, y actuar conforme al procedimiento establecido siguiendo instrucciones. Ver un video en el que se presenta paso por paso la técnica, no garantiza el aprendizaje del aprendiz ni su realización.

\section{Ejemplo}

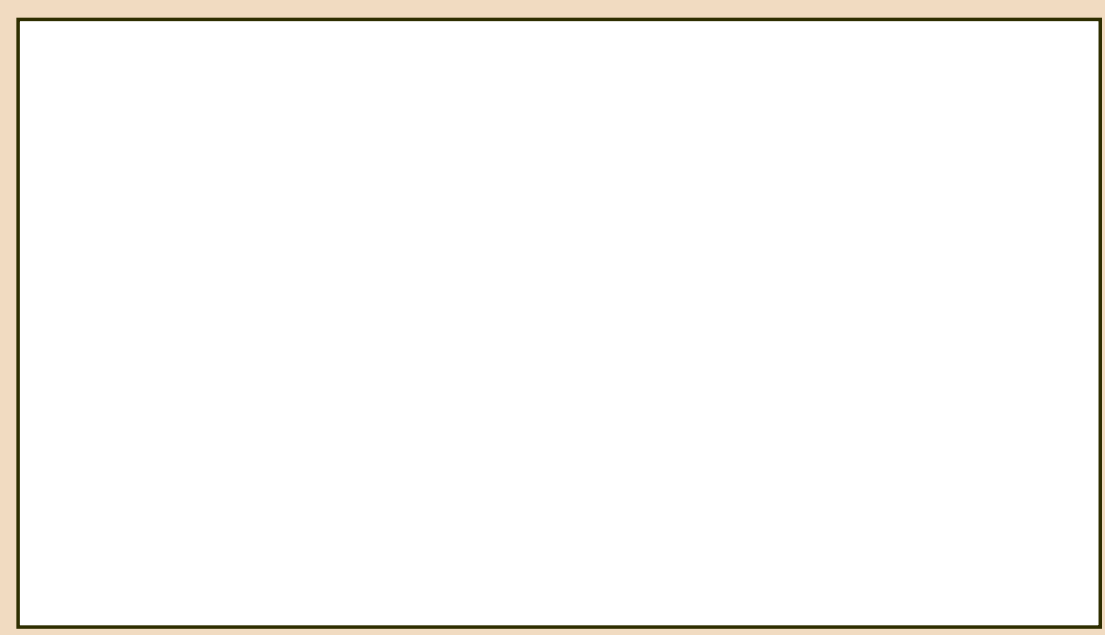

Justificación empleando terminología conceptual

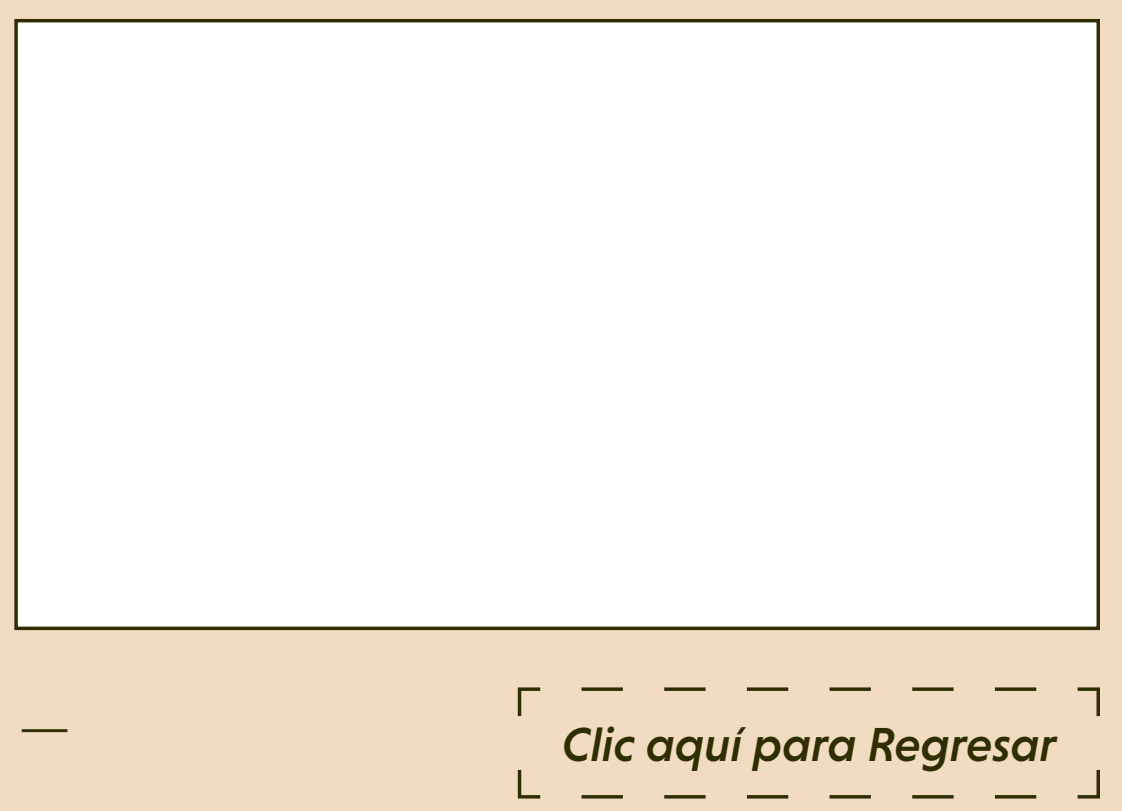




\section{Selector}

\section{Ejemplo}

\section{Descripción}

Es necesaria la presencia de una gama de objetos y la acción del alumno sobre ellos en función de los criterios aportados por el discurso. En este caso es fundamental contar con la más amplia diversidad posible de objetos o características de tal manera que sea factible la aplicación de los criterios en situaciones novedosas.

En el nivel selector, el discurso didáctico ofrece al alumno un "esquema de decisión" que le permita elegir o conducirse con precisión ante un objeto o característica, pertinente a una dimensión, grupo o clase de objetos o eventos, para producir un efecto específico.

Como ejemplo se puede citar el discurso didáctico que refiere un sistema para clasificar animales según sus atributos morfológicos (Ibáñez y Ribes, 2001).

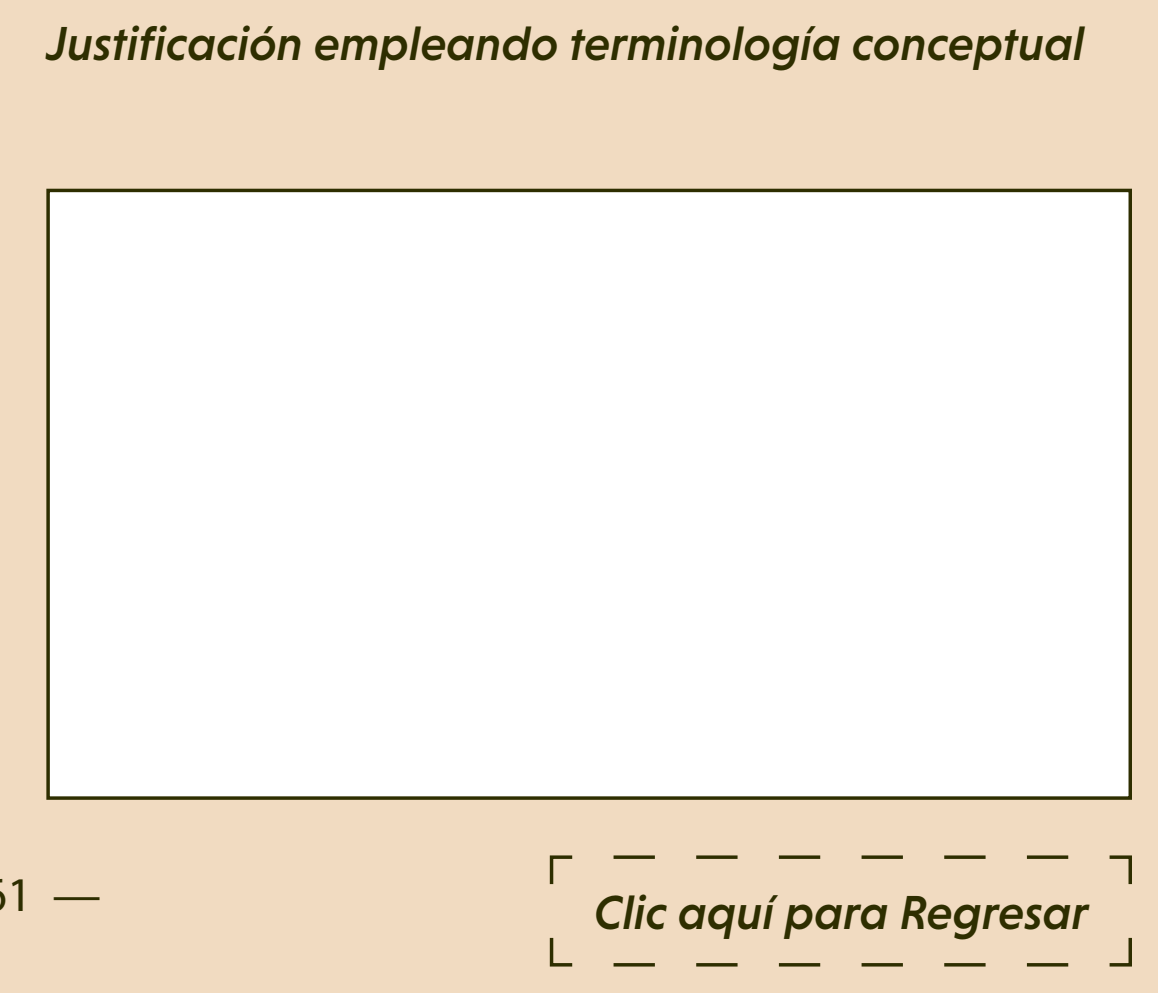




\section{Sustitutivo} referencial

\section{Descripción}

En este nivel se requiere que el alumno observe ejemplos de los fenómenos o procesos bajo estudio y la descripción discursiva simultánea de sus características y condiciones de ocurrencia.

En el nivel sustitutivo referencial, el discurso didáctico media sustitutivamente las relaciones del individuo con respecto a los objetos o eventos que ocurren en una situación a partir de la referencia -necesariamente vía lenguaje-, a los objetos o acontecimientos de una situación diferente. Puede decirse que este tipo de discurso hace referencia a lo que se ha dicho o planteado acerca de determinados objetos o eventos, con el propósito de presentar al alumno una especie de modelo o ejemplar de cómo funcionan o se desarrollan las cosas.

Un ejemplo de este tipo de discurso es aquel que refiere cómo ocurre un proceso natural, como la fotosíntesis o la conservación de la energía (Ibáñez y Ribes, 2001).

\section{Ejemplo}

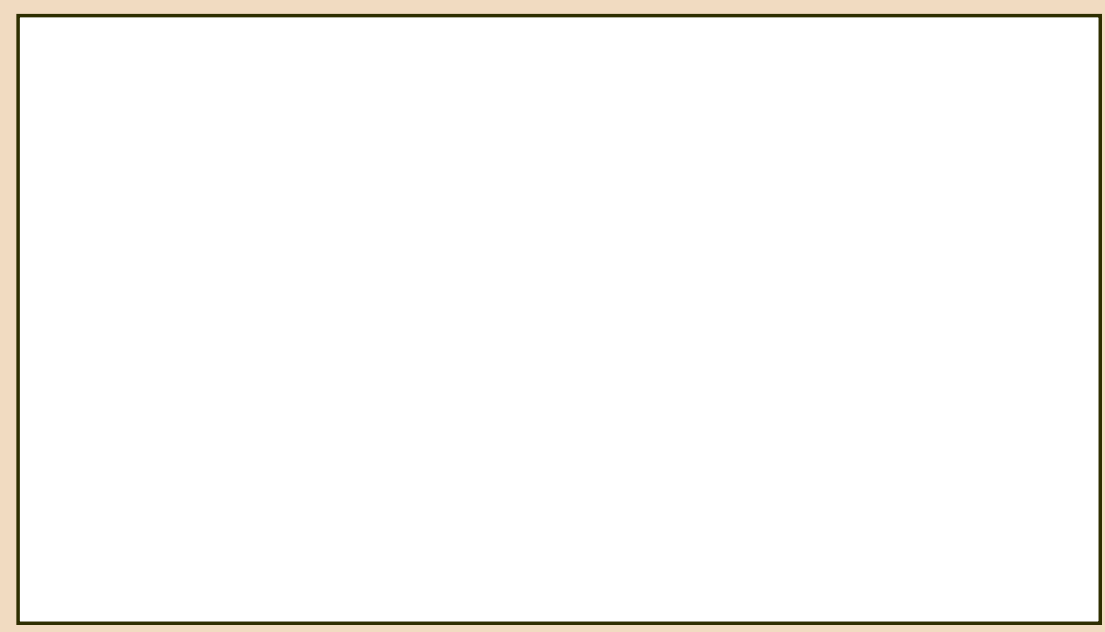

Justificación empleando terminología conceptual

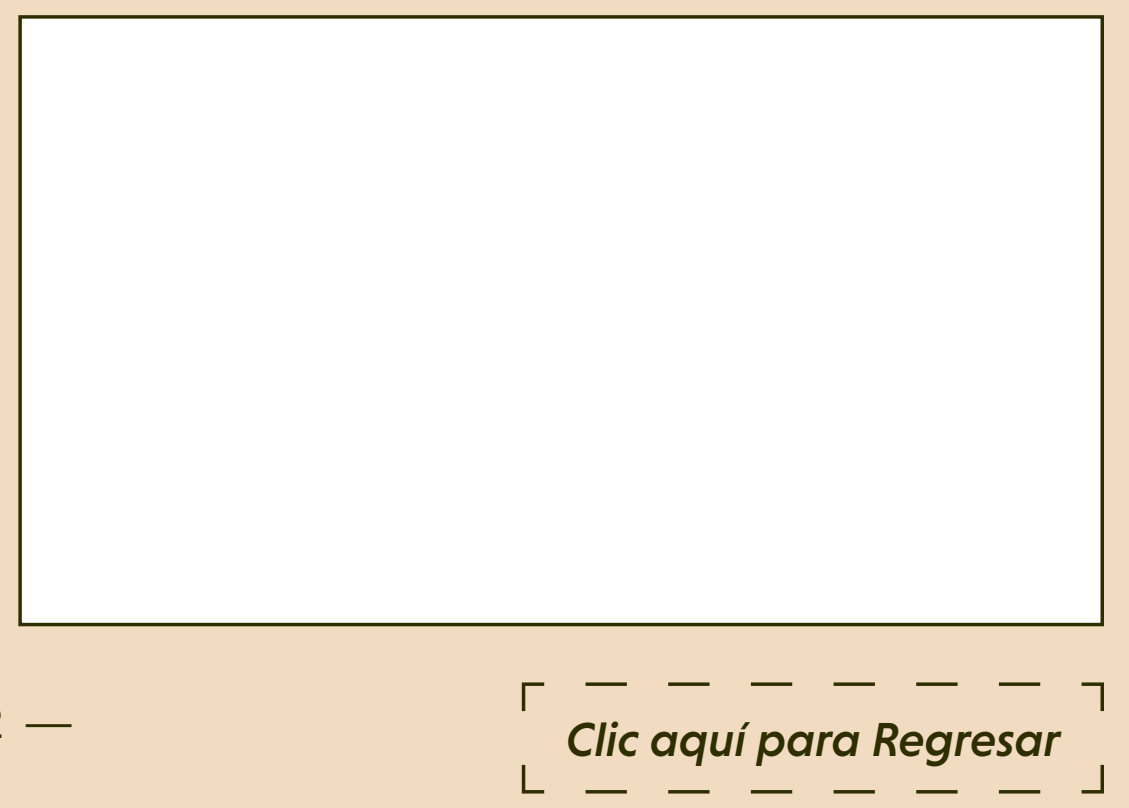




\section{Sustitutivo no referencial}

\section{Descripción}

En este nivel se requiere que el alumno actúe sobre una amplia diversidad de objetos convencionales (valores, reglas, reglamentos, lenguaje algebraico, método científico, aspectos culturales como el refrán) en función de los métodos de transformación provistos en el discurso didáctico.

En este nivel, el propósito de este discurso es proporcionar al alumno un método o conjunto de criterios que le permitan relacionar, analizar, evaluar, modificar o transformar lo que se dice o se ha dicho acerca de algo.

Como ejemplo de este discurso en el nivel sustitutivo no referencial podemos citar aquel que refiere la aplicación de métodos matemáticos o estadísticos para evaluar cuantitativamente las diferencias aparentes entre grupos u objetos.

\section{Ejemplo}

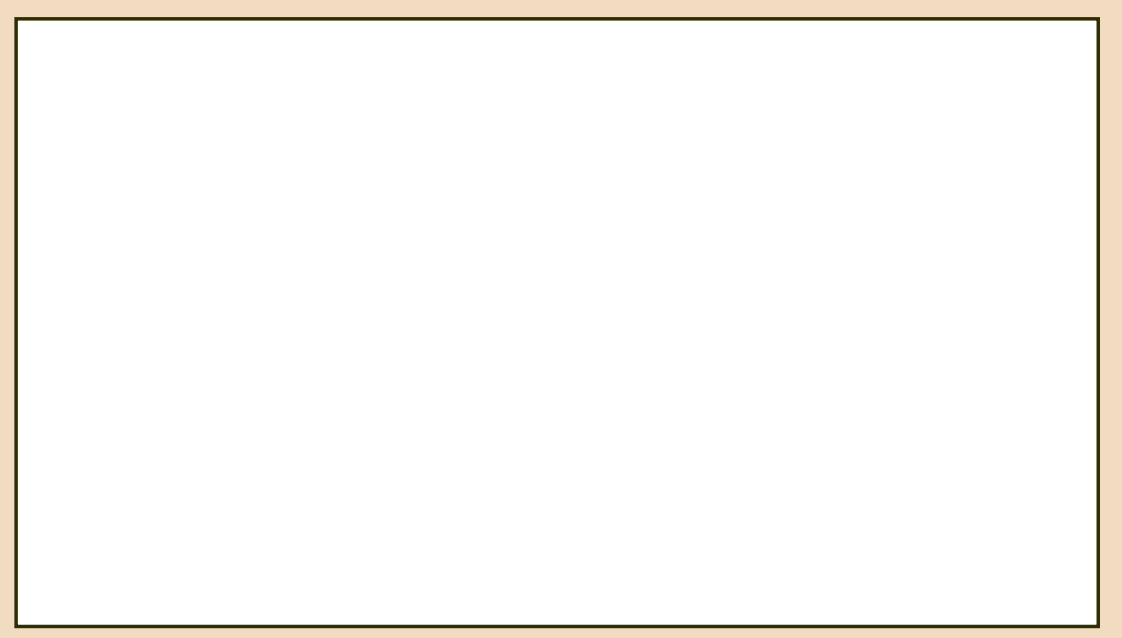

Justificación empleando terminología conceptual

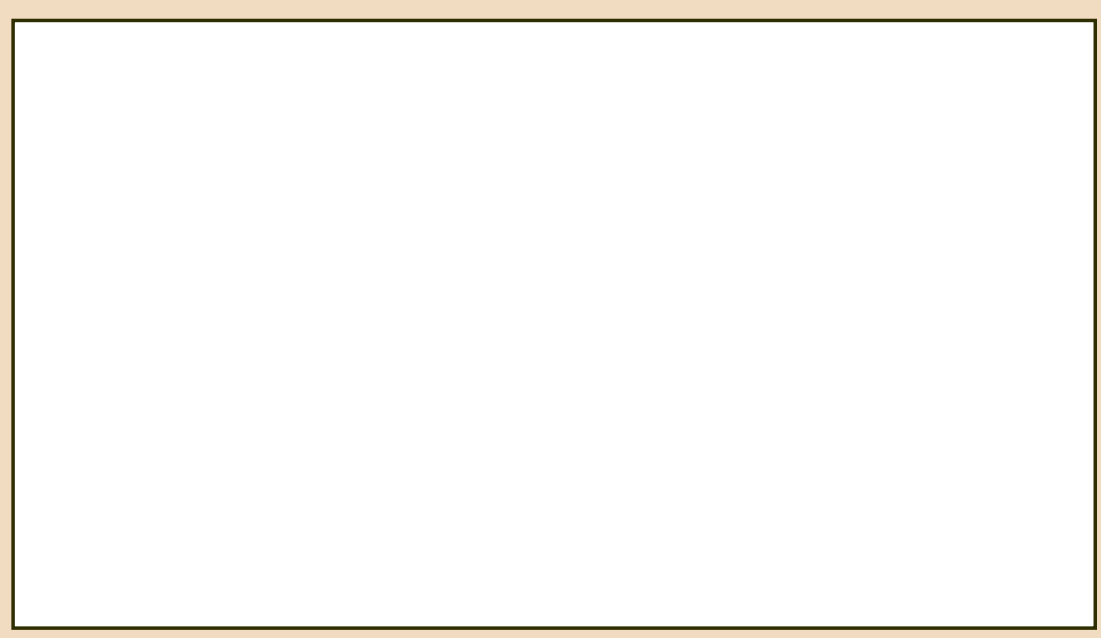

Una vez terminado el ejercicio se sugiere guardar. 
Rúbricas ejercicio 4.2. al 4.4.

\begin{tabular}{|c|c|c|}
\hline Niveles de ejecución & Puntaje & Descripción \\
\hline Inicial & 1 & $\begin{array}{l}\text { - El participante elabora un glosario que contiene más del } 40 \text { \% de los niveles } \\
\text { funcionales, las características enunciadas de los niveles funcionales son un poco } \\
\text { confusas o limitadas. } \\
\text { - Las características enunciadas son más bien explicaciones que se extienden sin } \\
\text { precisar lo importante. } \\
\text { - Tiene notables errores ortográficos, de acentuación o conjugación de verbos, escribe } \\
\text { de modo irregular pero se entiende. }\end{array}$ \\
\hline En desarrollo & 2 & $\begin{array}{l}\text { - El participante elabora un glosario que contiene el } 80 \text { \% de los niveles funcionales, las } \\
\text { características enunciadas de los niveles funcionales son bastante claras. } \\
\text { - Las características o explicaciones de los niveles funcionales expresan lo sustancial de } \\
\text { ellos pero se puede ser aún más sintético. } \\
\text { - Tiene muy pocos errores ortográficos de acentuación o conjunción de verbos. Su letra } \\
\text { es legible casi en su totalidad. }\end{array}$ \\
\hline Alcanzado & 3 & $\begin{array}{l}\text { - El participante elabora un glosario que contiene todos los niveles funcionales y las } \\
\text { características enunciadas son completas y concisas. } \\
\text { - La descripción de sus características es breve y sustanciosa, no hay exceso de palabras } \\
\text { ni dificultades ni circunlocuciones ociosas. } \\
\text { - No tiene errores ortográficos de acentuación, de conjunción de verbos y la letras es } \\
\text { legible, bien cuidada. }\end{array}$ \\
\hline
\end{tabular}




\section{Ejercicio 4.3. Identificación de los niveles de complejidad funcional}

\begin{tabular}{|c|c|c|c|}
\hline Niveles de ejecución & Puntaje & Descripción \\
\hline Inicial & 1 & $\begin{array}{l}\text { - El participante distingue actividades sin relación con los propósitos educativos. } \\
\text { Clasifica las actividades académicas generadas en la interacción didáctica mediante } \\
\text { el discurso didáctico pero no hay correspondencia con el nivel funcional. }\end{array}$ \\
\hline En desarrollo & 2 & $\begin{array}{l}\text { - El participante distingue actividades relacionadas con los propósitos educativos. } \\
\text { Identifica parcialmente los aspectos y la descripción de cada nivel funcional en las } \\
\text { actividades presentes en la interacción didáctica mediante el discurso didáctico. } \\
\text { Alcanzado }\end{array}$ & $\begin{array}{l}\text { Compara y clasifica las actividades académicas generadas en la interacción didáctica } \\
\text { mediante el discurso didáctico pero no todas corresponden al nivel funcional. }\end{array}$ \\
\hline 3 & $\begin{array}{l}\text { El participante distingue actividades relacionadas con los propósitos educativos. } \\
\text { Identifica diferencialmente los aspectos y la descripción de cada nivel funcional en las } \\
\text { actividades presentes en la interacción didáctica mediante el discurso didáctico. } \\
\text { Compara y clasifica las actividades académicas generadas en la interacción didáctica } \\
\text { mediante el discurso didáctico según el nivel funcional al que corresponde. }\end{array}$ \\
\hline
\end{tabular}




\section{Ejercicio 4.4. Elaboración de ejemplos}

\begin{tabular}{|c|c|c|c|}
\hline Niveles de ejecución & Puntaje & Descripción \\
\hline Inicial & 1 & $\begin{array}{l}\text { - El participante elabora ejemplos adecuados con situaciones didácticas. } \\
\text { Identifica aspectos principales y la descripción de uno o dos niveles funcionales y lo } \\
\text { reproduce literalmente a partir de lo que dice el texto. }\end{array}$ \\
\hline En desarrollo & 2 & $\begin{array}{l}\text { El participante elabora ejemplos adecuados y se relacionan con situaciones } \\
\text { didácticas y contenidos de la materia que imparte pero no aporta nuevas propuestas. } \\
\text { Identifica algunos de los aspectos principales así como la descripción de cada nivel } \\
\text { funcional y lo expresa con sus propias palabras. }\end{array}$ \\
\hline Alcanzado & 3 & $\begin{array}{l}\text { El participante elabora ejemplos adecuados y en algunos casos innovadores con } \\
\text { respecto de situaciones didácticas y contenidos de la asignatura. } \\
\text { Identifica los aspectos principales y la descripción de cada nivel funcional, los } \\
\text { interrelaciona y expresa con claridad con sus propias palabras. }\end{array}$ \\
\hline
\end{tabular}




\begin{tabular}{|c|c|c|c|}
\hline \multicolumn{4}{|c|}{ Ejercicio 4.4. Justificación de la pertinencia } \\
\hline Niveles de ejecución & Puntaje & \multicolumn{1}{c|}{ Descripción } \\
\hline \multirow{2}{*}{ Inicial } & 1 & $\begin{array}{l}\text { El participante sostiene su ejemplo sin basarse en los aspectos de los niveles } \\
\text { funcionales pero integra los contenidos de la asignatura. } \\
\text { Excluye los aspectos principales y la descripción de cada nivel funcional. } \\
\text { - El texto no es coherente y no hace entender qué es lo que quiere comunicar. }\end{array}$ \\
\hline Alcanzado & 2 & $\begin{array}{l}\text { El participante sostiene su ejemplo en algunos aspectos de los niveles funcionales } \\
\text { pero integra los contenidos de la asignatura. } \\
\text { Considera uno o dos aspectos principales y la descripción de cada nivel funcional } \\
\text { provenientes de la lectura como base de su justificación. } \\
\text { Comunica las razones que avalan el ejemplo pero no convence y utiliza algunos } \\
\text { términos. }\end{array}$ \\
\hline 3 & $\begin{array}{l}\text { El participante sostiene su ejemplo en los aspectos principales de los niveles } \\
\text { funcionales e integra los contenidos de la asignatura. } \\
\text { Considera los aspectos principales y la descripción de cada nivel funcional como base } \\
\text { de sujustificación. } \\
\text { Comunica bien las razones que avalan el ejemplo utilizando la terminología del texto. }\end{array}$ \\
\hline
\end{tabular}




\section{Módulo 5}

Descripción del aprendizaje esperado utilizando el nivel de complejidad funcional, el contenido disciplinar y la habilidad requerida en el estudiante

Objetivo: Emplear diferentes niveles de complejidad funcional en la especificación del aprendizaje esperado de un proyecto.

Instrucciones: Lea el Texto 4: "La planeación didáctica” y subraye los conceptos principales, para ubicar las tareas en los diferentes niveles de complejidad y justificarlo con la terminología revisada. Asimismo lea el Texto 5: “El aprendizaje esperado", para identificarlo posteriormente en un proyecto.

Aprendizaje esperado: Explicar la importancia de emplear diferentes niveles funcionales en la especificación del aprendizaje esperado. 
Texto 4.

La planeación didáctica

Como usted sabe, la planeación didáctica es un elemento fundamental en la práctica docente pues estructura los contenidos de los programas de la educación básica y contiene los siguientes elementos:

- Proyecto a planear.

- El aprendizaje esperado y su descripción.

- Los criterios de logro a satisfacer.

- Desarrollo de las actividades.

- Lugar donde se lleva a cabo la actividad.

- Materiales.

Para su diseño es importante recordar las definiciones de competencia, aprendizaje esperado, criterios de logro y niveles funcionales. Subrayamos que bajo la propuesta que se presenta, el término competencia se define como el desempeño mostrado por el alumno ante una determinada actividad y que regularmente es efectivo de acuerdo a las especificaciones establecidas por el profesor, en consecuencia el ser competente se define como "ser capaz de hacer o decir algo en una situación determinada, con determinados resultados" (Ribes, 2008, p. 201).
El aprendizaje esperado hace referencia al desempeño efectivo en una actividad académica que el alumno debe demostrar según los criterios de logro especificados en la asignatura, para conseguirlo se sugiere al docente promover una serie de actividades asociadas con diversos criterios de logro.

Los criterios de logro se asocian a niveles funcionales que describen diferentes grados de complejidad, puesto que refieren categorías cualitativamente distintas que expresan el desarrollo que se desea que consigan los estudiantes en el proceso de aprendizaje.

En este sentido, se dice que los criterios de logro son una medida definida claramente del nivel de aprendizaje que se pretende que el estudiante alcance en cada competencia particular estipulada en el programa. 


\section{Ejercicio 5.1.}

Lea el siguiente cuadro, el cual presenta los niveles de complejidad funcional y ejemplos de aplicación.

\begin{tabular}{|c|c|c|c|}
\hline \multicolumn{4}{|c|}{ Cuadro 5.1. Niveles funcionales asociados al aprendizaje (Ribes, 2008) } \\
\hline Nivel & Desempeño & Descripción & Actividad del Docente \\
\hline $\begin{array}{l}\text { Contextual: } \\
\text { Identificar }\end{array}$ & $\begin{array}{l}\text { Reconociendo: } \\
\text { Identificar, } \\
\text { nombrar, enlistar. }\end{array}$ & $\begin{array}{l}\text { Nombrar, marcar en un diagrama o mapa, } \\
\text { calificar afirmaciones como verdaderas o } \\
\text { falsas, parafrasear, reconocer, identificar, } \\
\text { enlistar. }\end{array}$ & $\begin{array}{l}\text { Pedir a sus alumnos que identi- } \\
\text { fiquen algo por su nombre. }\end{array}$ \\
\hline $\begin{array}{l}\text { Suplementario: } \\
\text { Realizar }\end{array}$ & \begin{tabular}{|c|} 
Ejecutando: \\
Aplicar, obtener, \\
producir, confeccio- \\
nar, ejecutar.
\end{tabular} & $\begin{array}{l}\text { Construir, trazar, aplicar procedimientos, } \\
\text { describir, dibujar, contestar preguntas } \\
\text { directas, resumir, obtener, producir, con- } \\
\text { feccionar, ejecutar, utilizar. }\end{array}$ & $\begin{array}{l}\text { Pedir a los alumnos que resuel- } \\
\text { van un problema de matemáti- } \\
\text { cas de manera efectiva. }\end{array}$ \\
\hline $\begin{array}{l}\text { Selector: } \\
\text { Tipificar }\end{array}$ & $\begin{array}{l}\text { Seleccionando: } \\
\text { Ordenando, } \\
\text { comparando, } \\
\text { modificando } \\
\text { criterio. } \\
\end{array}$ & $\begin{array}{l}\text { Clasificar, identificar o realizar cambios, } \\
\text { seleccionar, diagnosticar, prescribir, espe- } \\
\text { cificar. }\end{array}$ & $\begin{array}{l}\text { Pedir a los alumnos que clasi- } \\
\text { fiquen a un grupo de animales } \\
\text { de acuerdo a la clase a la que } \\
\text { pertenecen (mamíferos, aves, } \\
\text { peces y anfibios). }\end{array}$ \\
\hline $\begin{array}{l}\text { Sustitutivo } \\
\text { referencial: } \\
\text { Derivar una } \\
\text { explicación }\end{array}$ & $\begin{array}{l}\text { Teorizando: } \\
\text { Explicar, predecir, } \\
\text { esclarecer, } \\
\text { interpretar. }\end{array}$ & $\begin{array}{l}\text { Explicar, predecir, esclarecer, intervenir, } \\
\text { ejemplificar, interpretar situaciones, rela- } \\
\text { cionar con situaciones pasadas o actuales } \\
\text { ausentes, proponer nuevos artefactos, } \\
\text { usos o procedimientos. }\end{array}$ & $\begin{array}{l}\text { Pedir a los alumnos que expli- } \\
\text { quen o predigan los resultados } \\
\text { de un experimento. }\end{array}$ \\
\hline $\begin{array}{l}\text { Sustitutivo } \\
\text { no referencial: } \\
\text { Derivar un } \\
\text { argumento o juicio }\end{array}$ & $\begin{array}{l}\text { Analizando: } \\
\text { Evaluar, valorar, } \\
\text { calcular, juzgar, } \\
\text { apreciar. }\end{array}$ & $\begin{array}{l}\text { Argumentar, hipotetizar, proponer explica- } \\
\text { ciones, establecer nuevas relaciones, defi- } \\
\text { niciones o clasificaciones, evaluar, valorar, } \\
\text { calcular, juzgar, apreciar. }\end{array}$ & $\begin{array}{l}\text { Pedir a los alumnos que elabo- } \\
\text { ren un argumento. }\end{array}$ \\
\hline
\end{tabular}




\section{Texto 5.}

El aprendizaje esperado

La clasificación anterior permite identificar el grado de complejidad del aprendizaje esperado que debe cumplir el alumno, es importante señalar que los aprendizajes esperados están especificados en el programa de estudios, sin embargo, por motivos didácticos en este manual se propone como ejercicio adicional realizarlos y estructurarlos de manera congruente con los criterios de logro y las actividades.

A continuación se recomienda tomar en cuenta los siguientes elementos para identificar los componentes de los aprendizajes esperados:

- Elegir el aprendizaje esperado del proyecto;

- Identificar la situación problema que demanda solución mediante el desempeño del estudiante;

- Identificar el nivel funcional que permitirá abordar la situación problema;

- Identificar el verbo de logro o resultado para hacer referencia al cumplimiento de los criterios de logro en concordancia con el nivel funcional;

- Identificar los conocimientos disciplinarios que deberá "adquirir" el estudiante;

- Enunciar la habilidad requerida en el estudiante. 


\section{Ejemplo (Español)}

\begin{tabular}{|c|c|}
\hline $\begin{array}{l}\text { Nombre del proyecto } \\
\text { Bloque I } \\
\text { Primer grado }\end{array}$ & FICHAS DE TRABAJO \\
\hline Elegir el aprendizaje esperado. & Utilizar paráfrasis y recursos gráficos. \\
\hline $\begin{array}{l}\text { Identificar la situación problema que demanda } \\
\text { solución mediante el desempeño del estudiante. }\end{array}$ & Explicar un tema a partir de una lectura. \\
\hline $\begin{array}{l}\text { Identificar el nivel funcional que permitirá abordar } \\
\text { la situación problema. }\end{array}$ & Sustitutivo Referencial. \\
\hline $\begin{array}{l}\text { Indicar el verbo de logro o resultado para hacer } \\
\text { referencia al cumplimiento de los criterios en } \\
\text { concordancia con el nivel funcional. }\end{array}$ & Explicar. \\
\hline $\begin{array}{l}\text { Mencionar los conocimientos disciplinarios que } \\
\text { deberá "adquirir" el estudiante. }\end{array}$ & $\begin{array}{l}\text { Elaborar fichas de trabajo, identificar los recursos visuales } \\
\text { que presenta el texto para presentar la información, } \\
\text { identificar ideas en un texto, realizar una paráfrasis. }\end{array}$ \\
\hline Enunciar la habilidad requerida en el estudiante. & Sistematizar información sobre un tema. \\
\hline
\end{tabular}




\section{Ejemplo (Matemáticas)}

\begin{tabular}{|c|c|}
\hline $\begin{array}{l}\text { Nombre del proyecto } \\
\text { Bloque I } \\
\text { Primer grado }\end{array}$ & NÚMEROS ROMANOS \\
\hline Elegir el aprendizaje esperado. & $\begin{array}{l}\text { Utilizar el sistema romano de numeración para datar } \\
\text { hechos históricos. }\end{array}$ \\
\hline $\begin{array}{l}\text { Identificar la situación problema que demanda } \\
\text { solución mediante el desempeño del estudiante. }\end{array}$ & Aplicar el sistema romano de numeración. \\
\hline $\begin{array}{l}\text { Identificar el nivel funcional que permitirá abordar } \\
\text { la situación problema. }\end{array}$ & Suplementario. \\
\hline $\begin{array}{l}\text { Indicar el verbo de logro o resultado para hacer } \\
\text { referencia al cumplimiento de los criterios en } \\
\text { concordancia con el nivel funcional. }\end{array}$ & Utilizar. \\
\hline $\begin{array}{l}\text { Mencionar los conocimientos disciplinarios que } \\
\text { deberá "adquirir" el estudiante. }\end{array}$ & El sistema de numeración romano. \\
\hline Enunciar la habilidad requerida en el estudiante. & $\begin{array}{l}\text { Identificar las letras que conforman el sistema } \\
\text { numérico romano. }\end{array}$ \\
\hline
\end{tabular}


Ejemplos:

Por tanto, la especificación del aprendizaje esperado se enunciaría como se muestra en los siguientes ejemplos.

Ejemplo de Español:

\begin{tabular}{ll|l|l|}
\hline \multicolumn{2}{l}{$\begin{array}{l}\text { Verbo } \\
\text { El alumno }\end{array}$} & Contenido & \multicolumn{1}{l}{$\begin{array}{l}\text { Habilidad requerida } \\
\text { en el estudiante }\end{array}$} \\
\cline { 2 - 4 } & elabora & $\begin{array}{l}\text { fichas de trabajo utilizando } \\
\text { paráfrasis y recursos literarios }\end{array}$ & $\begin{array}{l}\text { para sistematizar información sobre } \\
\text { un tema. }\end{array}$ \\
\hline
\end{tabular}

Ejemplo de Matemáticas:

\begin{tabular}{|c|c|c|c|}
\hline \multirow{2}{*}{ El alumno } & Verbo & Contenido & $\begin{array}{l}\text { Habilidad requerida } \\
\text { en el estudiante }\end{array}$ \\
\hline & elabora & $\begin{array}{l}\text { las reglas de los signos en } \\
\text { operaciones con números enteros }\end{array}$ & $\begin{array}{l}\text { para resolver problemas } \\
\text { con números enteros. }\end{array}$ \\
\hline
\end{tabular}




\section{Ejercicio 5.2.1.}

Enuncie la habilidad tal como se muestra en los ejemplos anteriores.

Puede apoyarse en el programa de la asignatura.

\section{Ejemplo (Español)}

\begin{tabular}{|c|c|}
\hline $\begin{array}{l}\text { Nombre del proyecto } \\
\text { Bloque I } \\
\text { Primer grado }\end{array}$ & $\begin{array}{l}\text { INVESTIGAR SOBRE MITOS Y LEYENDAS } \\
\text { DE LA LITERATURA UNIVERSAL }\end{array}$ \\
\hline Elegir el aprendizaje esperado. & $\begin{array}{l}\text { Distinguir entre distintas versiones de un mismo mito o } \\
\text { leyenda en función del grupo social al que pertenece. }\end{array}$ \\
\hline $\begin{array}{l}\text { Identificar la situación problema que demanda } \\
\text { solución mediante el desempeño del estudiante. }\end{array}$ & $\begin{array}{l}\text { Identifica diferencias entre distintas versiones de un } \\
\text { mismo mito o leyenda en función del grupo social al que } \\
\text { pertenece. }\end{array}$ \\
\hline $\begin{array}{l}\text { Identificar el nivel funcional que permitirá abordar } \\
\text { la situación problema. }\end{array}$ & Selector. \\
\hline $\begin{array}{l}\text { Indicar el verbo de logro o resultado para hacer } \\
\text { referencia al cumplimiento de los criterios en } \\
\text { concordancia con el nivel funcional. }\end{array}$ & Identificar. \\
\hline $\begin{array}{l}\text { Mencionar los conocimientos disciplinarios que } \\
\text { deberá "adquirir" el estudiante. }\end{array}$ & $\begin{array}{l}\text { Las características y la función de los mitos y leyendas, } \\
\text { trascribir mitos y leyendas recuperados oralmente. }\end{array}$ \\
\hline Enunciar la habilidad requerida en el estudiante. & \\
\hline
\end{tabular}




\section{Ejercicio 5.2.2.}

Enuncie la habilidad tal como se muestra en los ejemplos anteriores.

Puede apoyarse en el programa de la asignatura.

\section{Ejemplo (Matemáticas)}

\begin{tabular}{|c|c|}
\hline $\begin{array}{l}\text { Nombre del proyecto } \\
\text { Bloque I } \\
\text { Primer grado }\end{array}$ & FÓRMULAS MATEMÁTICAS \\
\hline Elegir el aprendizaje esperado. & Aplicar las fórmulas para calcular el volumen. \\
\hline $\begin{array}{l}\text { Identificar la situación problema que demanda } \\
\text { solución mediante el desempeño del estudiante. }\end{array}$ & $\begin{array}{l}\text { Calcular el volumen de prismas y pirámides mediante } \\
\text { el uso de fórmulas matemáticas. }\end{array}$ \\
\hline $\begin{array}{l}\text { Identificar el nivel funcional que permitirá abordar } \\
\text { la situación problema. }\end{array}$ & Suplementario. \\
\hline $\begin{array}{l}\text { Indicar el verbo de logro o resultado para hacer } \\
\text { referencia al cumplimiento de los criterios en } \\
\text { concordancia con el nivel funcional. }\end{array}$ & Aplicar. \\
\hline $\begin{array}{l}\text { Mencionar los conocimientos disciplinarios que } \\
\text { deberá "adquirir" el estudiante. }\end{array}$ & $\begin{array}{l}\text { Fórmulas matemáticas para calcular prismas e } \\
\text { identificación de las características de dichas figuras. }\end{array}$ \\
\hline Enunciar la habilidad requerida en el estudiante. & \\
\hline
\end{tabular}


NOTA: Puede tomar como base los aprendizajes esperados que se han especificado y adaptarlos para desarrollar el ejercicio 5.2.2.

Ejemplo de Español:

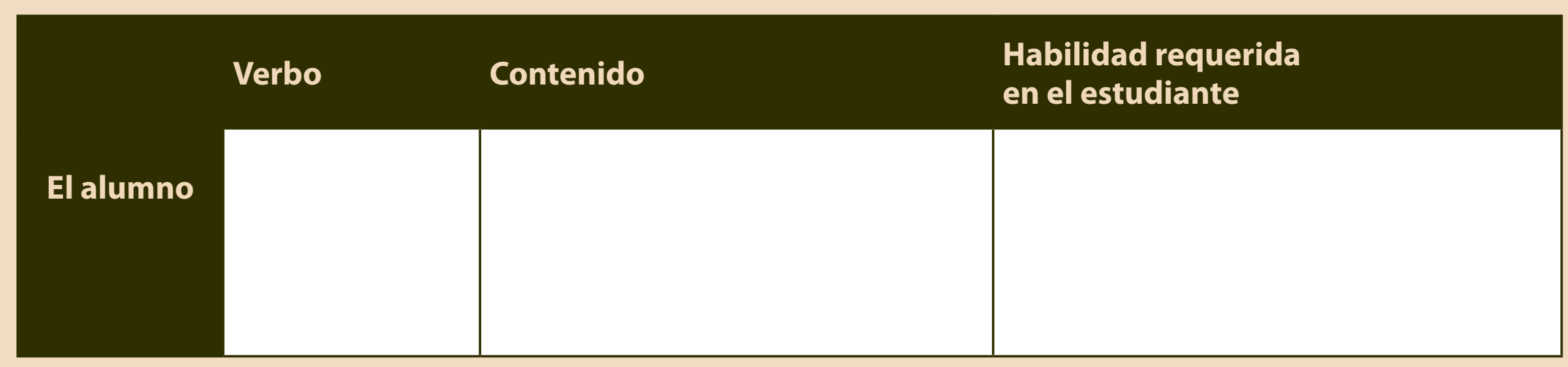

Ejemplo de Matemáticas:

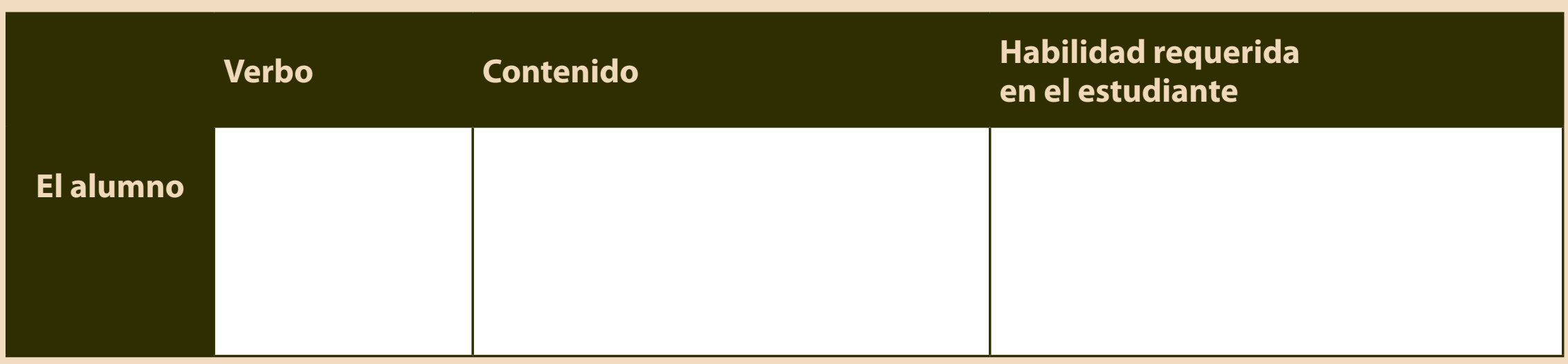




\section{Ejercicio 5.3.}

Lea cuidadosamente y responda la siguiente pregunta apoyándose en el apartado

"desempeño" del Cuadro 5.1. (página 70)

\begin{tabular}{|l|l|}
\hline $\begin{array}{l}\text { ¿Cuáles verbos se utilizarían si el profesor solicita a los alumnos que elaboren un juicio } \\
\text { con base en reglas o definiciones?, ¿cuál es el nivel funcional asociado? }\end{array}$ \\
\hline $\begin{array}{l}\text { Clasificar, identificar, realizar cambios, seleccionar. } \\
\text { Ejemplificar, interpretar, situaciones, relacionar con situaciones pasadas, actuales o ausentes, } \\
\text { proponer nuevos artefactos, usos o procedimientos. }\end{array}$ \\
\hline $\begin{array}{l}\text { Argumentar, hipotetizar, proponer explicaciones, establecer nuevas relaciones, definiciones o } \\
\text { clasificaciones. }\end{array}$ \\
\hline Nombrar, marcar en un diagrama o mapa, calificar afirmaciones como verdaderas o falsas. \\
\hline Construir, trazar, aplicar procedimientos, describir, dibujar, contestar preguntas directas, resumir. \\
\hline
\end{tabular}

\section{Nivel funcional asociado:}

Una vez terminado el ejercicio se sugiere guardar. 


\section{Ejercicio 5.4.}

Lea cuidadosamente el Cuadro 5.1. (página 70) y con base a su contenido redacte los aprendizajes esperados de acuerdo a la asignatura que imparte y a los niveles funcionales señalados.

\begin{tabular}{|c|c|}
\hline Niveles & Aprendizajes esperados del proyecto \\
\hline $\begin{array}{l}\text { Sustitutivo } \\
\text { no referencial }\end{array}$ & \\
\hline $\begin{array}{l}\text { Sustitutivo } \\
\text { referencial }\end{array}$ & \\
\hline Selector & \\
\hline Suplementario & \\
\hline Contextual & \\
\hline
\end{tabular}




\begin{tabular}{|c|c|l|}
\hline \multicolumn{3}{|c|}{ Ejercicio 5.2. Especificación del aprendizaje deseado } \\
\hline Niveles de ejecución & Puntaje & \multicolumn{1}{c|}{ Descripción } \\
\hline Inicial & 1 & El participante no reconoce los componentes que constituyen el aprendizaje esperado. \\
\hline En desarrollo & 2 & $\begin{array}{l}\text { El participante enuncia los componentes del aprendizaje, pero no detalla todos los } \\
\text { componentes que constituyen el aprendizaje esperado, el verbo y el nivel funcional tienen } \\
\text { correspondencia. }\end{array}$ \\
\hline Alcanzado & 3 & $\begin{array}{l}\text { El participante enuncia los componentes del aprendizaje esperado, detalla todos los } \\
\text { componentes que constituyen el aprendizaje esperado, el verbo y el nivel funcional tienen } \\
\text { correspondencia. }\end{array}$ \\
\hline
\end{tabular}




\section{Ejercicio 5.3. Identificación de verbos de logro}

\begin{tabular}{|c|c|c|}
\hline Niveles de ejecución & Puntaje & Descripción \\
\hline Inicial & 1 & $\begin{array}{l}\text { - El participante identifica las actividades académicas generadas en la interacción } \\
\text { didáctica mediante el discurso didáctico pero no hay correspondencia con el nivel } \\
\text { funcional. }\end{array}$ \\
\hline En desarrollo & 2 & $\begin{array}{l}\text { - El participante identifica parcialmente los aspectos y la descripción de cada nivel } \\
\text { funcional en las actividades presentes en la interacción didáctica mediante el discurso } \\
\text { didáctico. } \\
\text { - Compara y clasifica las actividades académicas generadas en la interacción didáctica } \\
\text { mediante el discurso didáctico pero no todas corresponden al nivel funcional. } \\
\text { - Elige los verbos generados en la interacción didáctica mediante el discurso didáctico } \\
\text { según el nivel funcional al que corresponde. }\end{array}$ \\
\hline Alcanzado & 3 & $\begin{array}{l}\text { - El participante identifica diferencialmente los aspectos y la descripción de cada nivel } \\
\text { funcional en las actividades presentes en la interacción didáctica mediante el discurso } \\
\text { didáctico. } \\
\text { - Compara y clasifica las actividades académicas generadas en la interacción didáctica } \\
\text { mediante el discurso didáctico según el nivel funcional al que corresponde. } \\
\text { - Elige los verbos generados en la interacción didáctica mediante el discurso didáctico } \\
\text { según el nivel funcional al que corresponde. }\end{array}$ \\
\hline
\end{tabular}




\begin{tabular}{|c|c|c|c|}
\hline \multicolumn{3}{|c|}{ Ejercicio 5.4. Niveles funcionales asociados al aprendizaje } \\
\hline Niveles de ejecución & Puntaje & \multicolumn{1}{c|}{ Descripción } \\
\hline Inicial & 1 & $\begin{array}{l}\text { - El participante elabora ejemplos adecuados con situaciones didácticas. } \\
\text { - Identifica aspectos principales y la descripción de uno o dos niveles funcionales pero } \\
\text { reproduce literalmente el aprendizaje esperado a partir de lo que dice el plan de } \\
\text { estudios. }\end{array}$ \\
\hline En desarrollo & $\begin{array}{l}\text { - El participante elabora ejemplos adecuados y se relacionan con situaciones } \\
\text { didácticas y contenidos de la asignatura que imparte pero no aporta nuevas } \\
\text { propuestas. }\end{array}$ \\
\hline Alcanzado & $\begin{array}{l}\text { Identifica algunos de los aspectos principales así como la descripción de cada nivel } \\
\text { funcional. } \\
\text { - El aprendizaje esperado incluye los verbos pero no todos tienen correspondencia } \\
\text { con el nivel funcional, hay correspondencia con el contenido de la asignatura y la } \\
\text { habilidad requerida del estudiante. } \\
\text { El participante expresa el aprendizaje esperado con sus propias palabras. }\end{array}$ \\
\hline 3 & $\begin{array}{l}\text { El participante elabora ejemplos adecuados y en algunos casos innovadores con } \\
\text { respecto de situaciones didácticas y contenidos de la asignatura que imparte. } \\
\text { Identifica los aspectos principales y la descripción de cada nivel funcional. } \\
\text { - El aprendizaje esperado incluye el verbo en correspondencia con el nivel funcional, el } \\
\text { contenido de la asignatura y la habilidad requerida del estudiante, los interrelaciona } \\
\text { yexpresa con claridad con sus propias palabras. }\end{array}$ \\
\hline
\end{tabular}




\section{Módulo 6}

\section{Especificación de los criterios de logro a satisfacer}

Objetivo: Redactar criterios de logro a satisfacer de acuerdo al nivel en que se desea que los alumnos se desempeñen y explicar por qué es necesario especificar estos criterios.

Instrucciones: Lea el Texto 6: "Introducción" y subraye los conceptos principales, para ubicar las tareas en los diferentes niveles de complejidad y justificarlo con la terminología revisada.

Aprendizaje esperado: Redacta los criterios de logro a satisfacer del proyecto. 
Texto 6.

Introducción

Desde la perspectiva teórica planteada en este manual, el desarrollo de competencias de distinto nivel funcional debe proceder gradualmente desde lo más simple, concreto y básico - contextual- a lo más complejo, abstracto y superior - sustitutiva no referencial- . Sin embargo, es importante mencionar que no todas las disciplinas exigen formación de competencias en los cinco niveles de aptitud funcional, como ocurre en algunos campos "técnicos" como la mecánica, la xerografía o la práctica de algunos deportes como la natación o el futbol.

En cuanto a la formación dentro de sólo un nivel de aptitud es teóricamente conveniente desarrollar primero competencias comunes o denominadas genéricas; aplicables a la mayor cantidad de situaciones problema e ir incidiendo paulatinamente en las competencias más específicas y particulares; aquellas aplicables a situaciones problema de carácter singular o peculiar. Por ejemplo, en la enseñanza de una lengua extranjera es importante desarrollar primero competencias de identificación de objetos comunes y cotidianos, para en otro momento abordar la identificación de objetos o sus propiedades particulares mediante terminología técnica. De igual manera, en la enseñanza de la anatomía del sistema óseo se debe iniciar desarrollando competencias de identificación general - ¿qué es el hueso?-, para después identificar los huesos por su nombre y posteriormente indicar nominalmente las propiedades de cada hueso.

También es deseable programar el desarrollo de competencias con base en la posible experiencia previa de los estudiantes para ir de lo familiar a lo desconocido, de lo cercano a lo distante, desde lo macro a lo molecular, de lo concreto a lo abstracto y de lo sincrético a lo diferenciado (lbáñez, 2007). 


\section{Texto 6.1.}

Guía para la especificación de los criterios de logro a satisfacer según el aprendizaje esperado

- Verifique si el nivel funcional del aprendizaje esperado se designó a partir del nivel sustitutivo no referencial, recuerde que es lo deseable pues genera aprendizajes de mayor complejidad, en caso de que no ser así, modifíquelo.

- Identifique el verbo que más se ajuste al criterio de logro para cumplir el aprendizaje esperado.

- Redacte los criterios de logro en secuencia ascendente a partir del nivel contextual, suplementario, selector, sustitutivo referencial, sustitutivo no referencial, seleccionando los verbos de cada nivel que se ajusten mejor para cumplir cada criterio de logro, asimismo tome en cuenta los contenidos de la asignatura para ese aprendizaje esperado. Recuerde que debe existir congruencia entre el aprendizaje esperado, el criterio de logro a satisfacer y los niveles funcionales. 


\begin{tabular}{|c|c|c|}
\hline $\begin{array}{l}\text { Desarrollar competencias comunes } \\
\text { y aplicables a varias situaciones }\end{array}$ & $\begin{array}{c}\text { para } \\
\text { posteriormente }\end{array}$ & $\begin{array}{c}\text { Desarrollar competencias específicas } \\
\text { y particulares }\end{array}$ \\
\hline $\begin{array}{l}\text { En la enseñanza de una lengua extrajera, } \\
\text { es importante desarrollar primero } \\
\text { competencias de identificación de objetos } \\
\text { comunes y cotidianos }\end{array}$ & \multirow{2}{*}{ Ejemplos } & $\begin{array}{c}\text { Abordar la identificación de objetos } \\
\text { o sus propiedades particulares mediante } \\
\text { terminología técnica }\end{array}$ \\
\hline $\begin{array}{c}\text { En la enseñanza de la anatomía del sistema } \\
\text { óseo se debe iniciar desarrollando compe- } \\
\text { tencias de identificación general — ¿qué es el } \\
\text { hueso?- }\end{array}$ & & $\begin{array}{c}\text { Identificar los huesos por su nombre y } \\
\text { posteriormente iniciar nominalmente las } \\
\text { propiedades de cada hueso }\end{array}$ \\
\hline
\end{tabular}

Es deseable programar el desarrollo de competencias con base en la posible experiencia previa de los estudiantes para ir de lo familiar a lo desconocido, de lo cercano a lo distante, desde lo macro a lo molecular, de lo concreto a lo abstracto y de lo sincrético a lo diferenciado (Ibáñez, 2007). 


\section{Ejercicio 6.1.}

Observe el ejemplo que se muestra en el siguiente cuadro, y escriba un criterio de logro por cada nivel funcional a partir de los contenidos relacionados con la materia que imparte.

\begin{tabular}{|c|c|}
\hline & $\begin{array}{l}\text { Utilizar estrategias de análisis y comprensión de diferentes } \\
\text { textos expositivos para ser un lector crítico. }\end{array}$ \\
\hline $\begin{array}{l}\text { Aprendizaje } \\
\text { esperado }\end{array}$ & Criterios de logro a satisfacer \\
\hline $\begin{array}{l}\text { Nivel funcional } \\
\text { contextual }\end{array}$ & $\begin{array}{l}\text { - Identificar tipos de textos expositivos (divulgativos o especializados) y su estructura } \\
\text { (introducción, desarrollo y conclusión). }\end{array}$ \\
\hline $\begin{array}{l}\text { Nivel funcional } \\
\text { suplementario }\end{array}$ & $\begin{array}{l}\text { - Aplicar estrategias de análisis de los textos expositivos: escribir predicciones del contenido de } \\
\text { los textos a partir de títulos y subtítulos; leer los textos y subrayar o marcar ideas principales de } \\
\text { los textos; escribir sobre el texto comentarios o preguntas que le surgen de la lectura; escribir un } \\
\text { resumen del texto leído y elaborar fichas de comentarios y de síntesis de lo comprendido. }\end{array}$ \\
\hline $\begin{array}{l}\text { Nivel funcional } \\
\text { selector }\end{array}$ & $\begin{array}{l}\text { - Clasificar los textos expositivos según su estructura de discurso y compararlos entre sí. } \\
\text { - Diferenciar los conectores lógicos según tipo de textos: temporales, de paralelismo, de contraste, } \\
\text { distributivos, causales, de consecuencia y de solución. } \\
\text { - Comparar el contenido de los textos leídos con las predicciones hechas a partir de los títulos y } \\
\text { subtítulos. }\end{array}$ \\
\hline $\begin{array}{l}\text { Nivel funcional } \\
\text { sustitutivo } \\
\text { referencial }\end{array}$ & $\begin{array}{l}\text { - Elaborar un esquema que ejemplifique lo que dice un texto leído y escribir un comentario propio } \\
\text { respecto del texto. } \\
\text { - Describir por escrito para que un lector cualquiera pueda analizar un texto expositivo divulgativo } \\
\text { o especializado de estructura descriptiva y argumentativa. }\end{array}$ \\
\hline $\begin{array}{l}\text { Nivel funcional } \\
\text { sustitutivo } \\
\text { no referencial }\end{array}$ & $\begin{array}{l}\text { - Escribir un párrafo largo con su opinión sobre la importancia de los textos expositivos } \\
\text { especializados de tipo argumentativo en la enseñanza de las ciencias naturales a un niño de } \\
\text { primaria. } \\
\text { - Escribir su opinión respecto a la importancia y las enseñanzas que se pueden derivar de los } \\
\text { textos que leyó y argumentar su comentario. } \\
\text { - Elaborar símbolos que representen el propósito de cada texto leído y analizado. }\end{array}$ \\
\hline
\end{tabular}



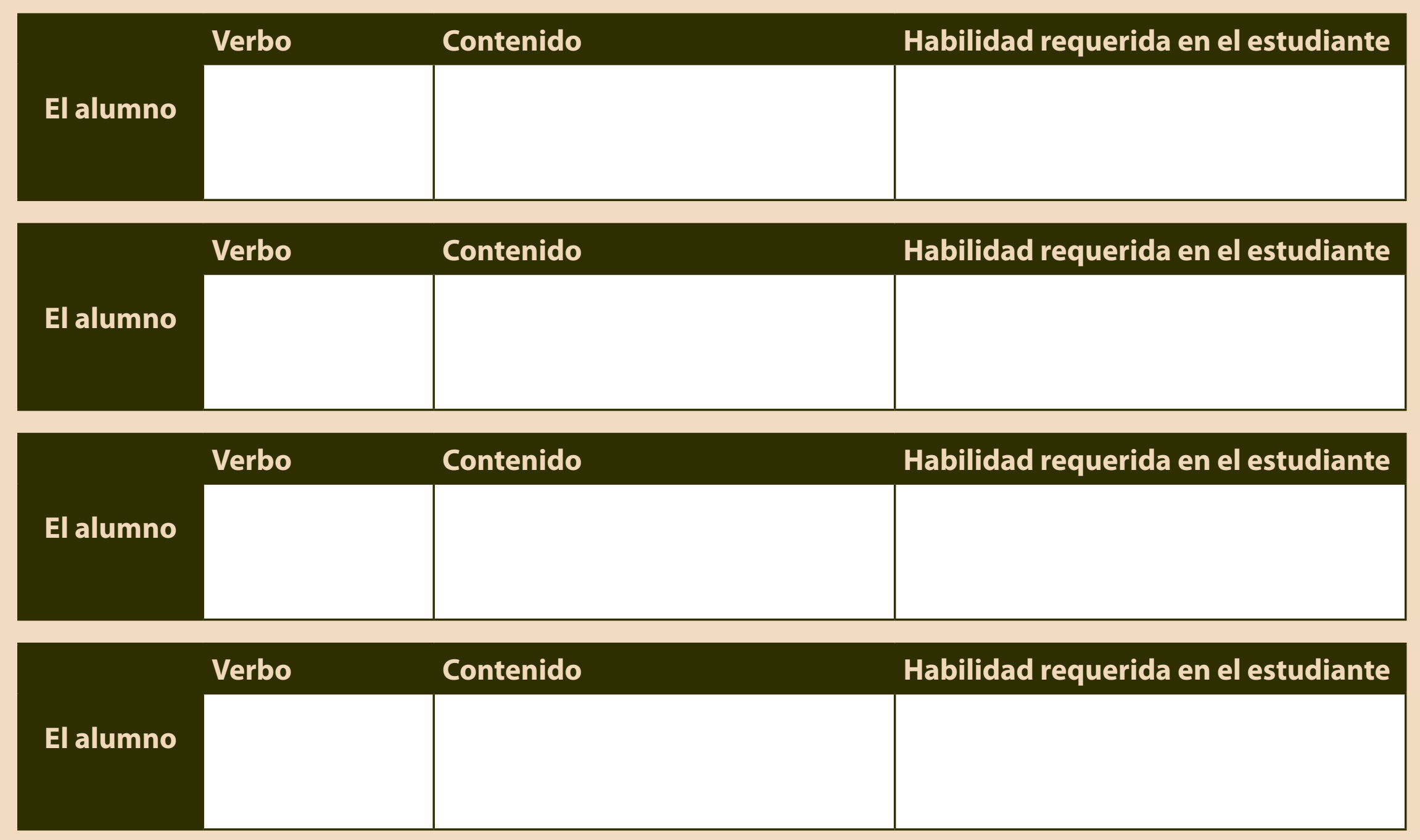

\begin{tabular}{|c|c|c|c|}
\hline & Verbo & Contenido & Habilidad requerida en el estudiante \\
\hline El alumno & & & \\
\hline
\end{tabular}




\section{Ejercicio 6.2.}

Lea el cuadro (página 87) y compare los criterios de logro a satisfacer de los niveles uno y cuatro.

Seleccione el inciso que considere correcto.

\begin{tabular}{|l|l|}
\multicolumn{1}{|c|}{ ¿Cuáles son las diferencias que encuentra entre ellos? } \\
\hline & No existen ninguna diferencia. \\
\hline $\begin{array}{l}\text { El nivel uno únicamente promueve que el alumno identifique un contenido: tipos de textos } \\
\text { expositivos y su estructura, mientras que el nivel cuatro promueve que el alumno produzca un } \\
\text { texto escrito el cual describe un tema que tiene como objetivo que otro lector pueda analizar un } \\
\text { contenido. }\end{array}$ \\
\hline $\begin{array}{l}\text { El nivel uno sólo promueve que el alumno identifique un contenido: tipos de textos expositivos y } \\
\text { su estructura a diferencia del cuatro donde elabora símbolos que representen el propósito de un } \\
\text { contenido. }\end{array}$ \\
\hline $\begin{array}{l}\text { El nivel uno el alumno clasifica y compara un contenido, mientras que el nivel cuatro promueve } \\
\text { que el alumno produzca un texto escrito el cual describe un tema que tiene como objetivo que } \\
\text { otro lector pueda analizar un contenido. }\end{array}$ \\
\hline $\begin{array}{l}\text { En el nivel uno aplica procedimientos asociados al análisis de un contenido mientras que el nivel } \\
\text { cuatro promueve que el alumno produzca un texto escrito el cual describe un tema que tiene } \\
\text { como objetivo que otro lector pueda analizar un contenido. }\end{array}$ \\
\hline
\end{tabular}

Una vez terminado el ejercicio se sugiere guardar. 


\section{Ejercicio 6.3.}

A partir de los aprendizajes esperados que usted redactó en el módulo anterior, correspondientes al proyecto ; incluido en el bloque redacte los criterios de logro.

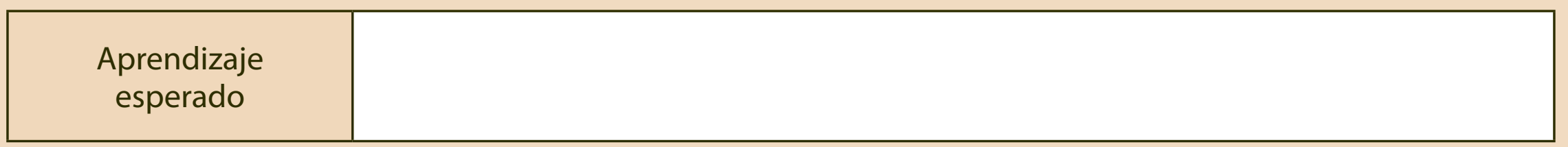

\begin{tabular}{|c|c|}
\hline \multicolumn{1}{|c|}{ NIVEL } & \multicolumn{2}{c|}{ CRITERIOS DE LOGRO A SATISFACER } \\
\hline Contextual & \\
\hline Suplementario & \\
\hline Selector & \\
\hline $\begin{array}{c}\text { Sustitutivo } \\
\text { referencial }\end{array}$ & \\
\hline $\begin{array}{c}\text { Sustitutivo } \\
\text { no referencial }\end{array}$ & \\
\hline
\end{tabular}


Ejercicio 6.4.

Explique: ¿Por qué es fundamental especificar los criterios de logro a partir de los niveles funcionales concretos a los abstractos? Anote su respuesta.

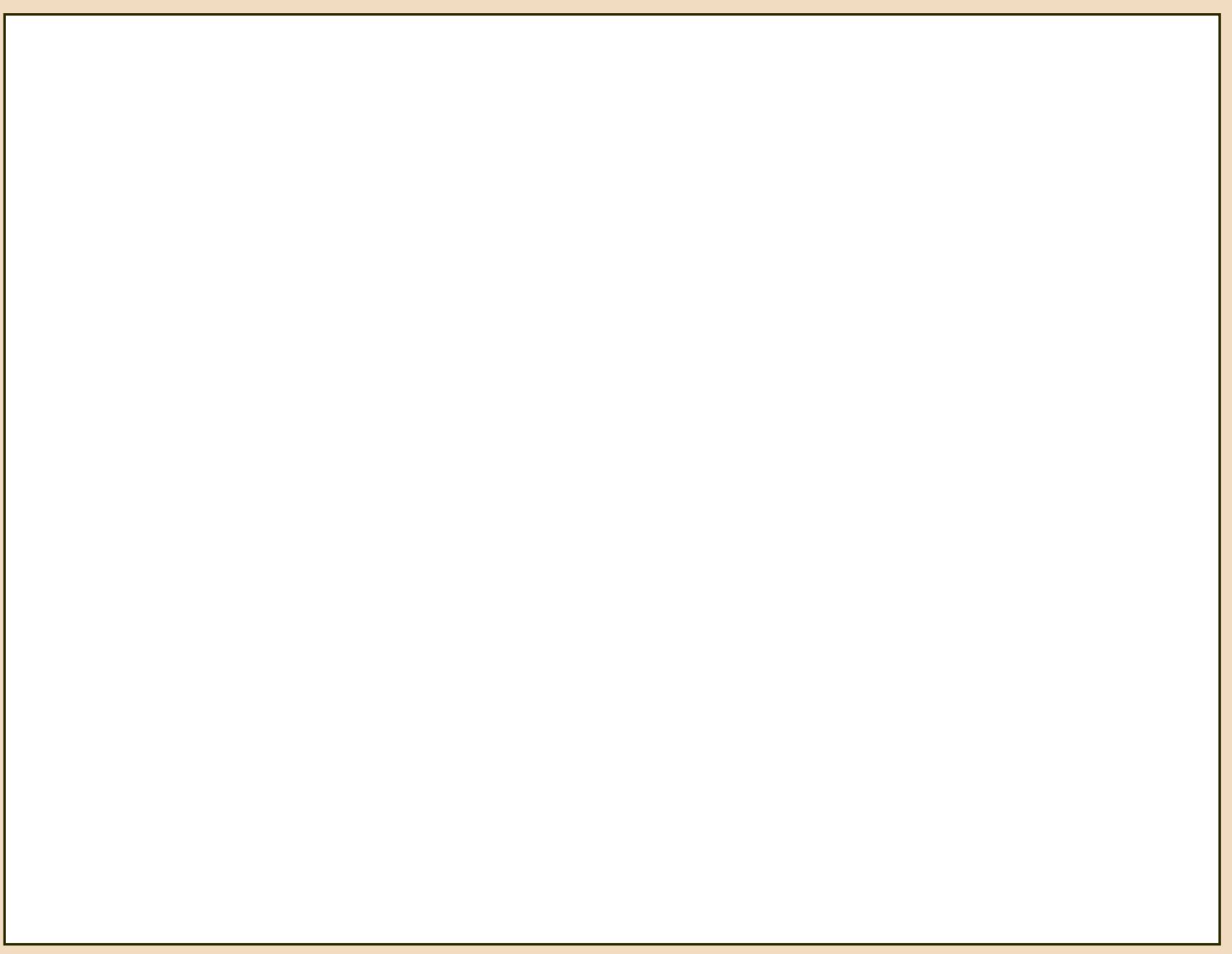

Una vez terminado el ejercicio se sugiere guardar. 
Rúbricas ejercicios 6.1. al 6.4.

\begin{tabular}{|c|c|c|c|}
\hline \multicolumn{2}{|c|}{ Ejercicio 6.1. Especificación del criterio de logro } \\
\hline Niveles de ejecución & Puntaje & \multicolumn{1}{c|}{ Descripción } \\
\hline Inicial & 1 & $\begin{array}{l}\text { El participante aplica erróneamente el procedimiento para describir los componentes } \\
\text { del criterio de logro, no reconoce los componentes que constituyen el criterio de logro. }\end{array}$ \\
\hline En desarrollo & 2 & $\begin{array}{l}\text { El participante aplica el procedimiento para describir los componentes del criterio de } \\
\text { logro, pero no detalla todos los componentes que lo constituyen. } \\
\text { Alcanzado }\end{array}$ & $\begin{array}{l}\text { El criterio de logro incluye los verbos pero no todos tienen correspondencia con los } \\
\text { habilidad requerida del estudiante. }\end{array}$ \\
\hline 3 & $\begin{array}{l}\text { El participante aplica con eficacia el procedimiento para describir los componentes } \\
\text { del criterio de logro, detalla todos los componentes que constituyen el criterio de } \\
\text { logro. } \\
\text { El criterio de logro incluye el verbo en correspondencia con cada nivel funcional, el } \\
\text { contenido de la asignatura y la habilidad requerida del estudiante. }\end{array}$ \\
\hline
\end{tabular}




\begin{tabular}{|c|c|c|c|}
\hline \multicolumn{4}{|c|}{ Ejercicio 6.2. Comparación entre diferentes niveles de complejidad funcional } \\
\hline Niveles de ejecución & Puntaje & \multicolumn{1}{c|}{ Descripción } \\
\hline Inicial & 1 & $\begin{array}{l}\text { - El participante compara las actividades académicas generadas en la interacción } \\
\text { didáctica mediante el discurso didáctico pero no hay correspondencia con el nivel } \\
\text { funcional. }\end{array}$ \\
\hline En desarrollo & 2 & $\begin{array}{l}\text { - El participante compara parcialmente los aspectos y la descripción de cada nivel } \\
\text { funcional en las actividades presentes en la interacción didáctica mediante el discurso } \\
\text { didáctico. } \\
\text { Clasifica las actividades académicas generadas en la interacción didáctica mediante } \\
\text { el discurso didáctico pero no todas corresponden al nivel funcional. } \\
\text { Elcanzado }\end{array}$ & $\begin{array}{l}\text { Elige los verbos generados en la interacción didáctica mediante el discurso didáctico } \\
\text { según el nivel funcional al que corresponde. }\end{array}$ \\
\hline 3 & $\begin{array}{l}\text { El participante compara diferencialmente los aspectos y la descripción de cada nivel } \\
\text { funcional en las actividades presentes en la interacción didáctica mediante el discurso } \\
\text { didáctico. } \\
\text { Clasifica las actividades académicas generadas en la interacción didáctica mediante } \\
\text { el discurso didáctico según el nivel funcional al que corresponde. } \\
\text { Elige los verbos generados en la interacción didáctica mediante el discurso didáctico } \\
\text { según el nivel funcional al que corresponde. }\end{array}$ \\
\hline
\end{tabular}




\section{Ejercicio 6.3. Formulación de criterios de logro}

\begin{tabular}{|c|c|c|}
\hline Niveles de ejecución & Puntaje & Descripción \\
\hline Inicial & 1 & $\begin{array}{l}\text { - El participante elabora ejemplos adecuados con situaciones didácticas. } \\
\text { - Identifica los aprendizajes esperados y la descripción de uno o dos niveles funcionales } \\
\text { pero reproduce literalmente el criterio de logro a partir de lo que dice el plan de } \\
\text { estudios. }\end{array}$ \\
\hline En desarrollo & 2 & $\begin{array}{l}\text { - Los ejemplos son adecuados y se relacionan con situaciones didácticas y contenidos } \\
\text { - de la asignatura que imparte pero no aporta nuevas propuestas. } \\
\text { funcional. } \\
\text { - Los criterios de logro incluyen los verbos pero no todos tienen correspondencia con } \\
\text { cada nivel funcional, hay correspondencia con el aprendizaje esperado, contenido de } \\
\text { la asignatura y la habilidad requerida del estudiante. }\end{array}$ \\
\hline Alcanzado & 3 & $\begin{array}{l}\text { - Los ejemplos son adecuados y en algunos casos innovadores con respecto de } \\
\text { situaciones didácticas y contenidos de la asignatura que imparte. } \\
\text { - Identifica los aprendizajes esperados y la descripción de cada nivel funcional. } \\
\text { - Cada criterio de logro incluye el verbo en correspondencia con cada nivel funcional, } \\
\text { habilidad requerida del estudiante, los interrelaciona y expresa con claridad con sus } \\
\text { propias palabras. }\end{array}$ \\
\hline
\end{tabular}




\begin{tabular}{|c|c|c|c|}
\hline \multicolumn{3}{|c|}{ Ejercicio 6.4. Criterios de logro y nivel funcional } \\
\hline Niveles de ejecución & Puntaje & \multicolumn{1}{c|}{ Descripción } \\
\hline Inicial & 1 & $\begin{array}{l}\text { El participante sostiene su explicación sin basarse en los aspectos de los niveles } \\
\text { funcionales ni en los criterios de logro pero integra los contenidos de la asignatura. } \\
\text { Excluye los aspectos principales y la descripción de cada nivel funcional, los criterios } \\
\text { de logro y las competencias. } \\
\text { En desarrollo }\end{array}$ & $\begin{array}{l}\text { El texto no es coherente y no hace entender qué es lo que quiere comunicar. } \\
\text { - El participante sostiene su explicación en algunos aspectos de los niveles funcionales, } \\
\text { los criterios de logro y las competencias pero integra los contenidos de la asignatura. } \\
\text { Considera uno o dos aspectos principales y la descripción de cada nivel funcional } \\
\text { provenientes de la lectura como base de su justificación. } \\
\text { Comunica las razones que avalan el ejemplo pero no convence y utiliza algunos } \\
\text { términos. }\end{array}$ \\
\hline 3 & $\begin{array}{l}\text { El participante sostiene su ejemplo en los aspectos principales de los niveles } \\
\text { funcionales, criterios de logro y competencias e integra los contenidos de la } \\
\text { asignatura. } \\
\text { Considera los aspectos principales y la descripción de cada nivel funcional como base } \\
\text { de sujustificación. } \\
\text { Comunica bien las razones que avalan el ejemplo utilizando la terminología del texto. }\end{array}$ \\
\hline
\end{tabular}




\section{Módulo 7 \\ Especificación de actividades según los criterios de logro a satisfacer}

Objetivo: Especificar las actividades de aprendizaje del proyecto a planear.

Instrucciones: Lea el Texto 7: "Las actividades en la planeación didáctica" e identifique las actividades y ubíquelas en términos de diferentes criterios de logro, posteriormente es necesario justificarlo con la terminología revisada.

Aprendizaje esperado: Redacta las actividades del proyecto. 


\section{Texto 7}

\section{Las actividades en la planeación didáctica}

Estimado Profesor:

Hasta este momento usted ha especificado el aprendizaje esperado y los criterios de logro que deben satisfacer los estudiantes como elementos que conforman una planeación didáctica.

Este módulo tiene como objetivo especificar las actividades de aprendizaje del proyecto a planear, asimismo se espera que usted al finalizar el módulo cumpla con los siguientes aprendizajes esperados:

- Redactar las actividades de aprendizaje del proyecto en cuestión; $y$

- Redactar un párrafo con una extensión de 20 líneas en el cual exprese su opinión respecto a lo aprendido en este módulo y las dificultades asociadas a la ejecución de los ejercicios y la forma en cómo lo resolvió.

El propósito de diseñar actividades de enseñanza-aprendizaje, es estructurar de manera integral la intervención docente en una secuencia y temporalización teniendo en cuenta los propósitos del módulo y los contenidos propuestos, para ello, se sugiere la siguiente guía.
Guía para la especificación de las actividades según los criterios de logro a satisfacer:

- Lea el aprendizaje esperado;

- Identifique el criterio de logro y su respectivo nivel funcional en congruencia con el aprendizaje esperado;

- Identifique el criterio de logro y la congruencia con el aprendizaje esperado;

- Identifique los contenidos de la asignatura;

- Redacte las actividades en forma ascendente a partir del nivel contextual, suplementario, selector, sustitutivo referencial, sustitutivo no referencial; $y$ los contenidos de la asignatura;

- Al finalizar, verifique la congruencia en la especificación de las actividades por cada nivel y la congruencia general con el aprendizaje esperado. 


\section{Ejemplo 1.}

Especificación de las actividades según los criterios de logro a satisfacer.

En el siguiente ejemplo se describe a detalle las actividades que promueve el profesor en sus alumnos tomando como base el aprendizaje esperado y los criterios de logro a satisfacer.

Aprendizaje esperado
Utilizar estrategias de análisis, síntesis y parafraseo de diferentes textos expositivos para ser un lector crítico. 
Lista de actividades según el aprendizaje esperado

CRITERIOS DE LOGRO A SATISFACER

ACTIVIDADES

\begin{tabular}{|c|c|c|}
\hline $\begin{array}{c}\text { Nivel } \\
\text { contextual }\end{array}$ & $\begin{array}{l}\text { Identificar tipos de textos expositivos } \\
\text { (divulgativos o especializados) y su } \\
\text { estructura (introducción, desarrollo y } \\
\text { conclusión). }\end{array}$ & $\begin{array}{l}\text { - Se solicita a los alumnos que lean en silencio los dos } \\
\text { textos expositivos de estructura narrativa entregados } \\
\text { en la actividad anterior e identifiquen, escribiendo en } \\
\text { la parte superior, el tipo de texto al que pertenece cada } \\
\text { uno de ellos. Posteriormente se les pide que marquen } \\
\text { dónde inicia cada uno de los componentes de una } \\
\text { estructura típica en cada texto (introducción, desarrollo y } \\
\text { conclusión). } \\
\text { - El profesor revisa las actividades señaladas y en caso de } \\
\text { que hubiera errores lo comenta con cada alumno. Se } \\
\text { hace un repaso final y se les pide que anoten lo que son } \\
\text { los textos expositivos, sus tipos y estructura. }\end{array}$ \\
\hline $\begin{array}{c}\text { Nivel } \\
\text { suplementario }\end{array}$ & $\begin{array}{l}\text { Aplicar estrategias de análisis de } \\
\text { los textos expositivos: escribir } \\
\text { predicciones del contenido de los } \\
\text { textos a partir de títulos y subtítulos; } \\
\text { leer los textos y subrayar o marcar } \\
\text { ideas principales de los textos; } \\
\text { escribir sobre el texto comentarios o } \\
\text { preguntas que le surgen de la lectura; } \\
\text { escribir un resumen del texto leído y } \\
\text { elaborar fichas de comentarios y de } \\
\text { síntesis de lo comprendido. }\end{array}$ & $\begin{array}{l}\text { - Cuando concluyan la actividad anterior, los estudiantes } \\
\text { deberán escribir un resumen del primer texto leído, } \\
\text { abarcando las ideas principales, posteriormente deberán } \\
\text { elaborar fichas donde escriban lo que comprendieron. } \\
\text { Cuando hayan concluido con el primer texto harán lo } \\
\text { mismo con el segundo. } \\
\text { - Los estudiantes deberán escribir en sus cuadernos los } \\
\text { aspectos más importantes sobre las técnicas de análisis } \\
\text { y comprensión de textos expositivos, describiendo los } \\
\text { pasos a seguir. }\end{array}$ \\
\hline
\end{tabular}




\section{Lista de actividades según el aprendizaje esperado}

\section{CRITERIOS DE LOGRO}

A SATISFACER

\section{ACTIVIDADES}

- Clasificar los textos expositivos según su estructura de discurso y compararlos entre sí.

- El profesor distribuye seis textos expositivos cortos de estructura de discurso diferentes (narrativo, expositivo, etc.), y explica brevemente en qué se caracteriza cada uno de ellos y los anota en el pizarrón.

- Los alumnos deben anotar sus predicciones del contenido de cada texto

- Identificar y diferenciar los conectores lógicos según el tipo de textos: temporales,

Nivel de paralelismo, selector de contraste, distributivos, causales, de consecuencia y de solución.

- Comparar el contenido de los textos leídos con las predicciones hechas a partir de los títulos y subtítulos. a partir de los títulos y subtítulos. Luego leen los textos cortos y con base en sus características, los clasifican según su estructura de discurso y los comparan entre sí, escribiendo en su cuaderno sus comentarios.

- El profesor explica la importancia de los conectores lógicos en los textos expositivos y pone ejemplos de conectores temporales y espaciales, de paralelismo, etc. Posteriormente solicita que identifiquen en cada uno de los textos los conectores lógicos y que escriban sobre las diferencias entre cada tipo de conectores lógicos según las estructuras discursivas de los textos expositivos.

- Los alumnos leen los seis textos aplicando estrategias de análisis de textos utilizados en la sección anterior (subrayados, comentarios, resúmenes y fichas) y comparan el contenido de los textos leídos con las predicciones que hicieron a partir de los títulos y subtítulos. El profesor revisa el trabajo de cada uno de los alumnos y comenta en grupo las dudas y dificultades que se hayan tenido.

- El profesor solicita a los alumnos que anoten en sus cuadernos los aspectos más importantes sobre los diversos textos expositivos de acuerdo a la forma de estructurar los discursos y el uso de diferentes conectores lógicos. 


\section{Lista de actividades según el aprendizaje esperado}

\section{CRITERIOS DE LOGRO A SATISFACER}

- Con los resúmenes y fichas construidas previamente, elaborar un esquema que ejemplifique lo que dice cada texto leído y escribir un

Nivel sustitutivo referencial

\section{ACTIVIDADES}

- Para cada uno de los seis textos leídos anteriormente, los alumnos elaborarán un esquema que ejemplifique el contenido de cada texto, utilizando los resúmenes y fichas construidas previamente, luego, escribirán sus posibles comentarios.

- Se solicita a los alumnos describan las características que le permita a cualquier lector, leer o analizar un texto expositivo divulgativo o especializado de estructura descriptiva y argumentativa, aplicando estrategias de lectura y de comprensión de textos.

- Se pide que lean nuevamente el texto argumentativo de causa y efecto, que presten mucha atención en el desarrollo y la conclusión, que cierren los ojos e imaginen qué pasaría si se cambiara la conclusión del texto, luego abran los ojos y escriban una nueva conclusión propia. Finalmente se les pide que expliquen cómo cambió y en qué el texto original con esa conclusión propia. 
Lista de actividades según el aprendizaje esperado

CRITERIOS DE LOGRO A SATISFACER

\section{ACTIVIDADES}

- Escribir un párrafo largo con su opinión sobre la importancia de los textos expositivos especializados de tipo argumentativo en la enseñanza de las ciencias

Nivel sustitutivo

no referencial naturales a un niño de primaria.

- Escribir su opinión respecto a la importancia y las enseñanzas que se pueden derivar de los textos que leyó y argumentar su comentario.

- Elaborar símbolos que representen el propósito de cada texto leído y analizado.
- Se solicita a los alumnos que escriban un párrafo no menor a 10 renglones, en el cual expresen su opinión y los argumentos sobre la importancia que tienen los textos expositivos especializados de tipo argumentativo en la enseñanza de los alumnos en las ciencias.

- Para cada uno de los seis textos leídos, los niños deben escribir su opinión respecto a la importancia del tema o contenido en ellos, mencionar las enseñanzas que se pueden derivar del texto y argumentar o proporcionar las razones de su comentario.

- Se solicita a los alumnos que elaboren símbolos que podrían representar mejor el propósito de cada uno de los seis textos analizados.

- El profesor revisa el trabajo de cada uno de los alumnos y comenta en grupo las dudas y dificultades que cada niño haya tenido. 


\section{Ejercicio 7.1.}

Lea la secuencia de los criterios de logro a satisfacer como se presentan en el Ejemplo 1: "Especificación de las actividades según los criterios de logro a satisfacer" y por cada nivel de complejidad funcional redacte los aprendizajes esperados.

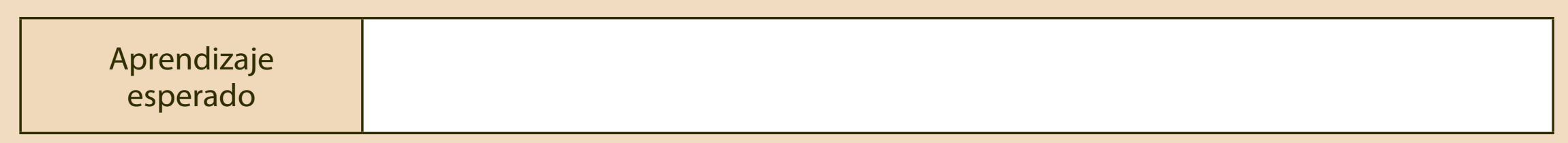

\begin{tabular}{|c|c|}
\hline NIVEL & Actividades \\
\hline Contextual & \\
\hline Suplementario & \\
\hline Selector & \\
\hline $\begin{array}{l}\text { Sustitutivo } \\
\text { referencial }\end{array}$ & \\
\hline $\begin{array}{c}\text { Sustitutivo } \\
\text { no referencial }\end{array}$ & \\
\hline
\end{tabular}




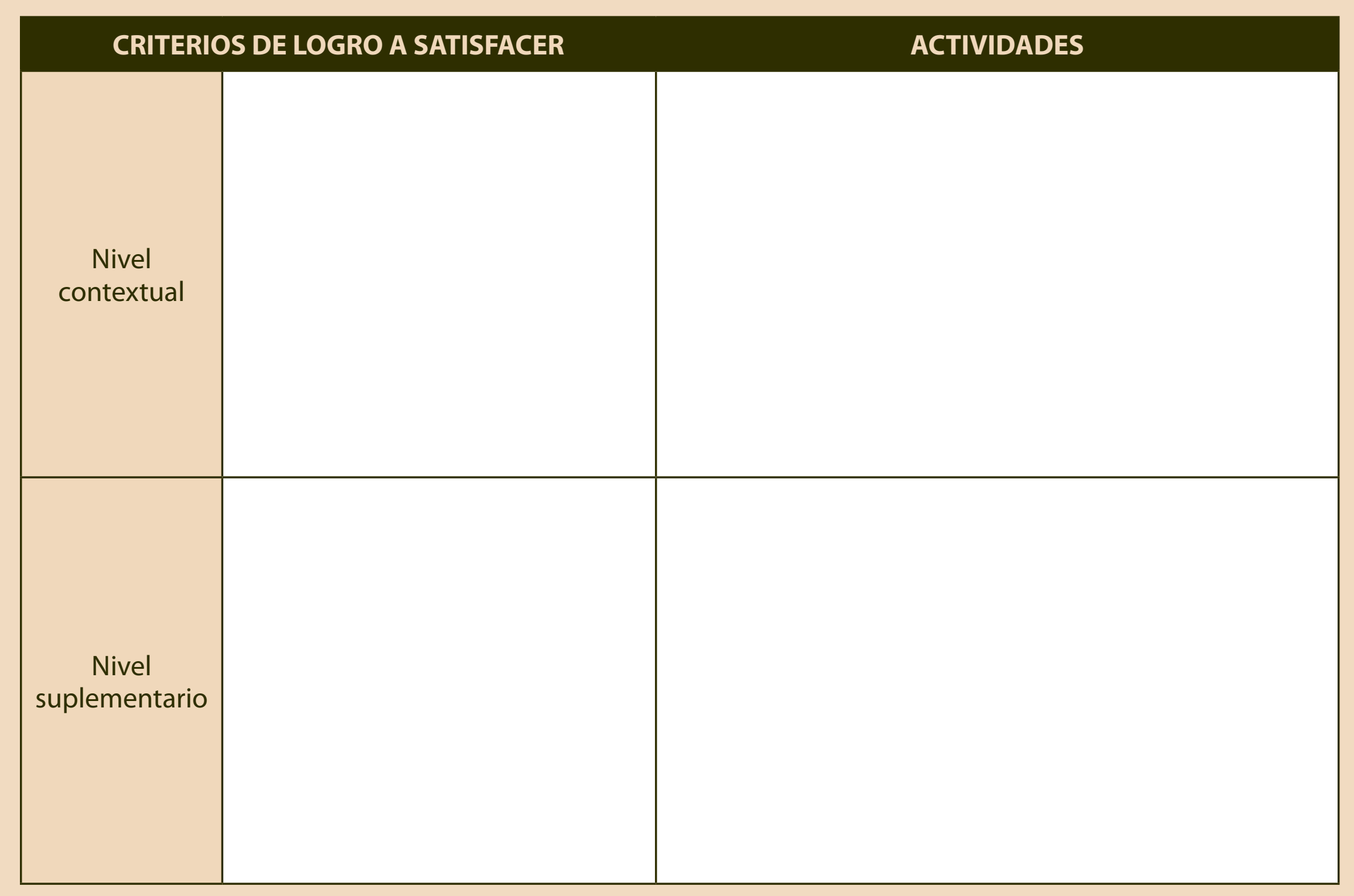




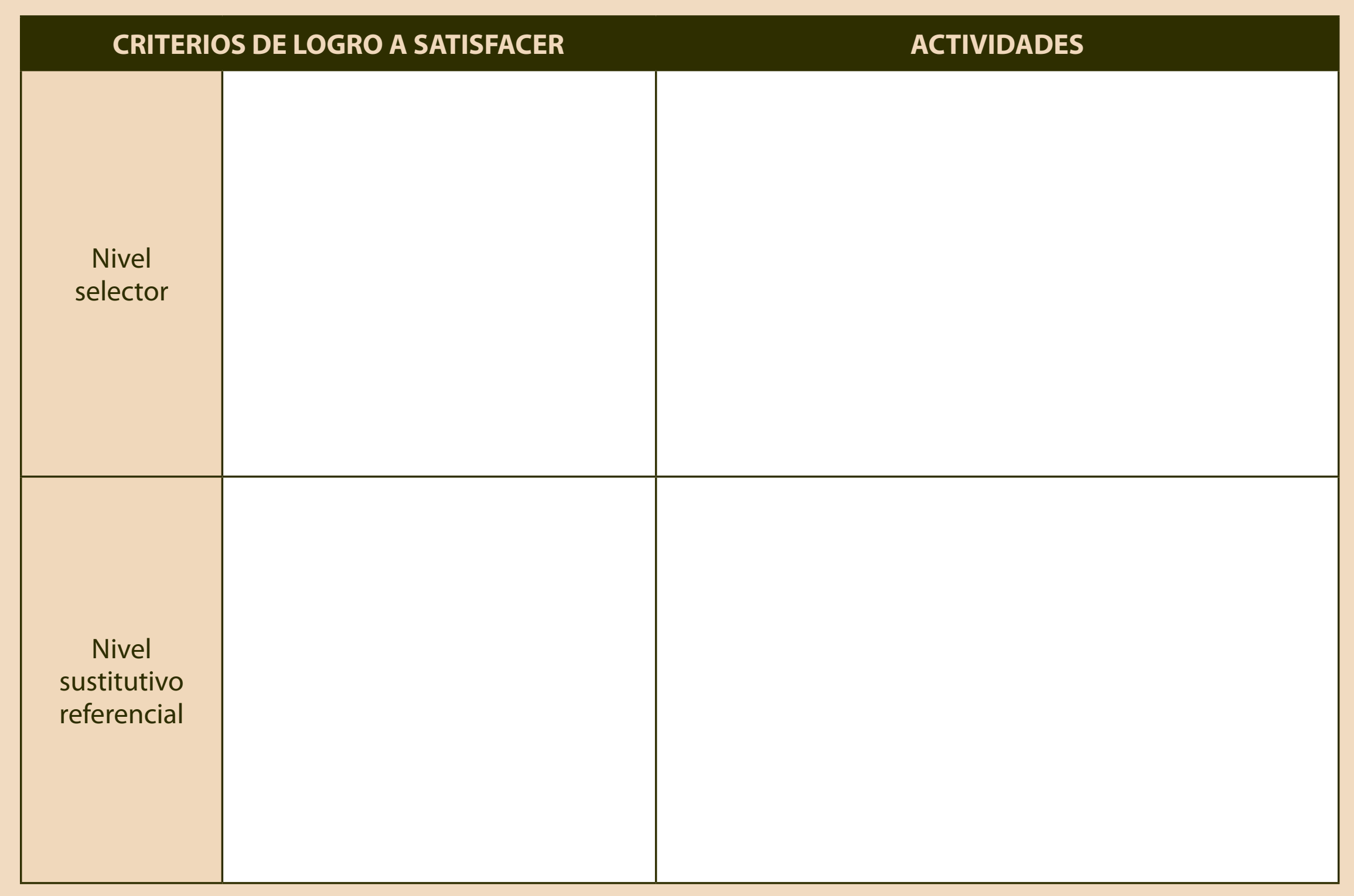




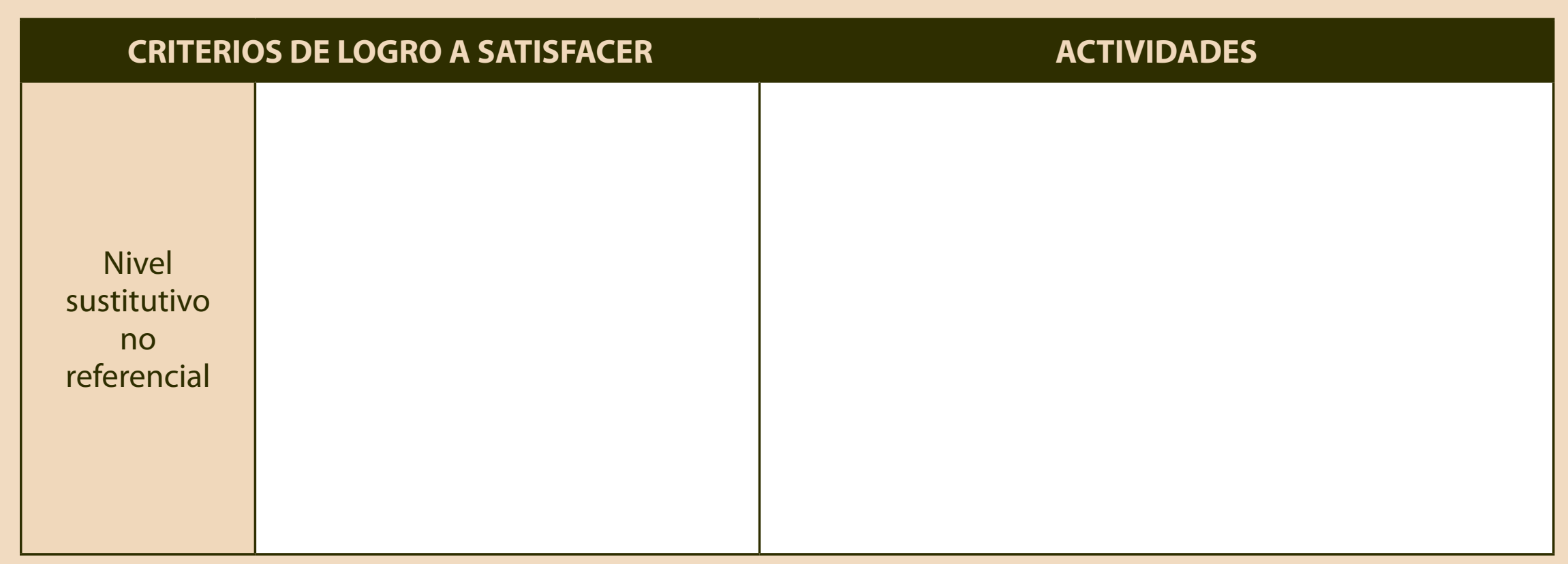

Por último agregue el lugar donde se realizarán las actividades y los materiales.

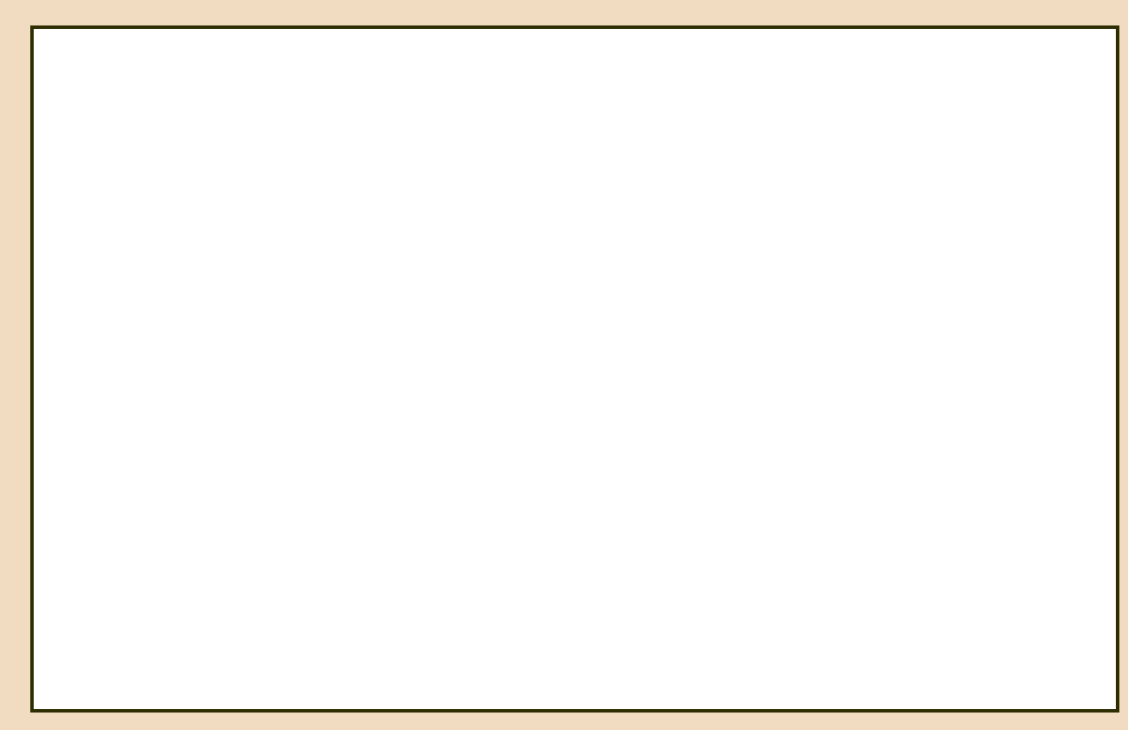




\section{Ejercicio 7.2.}

Verifique la congruencia en la especificación de las actividades por cada nivel funcional y en el aprendizaje esperado; adicionalmente identifique la congruencia del lugar seleccionado donde se llevará a cabo la actividad y el material a utilizar.

Lea cada condición y verifique las especificaciones de las actividades en el Proyecto del bloque _-_ que su compañero ha realizado, coloque una marca donde corresponda, es indispensable que responda cada condición.

\begin{tabular}{|l|l|l|l|l|}
\hline \multicolumn{2}{|c|}{ Condición } & & & \\
\hline $\begin{array}{l}\text { Existe congruencia entre las actividades, } \\
\text { el nivel funcional y su respectivo verbo. }\end{array}$ & & & & \\
\hline $\begin{array}{l}\text { Existe congruencia entre las actividades } \\
\text { y el criterio de logro. }\end{array}$ & & & & \\
\hline $\begin{array}{l}\text { Existe congruencia entre el criterio de } \\
\text { logro y el aprendizaje esperado. }\end{array}$ & & & & \\
\hline $\begin{array}{l}\text { Redacta actividades en forma ascendente } \\
\text { utilizando los cinco niveles. }\end{array}$ & & & & \\
\hline Enuncia los contenidos del proyecto. & & & & \\
\hline $\begin{array}{l}\text { El lugar es el idóneo para desarrollar las } \\
\text { actividades. }\end{array}$ & & & & \\
\hline $\begin{array}{l}\text { Los materiales son los adecuados para } \\
\text { desarrollar las actividades. }\end{array}$ & & & & \\
\hline
\end{tabular}




\section{Ejercicio 7.3.}

Escriba un párrafo con una extensión de 20 líneas en el cual exprese su opinión respecto a lo aprendido en este módulo y las dificultades asociadas a la ejecución del ejercicio y la forma en cómo lo resolvieron.

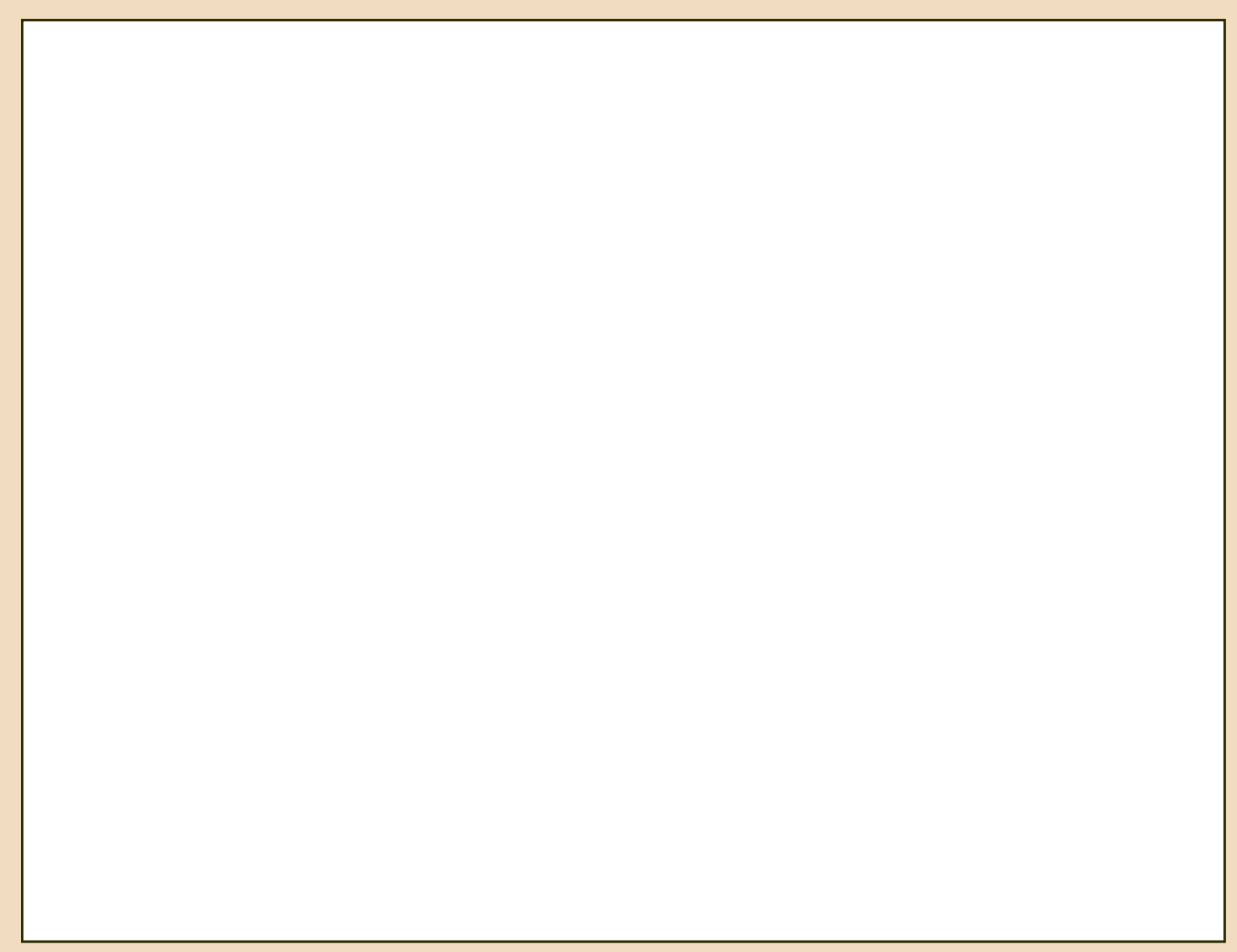

Una vez terminado el ejercicio se sugiere guardar. 
Estimado Profesor: ¡Felicidades! En este momento usted ha desarrollado una planeación didáctica en la cual existe congruencia entre el aprendizaje esperado y los criterios de logro que el estudiante debe mostrar al resolver las actividades de diferente nivel de complejidad funcional.

La actividad de planeación requiere tener una estructura formal, que se expresará en los formatos que los subsistemas de educación utilizan (Plan y Programa vigentes). Considere para e diseño y estructuración los contenidos revisados en este manual.

Recuerde que para elaborar una planeación didáctica debe:

- Seleccionar el proyecto de la asignatura que imparte y llenar los recuadros del primer formato.

- Identificar y formular el aprendizaje esperado; describir los criterios de logro a satisfacer; especificar las actividades de forma congruente con los niveles funcionales.

- Especificar el lugar donde se llevarán a cabo las actividades y los materiales a emplear.
Al finalizar podrá evaluar los diferentes elementos que deben estar incluidos en el diseño de la planeación didáctica elaborando una rúbrica, la cual permitirá identificar el nivel de desempeño, de acuerdo con el nivel usted identificará qué componentes sobre la planeación deberá enfatizar o reforzar. 
Rúbricas ejercicios 7.1. al 7.3.

\begin{tabular}{|c|c|c|c|}
\hline \multicolumn{4}{|c|}{ Ejercicio 7.1. Especificación de actividades } \\
\hline Niveles de ejecución & Puntaje & \multicolumn{1}{c|}{ Descripción } \\
\hline Inicial & 1 & $\begin{array}{l}\text { El participante aplica erróneamente el procedimiento para identificar los } \\
\text { componentes de las actividades y no reconoce los componentes que las constituyen. }\end{array}$ \\
\hline En desarrollo & 2 & $\begin{array}{l}\text { El participante aplica el procedimiento para identificar los componentes de las } \\
\text { actividades, pero no detalla todos los componentes que lo constituyen. } \\
\text { Las actividades incluyen los verbos pero no todos tienen correspondencia con los } \\
\text { niveles funcionales y criterios de logro. } \\
\text { Alcanzado }\end{array}$ & $\begin{array}{l}\text { Hay correspondencia con el contenido de la asignatura y la habilidad requerida del } \\
\text { estudiante. }\end{array}$ \\
\hline $\begin{array}{l}\text { El participante aplica con eficacia el procedimiento para identificar los componentes } \\
\text { de las actividades, detalla todos los componentes que constituyen las actividades. } \\
\text { Las actividades incluyen el verbo en correspondencia con cada nivel funcional, } \\
\text { los criterios de logro, el contenido de la asignatura y la habilidad requerida del } \\
\text { estudiante. }\end{array}$ \\
\hline
\end{tabular}




\begin{tabular}{|c|c|c|}
\hline Niveles de ejecución & Puntaje & Descripción \\
\hline Inicial & 1 & $\begin{array}{l}\text { - El participante redacta las actividades académicas de los contenidos de la asignatura } \\
\text { generadas en la interacción didáctica mediante el discurso didáctico pero no hay } \\
\text { correspondencia con el nivel funcional, ni con el criterio de logro ni el aprendizaje } \\
\text { esperado. } \\
\text { - No especifica materiales ni lugar. }\end{array}$ \\
\hline En desarrollo & 2 & $\begin{array}{l}\text { - El participante redacta parcialmente los aspectos y la descripción de cada nivel } \\
\text { funcional en las actividades presentes en la interacción didáctica mediante el discurso } \\
\text { didáctico. } \\
\text { - Compara y clasifica las actividades académicas de los contenidos de la asignatura } \\
\text { generadas en la interacción didáctica mediante el discurso didáctico pero no todas } \\
\text { corresponden al nivel funcional, con el criterio de logro ni con el aprendizaje esperado. } \\
\text { - Elige los verbos generados en la interacción didáctica mediante el discurso didáctico } \\
\text { según el nivel funcional al que corresponde. } \\
\text { - Especifica materiales y lugar. }\end{array}$ \\
\hline Alcanzado & 3 & $\begin{array}{l}\text { - El participante redacta los aspectos y la descripción de cada nivel funcional en las } \\
\text { actividades presentes en la interacción didáctica mediante el discurso didáctico. } \\
\text { - Compara y clasifica las actividades académicas de los contenidos de la asignatura } \\
\text { generadas en la interacción didáctica mediante el discurso didáctico según el nivel } \\
\text { funcional al que corresponde, al criterio de logro yel aprendizaje esperado. } \\
\text { - Elige los verbos generados en la interacción didáctica mediante el discurso didáctico } \\
\text { según el nivel funcional al que corresponde. } \\
\text { - Especifica materiales innovadores y lugares novedosos. }\end{array}$ \\
\hline
\end{tabular}




\section{Ejercicio 7.3. Formulación de párrafo describiendo opinión propia}

\begin{tabular}{|c|c|c|}
\hline Niveles de ejecución & Puntaje & Descripción \\
\hline Inicial & 1 & $\begin{array}{l}\text { - El participante evalúa su aprendizaje considerando aspectos disciplinares y su } \\
\text { - Experiencia. } \\
\text { - El participante considera que todavía no domina los contenidos de la asignatura que } \\
\text { - El participante menciona las dificultades pero no proporciona explicaciones de cómo } \\
\text { las solucionó. }\end{array}$ \\
\hline En desarrollo & 2 & $\begin{array}{l}\text { - El participante evalúa su aprendizaje considerando aspectos de su práctica docente y } \\
\text { - Enuncia algunos aspectos teóricos, de aplicación y de ejemplificación. } \\
\text { - } \quad \text { Dentinuo que se vinculan con la planeación didáctica. } \\
\text { aprendizaje esperado. }\end{array}$ \\
\hline Alcanzado & 3 & $\begin{array}{l}\text { - El participante evalúa su aprendizaje considerando aspectos de su práctica docente, } \\
\text { contenidos disciplinares y los vincula con los aspectos teóricos de aplicación y } \\
\text { ejemplificación. } \\
\text { - El participante vincula los contenidos de la asignatura con el diseño de la planeación } \\
\text { didáctica para generar aprendizajes en diferentes niveles de complejidad. } \\
\text { - El participante identifica las dificultades asociadas al desconocimiento e } \\
\text { interpretación de la terminología, desarrollo de las actividades, al evaluar su } \\
\text { aprendizaje y explica con detalle el cómo lo solucionó para lograr el aprendizaje } \\
\text { esperado. }\end{array}$ \\
\hline
\end{tabular}




\section{Referencias}




\section{Referencias}

- Gagné, R., \& Briggs, L. (1979). Principles of instructional design. New York: Holt, Rinehart \& Winston.

- Guevara, Y. (2006). Análisis interconductual de algunos elementos que constituyen la enseñanza básica. Revista Mexicana de Psicología, 1(30).

- Ibáñez, C. (2007). Metodología para la planeación de la Educación Superior. Hermosillo: Mora-CantúaUniversidad de Sonora.

- Ibáñez, C. (2009). Problemas de la psicología aplicada a la educación: Teoría psicológica general del aprendizaje vs. didácticas específicas. Revista Electrónica de Educación Especial y Familia, 2(1), 6-22.

- Ibáñez, C., \& Ribes, E. (2001). Un análisis interconductual de los procesos educativos. Revista Mexicana de Psicología, 18(3), 359-371.

- Irigoyen, J.J., Acuña, K., \& Jiménez, M. (2011a). Análisis de las interacciones didácticas: ¿cómo auspiciar la formación de estudiantes competentes en el ámbito científico? Enseñanza e Investigación en Psicología, 16(2), 227-244.
- Irigoyen, J.J., Acuña, K., \& Jiménez, M. (2011b). Evaluación de Desempeños Académicos. Hermosillo: Universidad de Sonora.

- León, A., Morales, G., Silva, H., \& Carpio, C. (2011). Análisis y evaluación del Comportamiento docente en el nivel educativo superior. En V. Pacheco, \& C. Carpio (Coords.), Análisis del comportamiento. Observación y métricas (pp. 83103). México: Universidad Nacional Autónoma de México.

- Ribes, E. (1990). Psicología General. México: Editorial Trillas.

- Ribes, E. (2008). Educación básica, desarrollo psicológico y planeación de competencias. Revista Mexicana de Psicología, 25(2), 193-207.

- Ribes, E. (2011). El concepto de competencia: su pertinencia en el desarrollo Psicológico y la educación. Bordón 63(1), 33-45. 
- Ribes, E. (2012). La educación especial: una perspectiva interconductual. En R. Jiménez, $S$. Viñas, J. Camacho, D. Gómez, E. Zepeta y M. Serrano, Educación Especial y Psicología: historia, aportaciones y prospectiva universitaria (pp. 173186). Tlaxcala: Universidad Autónoma de Tlaxcala.

- Ribes, E., \& López, F. (1985). Teoría de la conducta. Un análisis de campo y paramétrico. México: Editorial Trillas.

- Secretaría de Educación Pública (SEP). (2011). Programas de estudio 2011. Guía para el Maestro, Educación Básica. Secundaria. Español. México: SEP.
- Silva, H. (2009). El desarrollo de habilidades de investigación científica y planeación didáctica: redefiniendo el vínculo entre la investigación y la docencia (Tesis de maestría inédita). Universidad Nacional Autónoma de México: México.

- Silva, H., Morales, G., Pacheco, V., Camacho, A., Garduño, H., \& Carpio, C. (2014). Didáctica como conducta: una propuesta para la descripción de las habilidades de enseñanza. Revista Mexicana de Análisis de la Conducta, 40(3), 32-46. 
Qartuppi, S. de R.L. de C.V. está inscrita de forma definitiva en el Registro Nacional de Instituciones y Empresas Científicas y Tecnológicas (RENIECYT) con el número 1600052.

Qartuppi, S. de R.L. de C.V. es miembro activo de la Cámara Nacional de la Industria Editorial Mexicana (CANIEM) con número de registro 3751.

Manual de planeación didáctica para educación secundaria

1a. edición, diciembre 2016.

ISBN 978-607-97326-7-7

DOI 10.29410/QTP.16.11

Esta obra se terminó de producir en diciembre de 2016.

Su edición y diseño estuvieron a cargo de:

\section{Qartuppi.}

Qartuppi, S. de R.L. de C.V. http://www.qartuppi.com 
ISBN 978-607-97326-7-7
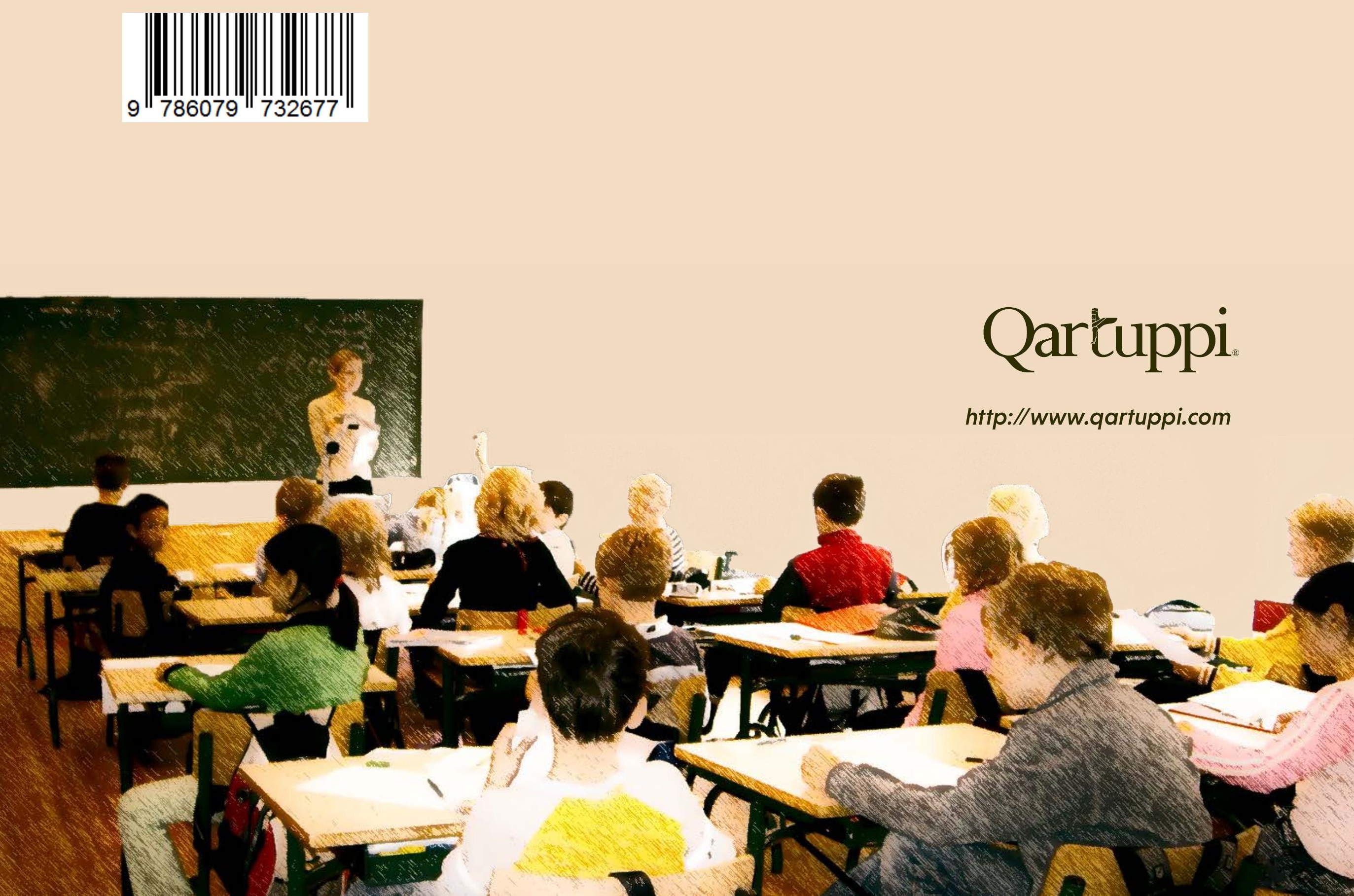